Illinois State University

ISU ReD: Research and eData

Theses and Dissertations

8-9-2021

\title{
Special Education Preservice Teachers Culturally Responsive Teaching Self-Efficacy: A Mixed Methods Study
}

Krystal Lewis-Pratl

Illinois State University, klewis@ilstu.edu

Follow this and additional works at: https://ir.library.illinoisstate.edu/etd

\section{Recommended Citation}

Lewis-Pratl, Krystal, "Special Education Preservice Teachers Culturally Responsive Teaching Self-Efficacy: A Mixed Methods Study" (2021). Theses and Dissertations. 1493.

https://ir.library.illinoisstate.edu/etd/1493

This Dissertation is brought to you for free and open access by ISU ReD: Research and eData. It has been accepted for inclusion in Theses and Dissertations by an authorized administrator of ISU ReD: Research and eData. For more information, please contact ISUReD@ilstu.edu. 


\section{SPECIAL EDUCATION PRESERVICE TEACHERS CULTURALLY RESPONSIVE TEACHING SELF-EFFICACY: A MIXED METHODS STUDY}

\section{KRYSTAL LEWIS-PRATL}

139 Pages

The racial and ethnic composition of our nation and schools are changing. Yet the demographics of teachers in the United States do not reflect the growing diversity that exists within classrooms today. There have been increases in the culturally and linguistically diverse (CLD) student population over the last two decades; however, these changes have not been realized in the diversification of educators in the field. Disproportionality data of CLD students in special education amplify the need to train all preservice educators to be culturally responsive in their practices in an effort to reduce the number of CLD learners who may be inappropriately referred for special education. This sequential explanatory mixed methods study examined preservice special education teachers' $(N=54)$ culturally responsive self-efficacy beliefs and the factors and experiences that influenced their self-efficacy through semi-structured interviews ( $n$ $=8$ ). This study sought to extend the work of Siwatu (2011a) by administering the culturally responsive teaching self-efficacy (CRTSE) scale and modifying it to include the language of disability (Chu \& Garcia, 2014). Results indicate that special education preservice teachers have moderately high CRTSE for teaching CLD learners with disabilities. Differences and commonalities between high and low self-efficacy groups are discussed.

KEYWORDS: preservice teachers, special education, culturally responsive, culturally and linguistically diverse, self-efficacy, teacher education programs, mixed methods 


\title{
SPECIAL EDUCATION PRESERVICE TEACHERS CULTURALLY RESPONSIVE TEACHING SELF-EFFICACY: A MIXED METHODS STUDY
}

KRYSTAL LEWIS-PRATL

\author{
A Dissertation Submitted in Partial \\ Fulfillment of the Requirements \\ for the Degree of \\ DOCTOR OF EDUCATION \\ Department of Special Education \\ ILLINOIS STATE UNIVERSITY
}


(C) 2021 Krystal Lewis-Pratl 


\section{SPECIAL EDUCATION PRESERVICE TEACHERS CULTURALLY RESPONSIVE TEACHING SELF-EFFICACY: A MIXED METHODS STUDY}

KRYSTAL LEWIS-PRATL

COMMITTEE MEMBERS:

Yojanna Cuenca-Carlino, Chair

Tara Kaczorowski

Jennifer Frieberg

Mark Zablocki 


\section{ACKNOWLEDGMENTS}

There are numerous people who helped me along this journey, and I would like to take a few moments to express my sincere gratitude. First, I would like to thank my exceptional chair, Dr. Yojanna Cuenca-Carlino, who has supported me from the beginning of my doctoral journey. I have learned so much from her and appreciate all of the times she would pick up the phone to offer encouragement and feedback. I would also like to thank Dr. Tara Kaczorowski, who so freely shared her knowledge, she is a wealth of information and I feel grateful to have learned from her. Thank you also to committee members Dr. Mark Zablocki and Dr. Jennifer Frieberg, I appreciate your insights and willingness to join me in the journey and helping me pivot when my original study was unable to be executed due to Covid.

Thank you also to the incredible professors who taught courses within my program. I felt humbled by the generosity you exhibited through sharing your knowledge and feedback to help me grow. I have appreciated the opportunities to join you on projects, articles and research studies. Thank you also to Dr. Karen Douglas, who first approached me about joining the doctoral cohort. I was apprehensive at first, but after my first semester, I was hooked! To Dr. Sara Jozwik and Dr. April Mustian I am so grateful for the kindness that you showed me as a new doc student and as a friend. You continue to be a support even from afar and I appreciate you both so very much.

To the Chicago cohort, you all became family! Anna, Ashley, Camille, Karla, and Mindi, I will forever hold you close in my heart and have learned so much from each of you! Such amazing educators, and I am so honored to have experienced this journey with you. 
Thank you to Dr. Latasha Schraeder for checking on me throughout the process, I have such gratitude for your willingness to encourage and offer support, and to Dr. LaTonya Harris, I will forever be grateful for our daily writing sessions near the end.

To my Bloomington Junior High School colleagues and students. Your influence is beyond measure. Each of you helped shape the educator I am today. In my book, you will always rank among the best of the best! And to the field-based co-coordinator extraordinaire, Courtney Feil, thank you for your encouragement and patience, I learn from you daily.

To my mom and dad, you have both been my biggest champions and believers since the beginning. You each cultivated my love of learning in different ways, but were always eager to listen, support and encourage. This accomplishment belongs as much to you as it does to me. A special thank you to my family, especially Debbie, my mother-in-love Kathy, and my siblings. To my precious nieces and nephews, follow your big dreams!

Finally, there should be an honorary doctorate for the spouse of a doctoral candidate! Kelly, your unwavering support, love and understanding are beyond measure. You listened to every research idea, read every draft, and helped me re-focus through the days when I doubted myself. Your love and support mean everything!

K.L.P. 


\section{CONTENTS}

Page

ACKNOWLEDGMENTS

TABLES viii

FIGURES

CHAPTER I: INTRODUCTION 1

Statement of the Problem $\quad 2$

Culturally Responsive Practice in Special Education 3

The Intersection of CRP and special education $\quad 4$

Seminal Frameworks for Culturally Responsive Pedagogy 5

$\begin{array}{ll}\text { Culturally Responsive Teacher Self-Efficacy } & 8\end{array}$

$\begin{array}{ll}\text { Purpose } & 9\end{array}$

$\begin{array}{ll}\text { Research Questions } & 11\end{array}$

$\begin{array}{ll}\text { Definitions of Terms } & 11\end{array}$

CHAPTER II: LITERATURE REVIEW 13

$\begin{array}{ll}\text { Literature Search Procedures } & 13\end{array}$

$\begin{array}{ll}\text { Theoretical Framework } & 14\end{array}$

$\begin{array}{ll}\text { Culturally Responsive Teaching Self-Efficacy } & 17\end{array}$

$\begin{array}{ll}\text { Theoretical Perspectives } & 17\end{array}$

$\begin{array}{ll}\text { Participants } & 18\end{array}$

$\begin{array}{ll}\text { Inservice Teachers } & 18\end{array}$

$\begin{array}{ll}\text { Preservice Teachers } & 19\end{array}$

$\begin{array}{ll}\text { Instruments } & 20\end{array}$ 
$\begin{array}{lr}\text { CRTSE Survey } & 20\end{array}$

Other Instruments 22

$\begin{array}{ll}\text { Methodology } & 22\end{array}$

$\begin{array}{ll}\text { Quantitative Studies } & 23\end{array}$

$\begin{array}{ll}\text { Mixed Methods Studies } & 23\end{array}$

Quantitative and Qualitative Studies $\quad 24$

$\begin{array}{ll}\text { Results } & 25\end{array}$

Teacher Education Programs' Inclusion of CRP 30

CRP Frameworks Utilized by TEPs 31

Redesigning TEPS to Include Cultural Competencies 33

$\begin{array}{ll}\text { Course redesigns } & 34\end{array}$

$\begin{array}{ll}\text { Combined programs } & 36\end{array}$

$\begin{array}{ll}\text { Field-Experiences } & 38\end{array}$

$\begin{array}{ll}\text { Outcome Data } & 41\end{array}$

$\begin{array}{ll}\text { Implications } & 46\end{array}$

CHAPTER III: METHODOLOGY AND METHODS 49

$\begin{array}{ll}\text { Methodology } & 49\end{array}$

$\begin{array}{ll}\text { Mixed Methods Design } & 50\end{array}$

Sequential Explanatory Design $\quad 51$

Implementation $\quad 51$

$\begin{array}{ll}\text { Priority } & 52\end{array}$

Integration $\quad 53$

Researcher Positionality 53 
Conceptual Frameworks $\quad 55$

$\begin{array}{ll}\text { Research Questions } & 58\end{array}$

$\begin{array}{ll}\text { Phase } 1 & 58\end{array}$

$\begin{array}{ll}\text { Ethical Considerations } & 58\end{array}$

Identification and Recruitment $\quad 59$

$\begin{array}{ll}\text { Population and Sampling } & 60\end{array}$

Data Collection for Quantitative Phase $\quad 62$

Demographic and Academic Information $\quad 63$

$\begin{array}{ll}\text { Survey Instrument } & 63\end{array}$

Data Analysis for Quantitative Phase $\quad 64$

$\begin{array}{ll}\text { Phase } 2 & 65\end{array}$

Identification and Recruitment $\quad 65$

$\begin{array}{ll}\text { Study Participants and Setting } & 66\end{array}$

Data Collection for Qualitative Phase $\quad 66$

$\begin{array}{ll}\text { Data Analysis for Qualitative Phase } & 67\end{array}$

$\begin{array}{ll}\text { First Round Coding } & 68\end{array}$

$\begin{array}{ll}\text { Second Round Coding } & 68\end{array}$

$\begin{array}{ll}\text { Fine Coding } & 69\end{array}$

$\begin{array}{ll}\text { Matrix } & 69\end{array}$

Reliability, Validity, and Ethics $\quad 69$

$\begin{array}{ll}\text { Summary } & 71\end{array}$

$\begin{array}{ll}\text { CHAPTER IV: RESULTS } & 73\end{array}$

$\begin{array}{ll}\text { Culturally Responsive Self-Efficacy Beliefs } & 73\end{array}$ 
Participant Mean Scores

Descriptive Statistics for Survey Items

Impact of Academic and Demographic Backgrounds on CRTSE

Data to Inform Participant Selection for Phase 2

Factors and Experiences that Impact CRTSE

Participant Response to High and Low Survey Items

Survey Items with the Lowest Mean Scores

Survey Items with the Highest Mean Scores

Qualitative Themes from Interviews

Acquiring Knowledge of CRT

Special Education Coursework

Thread Throughout

Coursework Outside of Special Education

Professor Impact

Low Self-efficacy

High Self-Efficacy

Culturally Responsive Teaching in Action

Learning through Observation

Application of CRT

Experiences with CRT

Personal Growth 
$\begin{array}{ll}\text { CHAPTER V: DISCUSSION } & 103\end{array}$

$\begin{array}{ll}\text { Interpretation of the Findings } & 105\end{array}$

$\begin{array}{ll}\text { Item Specific-Means } & 106\end{array}$

$\begin{array}{ll}\text { Qualitative Themes } & 108\end{array}$

$\begin{array}{ll}\text { Acquiring Knowledge of CRT } & 108\end{array}$

$\begin{array}{ll}\text { Professor Impact } & 110\end{array}$

Culturally Responsive Teaching in Action 112

$\begin{array}{ll}\text { Experiences with CRT } & 114\end{array}$

$\begin{array}{ll}\text { Limitations } & 115\end{array}$

Recommendations for Practice and Future Research 116

$\begin{array}{ll}\text { Conclusion } & 119\end{array}$

$\begin{array}{lr}\text { REFERENCES } & 121\end{array}$

APPENDIX A: DEMOGRAPHIC AND SURVEY ITEMS 133

APPENDIX B:INTRODUCTION SCRIPT AND INTERVIEW QUESTIONS 136

APPENDIX C: CODEBOOK FRAMEWORK AND DEFINITIONS 137 


\section{TABLES}

Table

Page

1. Summary of Literature Review Results on Culturally Responsive Teaching Self-Efficacy

2. Summary of TEP and CRP Literature Review Results

3. Summary of Academic and Demographic Background Information

4. Participant Mean Score Ranges

5. Descriptive Statistics for each Survey Item

6. Non-Parametric Kruskal-Wallis Test for Demographic Group Differences

7. Descriptive Statistics of Independent Variables

8. Participant Demographics for Phase 2

9. CRTSE Beliefs Among Phase 2 Participants

10. Average Number of CRTSE Practices that were Discussed, Observed, Practiced

11. Survey Items with Lowest and Highest Mean Scores 


\section{FIGURES}

Figure

Page

1. Visual Representation of Mixed Methods Design

2. Qualitative Coding Process

3. Interview Themes and Subthemes 


\section{CHAPTER I: INTRODUCTION}

The student population of the United States reflects the multitude of cultures and languages present in our country. The National Center for Education Statistics (NCES) prediction trends indicate the changes in student populations from 2010 to 2018. There has been an increase in Hispanic learners and students who belong to two or more ethnic groups (22\% to $27 \%$ and $1 \%$ to $4 \%$ respectively); while White and Black student populations have decreased ( $54 \%$ to $47 \%$, and $17 \%$ to $15 \%$, respectively; (U.S. DOE, 2021). Hussar and Bailey (2020) project that by 2028 the percentage of White students will decrease an additional 7\%. In contrast, there will be an increase of Black (1\%), Hispanic (8\%), Asian/Pacific Islanders (20\%), and students who are from two or more racial/ethnic groups (51\%).

The racial and ethnic composition of our nation and schools are changing. Yet the demographics of teachers in this country do not reflect the growing diversity that exists within classrooms today. There have been increases in the culturally and linguistically diverse (CLD) student population over the last two decades; however, these changes have not been realized in the diversification of educators in the field. In $1988,87 \%$ of the teaching workforce was White; three decades later, $82 \%$ percent of the teachers in our schools are White, with only $18 \%$ of the teachers being from CLD backgrounds (U.S. DOE, 2016). Preservice and inservice teachers are predominantly White females from suburban or rural settings that may have little knowledge of learners with CLD backgrounds (Imler, 2009; Kahn et al., 2014; Taylor, 2010; Trent et al., 2008).

Educators bring their values and experiences into the classroom (DeCastro-Ambrosetti \& Cho, 2011). If the values and experiences that teachers bring into the classroom differ from their learners, and the teacher lacks cultural awareness, there is a potential for cultural dissonance 
(Kahn et al., 2014; Williams Shealey, 2006), which can lead to inequitable opportunities for CLD learners. However, an emerging body of evidence suggests that culturally responsive teaching (CRT) can provide equitable experiences for CLD learners (Cruz et al., 2020).

\section{Statement of the Problem}

Including culturally responsive pedagogy (CRP) as part of the core curriculum is essential for all teacher candidates; however, it is especially paramount for teacher candidates working with learners with disabilities who are also from CLD backgrounds. Culturally responsive practices should be taught to special education teachers so they can identify and service diverse learners (Moore, 2018). In 2007, the National Education Association (NEA) and the National Association of School Psychologists (NASP) both reported that there is a disproportionate representation of CLD learners in special education, and this has been a concern for nearly four decades (Cyr et al., 2012). Determining causality of disproportionality is a complex and multidimensional issue that likely does not recognize the cultural capital of CLD learners, which in turn inhibits their success (Yosso, 2005). Cultural dissonance also has a role in the overrepresentation of minority learners in special education, especially in disability categories where eligibility criteria are more subjective such as cognitive impairment, emotional disability, and learning disabilities (Skiba et al., 2008, 2016). Overall, both general and special education teachers have had inadequate preparation to teach CLD learners, which has resulted in more referrals and over-identification of CLD learners in special education (Skiba et al., 2008). Trent and colleagues (2008) discussed cultural dissonance as an area for teacher education programs (TEPs) to address. Cultural dissonance is one of the complex factors that leads to disproportionality of CLD learners in special education. Preservice teachers can learn to foster 
their cultural awareness, so that cultural dissonance can be disrupted (Moore, 2018) when TEPs intercede by including CRP in their curriculum.

Disproportionality data of CLD students in special education amplify the need to train all preservice educators to be culturally responsive in their practices in an effort to reduce the number of avoidable referrals of CLD learners in special education programs (Skiba et al., 2008; Taylor, 2010). Furthermore, special educators must understand the difference between cultural and linguistic needs versus those that are characteristic(s) of a disability so that they can make more equitable and educated decisions (Hoover, 2012; Skiba et al., 2008).

The Individuals with Disabilities Education Act (IDEA) P.L. 105-17, section 674, included a response to disproportionality that outlined efforts to monitor and reduce overidentification of CLD learners in the local education agency (LEA). In the Individuals with Disabilities Education Improvement Act (IDEIA) of 2004, placement type (i.e., included in general education or excluded) was monitored as well as disproportionality rates in suspension/expulsion, and other disciplinary actions (Williams, 2007). If it is determined that an LEA has disproportionate disciplinary rates or restrictive placements, then it is required by IDEIA for the LEA to use their federal dollars to provide intervention services to the groups impacted. Evaluation of existing policies, procedures, and practices for referring students to special education must also be assessed with these funds (Williams, 2007). IDEIA also included language regarding the need to prepare teachers for working with CLD learners.

\section{Culturally Responsive Practice in Special Education}

Several critical issues impact learners identified as having a disability and belonging to a cultural group(s) outside of the dominant culture. Some of these challenges can be derived from the preparation that general and special education teachers receive in their training programs. 
Another factor relates to teacher performance evaluations, which are based on student growth and how this may lead to the overidentification of CLD learners in special education. The compartmentalization of general education, bilingual, or special education programs has resulted in preservice teachers being educated in silos. By compartmentalizing programs and courses on disability and diversity, an unintentional message has been relayed to novice teachers that it takes a specialized type of teacher to teach learners from backgrounds different than their own (Rueda \& Stillman, 2012). Teacher educators have focused on educational equity for decades; however, these conversations tend to occur within niche communities, such as urban education, special education, and bilingual education, rather than across them (Pugach et al., 2012).

\section{The Intersection of CRP and special education}

Intersectionality is the complex and concurrent interaction of identity markers such as race, social class, gender, culture, and disability (Robinson \& West, 2012). These identity markers shape and influence our practices within schools. Identity categories cannot be treated as autonomous characteristics, as it is the intersection of these markers that marginalize or oppress a person who belongs to two or more of these groups. Certain markers may lessen the stigma for some and disadvantage others even more (Garcia \& Ortiz, 2013). Within schools, when educators view the intersection of identity categories as static, we begin to stereotype learners as evidenced by discipline referrals, special education referrals, and program placements (Garcia \& Ortiz, 2013).

Previous research has established the need to develop culturally responsive and competent special educators (Dykes et al., 2012; Imler, 2009; Kea \& Trent, 2013; Sobel et al., 2011; Taylor, 2010). Urbach et al., (2015) posit that special educators hold the possibility to act as change agents due to their ability to recognize the unique strengths of their learners and 
advocate for their needs. Specifically, TEPs should explore pedagogies that assist teachers in developing asset-based versus deficit-based ideologies (Dray \& Basler-Wisneski, 2011).

Teachers must first establish reflective practices to understand the assumptions and misunderstandings they hold, which can lead to tensions between teachers and their learners (Dray \& Basler-Wisneski, 2011). TEPs must consider and address Whiteness when preparing future teachers so they are ready to make choices for social justice in education actively (Hayes \& Juarez, 2012). Racial equity should be a value on which teacher preparers shine a light as they uncover how schools have historically under-supported and problematized CLD learners (GulatiPartee \& Potapchuk, 2014). Teachers must also regard the community in which schools are situated as a resource that has funds of knowledge (Moll et al., 1992) instead of perpetuating the notion that learners should assimilate to the unquestioned standards of the dominant culture (Gulati-Partee \& Potapchuk, 2014). To implement CRT effectively, preservice teachers must engage and experience implementing this pedagogy within their TEP (Cruz et al., 2020).

\section{Seminal Frameworks for Culturally Responsive Pedagogy}

Culturally responsive pedagogy was first theorized by Ladson-Billings (1995) when she flipped the narrative of what is wrong with Black learners to what is right with them. She also investigated the types of pedagogical decisions that successful teachers incorporated as they taught Black learners (Ladson-Billings, 2014). After the initial findings were published, LadsonBillings' CRP framework has been widely used and expanded in TEPs to include cultural considerations for learners who are culturally and linguistically diverse (CLD).

Since its inception, CRP has been examined within TEPs by many scholars in teacher preparation (Hayes \& Juarez, 2012). It concerns scholars of CRP to see it minimized to a set of 
checklists that have strayed from its original intent and rather is viewed as a set of steps to perform instead of a transformative process that should inform practice (Allen et al., 2017).

In addition to Ladson-Billings CRP framework, there are other theoretical and conceptual frameworks frequently utilized by teacher educators to include CRP into their curricula. Critical Race Theory includes five tenets that should inform theory, research, pedagogy, curriculum, and policy (Yosso, 2005). A framework that was developed by Villegas and Lucas (2002) includes six strands focusing on sociocultural consciousness, affirmation of attitudes, agents of change, construction of new knowledge, inclusion of students, families and communities as resources, and cultivation of CRP (Villegas \& Lucas, 2002). Each of these frameworks include critical components that the authors expand upon to move teacher educators and preservice teachers towards cultural competence.

Distinct differences and similarities exist amongst the aforementioned CRP frameworks. The salient features that the three frameworks have in common include: (a) rejecting deficit views of culture and having an asset-based philosophy when teaching CLD learners, (b) having a sociopolitical/sociocultural awareness of how people's thoughts and behaviors are influenced by factors such as social class, language, race and ethnicity, (c) examining attitudes, beliefs, and perceptions about CLD learners and finally, (d) including family and community as educational partners.

Having an affirmative attitude toward students from backgrounds that are different from the dominant culture means that teachers understand there are numerous ways of thinking and evidencing knowledge (Villegas \& Lucas, 2002). The primary focus of the CRP framework was to improve teacher education by encouraging preservice teachers to stop looking at what CLD learners cannot do and begin viewing the strengths that they bring to the learning environment 
(Ladson-Billings, 2014). One of the five tenets of Critical Race Theory is the centrality of experiential knowledge, which recognizes experiences such as storytelling, sharing of family histories, and parables as valuable expressions of knowledge (Yosso, 2005). As teachers expand their cultural competence, they will likely need to challenge the dominant ideology of how knowledge is evidenced and recognize cultural differences as assets to learning.

Factors such as race, social class, and language have a significant impact on the ways in which people think and behave (Villegas \& Lucas, 2002). Inservice and preservice teachers must first examine their own sociocultural identities in order to understand that some social positions are bestowed greater status, which ultimately equates to power. A lens of differential power influences and shapes experiences in the classroom and ultimately how students view the world (Villegas \& Lucas, 2002). Social justice agendas such as CRT aim to eliminate racism, sexism, and poverty, while empowering People of Color and other marginalized groups (Yosso, 2005). Having an understanding of cultural and political influences and the ability to take learning beyond the classroom are characteristics that Ladson-Billings (2014) recognized in teachers that were successful with CLD learners.

When teachers manifest an affirming attitude, it has been shown to increase achievement (Ladson-Billings, 1995). Expectations for learners are significantly shaped by the attitudes that teachers hold toward students and ultimately impact what they learn (Villegas \& Lucas, 2002). Critical Race Theory challenges the notions of White privilege and refutes claims of objectivity, race neutrality, and equal opportunity within institutions of education. According to Yosso (2005), layers of deficit-informed views should be challenged to dismantle the power and privilege of dominant groups. 
White, middle class culture has long been the dominant culture within educational communities. Critical Race Theory aims to better understand how cultural capital can be shifted from being solely based on income and wealth, but to extend this lens to community cultural capital that serves as a collective identity to empower an entire group (Yosso, 2005). When teachers become interested in the family and community influences of their learners, it enables them to draw on those experiences and incorporate them into learning activities within the classroom (Villegas \& Lucas, 2002). Teachers who engage in CRP understand the importance of involving students and the community to make learning meaningful (Ladson-Billings, 2014).

\section{Culturally Responsive Teacher Self-Efficacy}

When it comes to preparing the next generation of culturally responsive teachers entering our nation's classrooms, TEPs are at the helm (Allen et al., 2017). The existing literature indicates the need for CRP in TEPs; however, few have effectively equipped teacher candidates with truly transformative pedagogies that move beyond cultural celebrations and symbols (Brown-Jeffy \& Cooper, 2011). Irvine (2012) asserts that CRP should be considered foundational to the curriculum for all educators, and Gay (1995) posits that no teacher candidate should graduate from a TEP without understanding the impact that culture has on teaching and learning. To accomplish this, TEPs need to make structural changes to their programs to enhance dialogue around curriculum, field experiences, research methodology, pedagogy, and assessments (Irvine, 2012). While TEPs have been restructuring their courses and programs to better prepare preservice teachers to use evidence-based practices with CLD learners (Scott et al., 2014), how do we know if these efforts are successful? Recent literature reviews on special education TEPs and their inclusion of CRP (Lewis-Pratl et al., 2021; Trent et al., 2008) indicate that several teacher educators have worked to redesign their curriculums to include cultural 
competencies few studies include any type of outcome data to understand if the changes that they have made have resulted in preparing preservice special educators for the CLD learners that they will encounter. Evaluation measures are needed to understand the factors that influence a teacher's capacity to include CRT in their professional practice (Cruz et al., 2020). A possibility for TEPs to explore is the use of self-efficacy measures to determine how teacher candidates perceive their ability to teach learners with disabilities from CLD backgrounds.

Over the last forty years, teacher educators have been examining teachers' beliefs on their abilities to teach effectively. Bandura (1977) posits that teacher efficacy beliefs are causal and that certain behaviors will produce specific outcomes. Teacher self-efficacy is a teacher's belief in their ability to influence student learning and achievement. Recently, teacher self-efficacy of culturally responsive practices has focused on the role of culture and ethnicity in teaching and learning (Chu \& Garcia, 2014). A student's cultural and linguistic identity is imperative to learning, and it is essential to understand if teacher candidates feel prepared for this responsibility. As TEPs continue to put effort into preparing culturally responsive teachers, there is a need to understand if preservice teachers are efficacious in their beliefs that they can employ CRP in their classrooms (Siwatu, 2007).

\section{Purpose}

In this study, I plan to replicate and extend previous studies on the Culturally Responsive Teaching Self Efficacy (CRTSE) scale (Siwatu, 2007). Siwatu (2007) developed the CRTSE scale based on the culturally responsive teaching competencies and utilized Bandura's (1977) self-efficacy construct. The purpose of the CRTSE scale was to extract information from preservice teachers to understand their efficacy better as it relates to specific culturally responsive teaching practices. Two hundred and seventy-five preservice teachers in the 
elementary, middle level and secondary programs from two different TEPs in the Midwest completed the survey in the original study. The scale consisted of 40 Likert-type questions where participants rated their perceived confidence level to be culturally responsive in their future classrooms. A higher total score equated to higher self-efficacy. Chu and Garcia (2014) adapted the original CRTSE scale by reducing the number of items on the survey and included language around disability for each question. Researchers administered the survey to inservice special education teachers that had been teaching for less than a year, and up to 15 years. As part of their work, Chu and Garcia (2014) also sought to understand collective self-efficacy versus individual self-efficacy scores. To expand the body of literature, I plan to conduct a mixed methods study to explore the overall CRTSE of preservice special educators (quantitative), as well as explore the factors and experiences (mixed) that preservice special educators attribute to their CRTSE selfefficacy. This will be the first mixed methods CRTSE study that focuses solely on preservice special educators and understanding why they rank themselves the way they do in regards to their culturally responsive teaching self-efficacy of learners with disabilities.

The objective of this mixed methods study, which employs a pragmatic paradigm, is to understand better the culturally responsive teaching self-efficacy beliefs of special education preservice teachers. To accomplish this, an adapted CRTSE was administered to preservice special educators and includes language that encompasses disability. This study also identifies the types of experiences (coursework or personal) through semi-structured interviews that preservice teachers have encountered (or lack thereof) during their teacher preparation program and how those experiences have influenced their culturally responsive self-efficacy beliefs. 


\section{Research Questions}

1. [QUANT] (a) What are preservice special educators' culturally responsive self-efficacy beliefs? (b) To what extent do these beliefs differ based on academic and/or demographic backgrounds?

2. [MIXED] (a) What factors and/or experiences do preservice special educators describe as impacting their CRT self-efficacy? (b) How do these factors and/or experiences differ among those with high/low CRT self-efficacy scores?

\section{Definitions of Terms}

Culturally and Linguistically Diverse (CLD): Culturally and linguistically diverse students are defined by the U.S. Department of Education (U.S. DOE) as either non-English proficient or limited-English proficient. The definition also includes students from diverse social, cultural, and economic backgrounds and/or homes where English is not the primary language (Terry \& Irving, 2010). For this paper, CLD also includes students from diverse racial and ethnic backgrounds where English is the primary language.

Culturally Responsive Teaching Self-Efficacy (CRTSE): A teacher's belief in their ability to execute specific teaching practices and tasks that are associated with teachers who are believed to be culturally responsive. These teaching practices are based on the theoretical findings of seminal authors who have researched culturally responsive pedagogy (Gay, 2010; LadsonBillings, 1995; Villegas \& Lucas, 2002).

Culturally Responsive Pedagogy (CRP): When seeking a definition of CRP in the literature, other terms include, culturally responsive instruction, culturally relevant pedagogy, funds of knowledge, and culturally sustaining pedagogies. While there are differences between each, they all share commonalities, such as rejecting deficit views of CLD students and view cultural norms 
as significant to learning (Nasir et al., 2006). Culturally responsive pedagogy recognizes the importance of including student's culture in all aspects of learning (Ladson-Billings, 1995) and rejects notions of color-blindness or deficit views of culture. CRP is an asset-based philosophy for teaching learners while having a sociopolitical/sociocultural awareness of how people's thoughts and behaviors are influenced by factors such as social class, language, race and ethnicity; examining attitudes, beliefs, and perceptions about CLD learners; and finally, including family and community as educational partners.

Culturally Responsive Teaching (CRT): Geneva Gay is one of the seminal authors in the field of CRP and her definition of culturally responsive teaching is widely cited in the literature (BrownJeffy \& Cooper, 2011; Ellerbrock et al., 2016; Garcia et al., 2010; Rychly \& Graves, 2012). She defines culturally responsive teaching as a set of values that are contingent on seeing cultural differences as assets where teachers create caring learning environments, leveraging cultural knowledge to guide curriculum development, instructional strategies and relationship building with learners. Gay goes on to assert that stereotypes should be challenged while engaging in social justice and academic equity (Gay, 2010).

Inservice Teachers: Teachers who hold licensure and are currently teaching in a PK-12 school. Preservice Teachers: Teacher candidates who are enrolled in a teacher education program and are participating in clinical experiences such as practicums, field-work and/or student teaching 


\section{CHAPTER II: LITERATURE REVIEW}

This chapter presents an overview of the literature that is threefold. First this review presents the theoretical framework of Bandura's self-efficacy theory as well as the sources of information that develop self-efficacy. Secondly, a review of published studies that measured culturally responsive teaching self-efficacy of preservice or inservice teachers. Lastly, an overview of the ways that TEPs have included culturally responsive competencies into their coursework and licensure programs.

The current research base offers direction for future research. Through the examination of TEPs across the country, it was noted that there is little published research on special education TEPs and even less that include outcome data to determine the effectiveness of faculty efforts to include cultural competence in their programs. Additionally, the current research base emphasizes the importance of experiential and field experiences to develop cultural competence.

\section{Literature Search Procedures}

I conducted a comprehensive search of the literature using three methods: (a) keyword searches in subject indexes, (b) browsing, and (c) hand-search. The following procedures were executed to identify relevant articles. First, I conducted a comprehensive search of key online databases (i.e., Eric Resources Information Center (ERIC) in Ebsco, Academic Search Complete, Professional Development Collection, Primary Search, and PsychINFO). I used the following descriptors and keywords to locate unpublished dissertations or articles published in peerreviewed journals pertaining to teacher preparation and culturally responsive practices: teacher preparation OR teacher education programs, culturally responsive pedagogy OR the truncated term culturally re* (to include responsive, relevant, responsive pedagogy, relevant pedagogy, 
etc.) along with special education, and self-efficacy. The second step involved conducting a hand-search by reviewing reference lists of the articles from the systematic review.

To determine which articles to include in the review, I established four criteria. Articles were chosen that met the following inclusionary criteria: (a) focused on teacher preparation programs and/or preservice teachers (b) provided detailed information on the curricular process for including CRP (c) or included conceptual or theoretical frameworks for rethinking CRP in TEPs and (d) studies on culturally responsive teaching self-efficacy with either preservice or inservice teachers.

Since the purpose of the literature review is threefold, findings will be presented in multiple sections. The first focus of the literature review was to explore the theoretical framework of self-efficacy, the second focus was on published studies that measured culturally responsive teacher self-efficacy, which will be discussed later in this chapter. Lastly an overview of the ways that TEPs are including culturally responsive competencies into their coursework to better prepare preservice teachers for their work with CLD students.

\section{Theoretical Framework}

Bandura's $(1977,1986,1997)$ theory of self-efficacy is grounded in Social Learning Theory and has been used to explore the importance of teacher beliefs for the last four decades (Malo-Juvera et al., 2018). Teacher self-efficacy has been characterized as a teacher's belief in their ability to positively affect student learning and achievement (Gibson \& Dembo, 1984). Additionally, it means having the resiliency to persist when teaching becomes challenging (Gibson \& Dembo, 1984). The construct of self-efficacy is based on the belief that to be an effective teacher; one must possess more than knowledge and skills but a strong belief in their ability to put those skills into action (Bandura, 1993). Teacher self-efficacy beliefs may predict 
whether preservice teachers will actualize CRT practices that they have learned in their coursework once they enter the classroom (Bandura, 1997). Researchers have shown that high teacher self-efficacy results in effective decision-making regarding students, particularly students that are considered difficult to reach (Malo-Juvera et al., 2018).

Teachers with high self-efficacy have been associated with positive learning outcomes for themselves and their learners (Cruz et al., 2020). Furthermore, those with higher levels of self-efficacy have been linked to having greater flexibility, perseverance and endurance (Pajares et al., 2001). Cultivating self-efficacy in targeted areas such as CRT provides an opportunity for preservice teachers to develop their skills (Cruz et al., 2020). For preservice teachers to develop their self-efficacy, it is crucial for teacher educators to understand the process and sources of information that are attributed to increasing self-efficacy.

Bandura (1977) described the effective sources of information required for a person to develop their self-efficacy. He theorized that there are four distinct sources of information (physiological and emotional states, vicarious experiences, mastery experiences, and verbal and social persuasion) that contribute to developing self-efficacy beliefs. Of the four sources of information, Bandura (1977) asserts that the mastery experience is the most powerful source for increasing self-efficacy. As it relates to teacher self-efficacy, actual teaching experiences, whether in small or whole group instruction, are what shapes confidence (Clark, 2020). It is through these teaching experiences that preservice teachers are able to amass an opinion on their effectiveness in the classroom. Bandura (1977) discussed the importance of mastery experiences that provide challenge, as it is these challenging experiences that allow people to grow in their efficacy. Self-efficacy increases when a teacher perceives that their learners benefited from their instruction, which in-turn increases their confidence that future teaching experiences will also be 
successful. In the upcoming section on TEPs and their inclusion of CRP, field-experiences are discussed as a critical component of increasing CRT through mastery experiences in the field while still under the supervision of university faculty.

Vicarious experiences are another source of information that impacts self-efficacy (Bandura, 1977). In the teaching context, modeling is key to increasing self-efficacy beliefs. When we observe someone successfully execute a task, this can influence our own beliefs and help us to believe that we too can be successful because of this vicarious experience (Bandura, 1977). During clinical experiences, preservice teachers have many opportunities to see teaching modeled and are then able to follow-up through discussions to learn about effective strategies that were observed (Clark, 2020). Having strong models of CRT during clinical experiences are explored further in the section on TEPs and how they are including CRP into their existing programs.

Finally, Bandura (1977) asserts the importance of verbal and social persuasion. Bandura theorized that people gather information from the verbal messages of those with experience. During field-experiences, preservice teachers are the recipients of verbal feedback on their teaching performance. Self-efficacy can be developed as a result of encouragement, positive and critical feedback that is shared from mentors, cooperating teachers, university supervisors, and peers to increase their sense of self-efficacy (Clark, 2020; Lee \& Klein, 2002). Understanding the varied sources of information for increasing self-efficacy will inform the analysis of interviews and understanding of the specific sources of information that participants describe as meaningful to their self-efficacy growth. 


\section{Culturally Responsive Teaching Self-Efficacy}

The second focus of this literature review was to explore existing research studies on culturally responsive teaching self-efficacy. A total of 18 research studies on teachers' culturally responsive teaching self-efficacy beliefs (Table 2), published within the last 15 years were reviewed (i.e., Chu \& Garcia, 2014; Cruz et al., 2020; Debnam et al., 2015; Dickson et al., 2016; Fitchett et al., 2012; Larson et al., 2018; Malo-Juvera et al., 2018; Siwatu, 2007, 2008, 2009, 2011a, 2011b; Siwatu \& Polydore, 2010; Siwatu \& Starker, 2010; Siwatu et al., 2009, 2016, 2017; Whitaker \& Valtierra, 2018).

Researchers have examined CRTSE in a variety of ways. The following is an examination of existing CRTSE studies to better understand the design decisions that researchers included when designing their studies. Findings of this exploration are presented by salient features noted within their design, including: (a) theoretical perspectives used, (b) population of participants, (c) instruments used to determine culturally responsive self-efficacy, (d) methodology choices and, (e) results or outcomes of the study.

\section{Theoretical Perspectives}

All but one of the studies examined grounded their study in Bandura's Social Learning Theory (i.e., Chu \& Garcia, 2014; Cruz et al., 2020; Debnam et al., 2015; Dickson et al., 2016; Fitchett et al., 2012; Larson et al., 2018; Malo-Juvera et al., 2018; Siwatu, 2007, 2008, 2009, 2011a, 2011b; Siwatu \& Polydore, 2010; Siwatu \& Starker, 2010; Siwatu et al., 2009, 2016, 2017). In addition to Social Learning Theory, Siwatu and colleagues (2016), also included Skinner's Taxonomy of Control Beliefs to build a foundation for understanding the self-efficacy doubts that preservice teachers held. 
Whitaker and Valtierra (2018) acknowledged that while Bandura's framework is commonly used to evaluate self-efficacy, they intended to extend the theoretical framework by grounding their work in expectancy-value. The researchers wanted to understand preservice teachers' self-efficacy and also understand their emotional response as they imagined working in a CLD classroom. The researchers drew on variables such as self-schemata, expectations of success, and their interest in teaching diverse learners.

\section{Participants}

The majority of studies reviewed focused on either inservice or preservice teachers. However, one study (i.e., Dickson et al., 2016) surveyed middle school students $\left(7^{\text {th }}\right.$ and $8^{\text {th }}$ grade) to evaluate the self-efficacy of their teachers. Two studies included both preservice and inservice teachers (i.e., Cruz et al., 2020; Siwatu et al., 2017). All but two of the studies included general education preservice or inservice teachers (i.e., Debnam et al., 2015; Fitchett et al., 2012; Larson et al., 2018; Malo-Juvera et al., 2018; Siwatu, 2007, 2008, 2009, 2011a, 2011b; Siwatu et al., 2009, 2016, 2017; Siwatu \& Polydore, 2010; Siwatu \& Starker, 2010; Whitaker \& Valtierra, 2018), and two studies included special education teachers (i.e., Chu \& Garcia, 2014; Cruz et al., 2020). Participants in the Chu and Garcia (2014) study were all inservice special education teachers, whereas Cruz and colleagues (2020) included both special education and general education preservice and inservice teachers.

\section{Inservice Teachers}

Five culturally responsive teaching self-efficacy studies were conducted with inservice teachers (i.e., Chu \& Garcia, 2014; Debnam et al., 2015; Fitchett et al., 2012; Larson et al., 2018; Malo-Juvera et al., 2018), and two studies included both preservice and inservice teachers (i.e., Cruz et al., 2020; Siwatu et al., 2017). The number of inservice teachers surveyed in each study 
varied. The most extensive study included 344 special educators from 10 large districts with, 155 participants having EL experience (i.e., Chu \& Garcia, 2014). The other studies with inservice participants (i.e., Debnam, et al., 2015; Larson et al., 2018), had 142 and 274 participants, respectively, and both included participants from several schools.

Two studies included fewer than 30 participants, with the fewest participants being 20 social studies teachers who were part of a Master's level course that focused on social studies methods (i.e., Fitchett et al., 2012). Malo-Juvera and colleagues (2018) conducted their study with 26 elementary teachers from a Midwestern elementary school.

\section{Preservice Teachers}

Ten of the culturally responsive teaching self-efficacy studies were conducted with preservice teacher candidates in general education programs (i.e., Siwatu, 2007, 2008, 2009, 2011a, 2011b; Siwatu et al., 2009, 2016; Siwatu \& Polydore, 2010; Siwatu \& Starker, 2010; Whitaker \& Valtierra, 2018). Additionally, most of the participants at the preservice level were in an undergraduate teacher preparation with the exception of one (i.e., Whitaker \& Valtierra, 2018) whose participants were part of a master's cohort.

The majority of studies conducted with general education preservice teachers had fewer than 100 participants (i.e., Siwatu, 2008, 2009, 2011b; Siwatu et al., 2016; Siwatu \& Polydore, 2010; Siwatu \& Starker, 2010; Whitaker \& Valtierra, 2018), with the fewest participants being 8 (Siwatu et al., 2016) and an overall mean score of 51 participants. There were three studies with more than 100 participants (i.e., Siwatu, 2007, 2011a; Siwatu et al., 2009), with the largest being 275 participants (Siwatu, 2007). Table 2 specifies participants across all research studies. 


\section{Instruments}

Sixteen of the articles reviewed used the CRTSE developed by Siwatu (2007) either in its entirety or some modification of the scale or number of items included (i.e., Chu \& Garcia, 2014; Cruz et al., 2020; Debnam et al., 2015; Dickson et al., 2016; Fitchett et al., 2012; Malo-Juvera et al., 2018; Siwatu, 2007, 2008, 2009, 2011a, 2011b; Siwatu \& Starker, 2010; Siwatu et al., 2009, 2016, 2017; Whitaker \& Valtierra, 2018).

Two sets of researchers did not use the CRTSE survey as part of their evaluation of selfefficacy (i.e., Larson et al., 2018; Siwatu \& Polydore, 2010). Larson and colleagues (2018) used the Multicultural Efficacy Scale which, utilized a 6-point Likert scale survey. Siwatu and Polydore (2010) used a case study to determine the self-efficacy of preservice teachers which, will be explained further in the instruments section.

\section{CRTSE Survey}

Siwatu's (2007) development of the CRTSE scale was rooted in Bandura's (1977) constructs and guided by: (a) the need to evidence culturally responsive teaching practices that focused on instructional effectiveness, behavior management, and student learning, and (b) the lack of an effective tool to assess the effectiveness of CRP in TEPs. As a result, Siwatu (2007) developed the 40-item CRTSE that measures teachers' confidence in their abilities to employ culturally responsive teaching practices. The scale uses a 0 (no confidence at all) to 100 (completely confident) Likert-type scale that has been validated with a Cronbach's alpha of .96.

When developing the CRTSE, Siwatu (2007) relied on Bandura's (1977) constructs to ensure that he included a variety of items from easy to hard to avoid ceiling effects (Siwatu, 2007). Additionally, Siwatu subscribed to Bandura's (1977) positionality that the best way to measure teacher self-efficacy was to use a continuum scale that allows for differences between 
individuals who respond similarly. Other teacher efficacy scales have condensed to a 5- or 6point Liker-type scale (Chu \& Garcia, 2014; Debnam et al., 2015; Gibson \& Dembo, 1984; Larson et al., 2018). However, Pajares and colleagues (2001) asserted that a 0-100 scale is psychometrically stronger than using a Likert Scale from 1-5.

While the CRTSE was the instrument used in most research studies, some researchers did include an additional instrument such as another survey, observation tool, or questionnaire. For example, the culturally responsive teaching outcome expectancy survey (CRTOE), was developed by Siwatu (2007) and also used by Chu and Garcia (2014) to determine If there was a correlation between a teacher's CRTSE score and their CRTOE score which is how they perceive they would impact student learning.

One research team paired the CRTSE scale with teacher observations (Debnam et al., 2015). Inservice teachers first completed a modified version of the CRTSE with fewer items (15) and included a Likert scale (1-6) that differed from the original design. The Assessing School Settings: Interactions of Students and Teachers (ASSIST) observational measure was used during teacher observations. Training occurred for the five individuals that conducted the 15minute scheduled observations. Each of the five observers conducted 13-14 teacher observations. ASSIST was used to measure proactive behavior management, as well as the number of opportunities that students had to respond to, the type of approval, disapproval, and reactive behavior management that was used.

Of the sixteen research teams that used the CRTSE survey instrument in their study, seven of them (i.e., Chu \& Garcia, 2014; Cruz et al., 2020; Debnam et al., 2015; Dickson et al., 2016; Siwatu, 2007; Siwatu et al., 2016; Siwatu \& Starker, 2010) included a demographic 
questionnaire to better understand if self-efficacy was impacted by factors such as gender, race/ethnicity, and academic levels.

\section{Other Instruments}

Larson and colleagues (2018) were the only researchers that used a different approach to measure the outcomes of teacher self-efficacy as it relates to cultural competence. They sought to compare culturally responsive self-efficacy ratings with observed classroom outcomes utilizing the ASSIST observation tool that was previously discussed (Debnam et al., 2015). The researchers used the MES (multicultural efficacy scale), a 14 item self-efficacy scale to determine a teacher's comfort in multicultural environments. There were 274 general and special education teachers across 18 schools who participated in the study. Similarly, in the Debnam et al., (2015) study, one 15-minute scheduled observation was used to determine if proactive behavior management strategies were being used. The authors reported that they were surprised that they did not find that culturally responsive self-efficacy and behavior management were not positively associated with the observed outcomes. It was also noted that general education teachers were less self-efficacious with behavior management strategies than their special education colleagues. However, general education teachers were observed using more CRT strategies in their scheduled observations. The authors note that these unexpected results could be due to abbreviating the items on the self-report and for only conducting one classroom observation (Larson et al., 2018).

\section{Methodology}

Across all studies that were reviewed, researchers leveraged a variety of method designs to answer their research questions that related to the level of self-efficacy of either inservice or preservice teachers. The majority of researchers chose quantitative measures $(n=13)$, mixed 
methods was the next most frequent choice $(n=3)$, followed by both quantitative and qualitative approaches that were not mixed $(n=2)$.

\section{Quantitative Studies}

Thirteen of the 18 research studies included in the literature review chose quantitative measures to determine the culturally responsive self-efficacy of preservice or inservice teachers (i.e., Chu \& Garcia, 2014; Cruz et al., 2020; Debnam et al., 2015; Dickson et al., 2016; Fitchett et al., 2012; Larson et al., 2018; Siwatu, 2007, 2008, 2009, 2011b; Siwatu \& Starker, 2010; Siwatu et al., 2009, 2017). In addition, all but one of the research studies (i.e., Larson et al., 2018) used the results from the CRTSE scale as their primary data collection tool.

Descriptive statistics were calculated most often to determine overall CRTSE score or item-specific means (i.e., Cruz et al., 2020; Debnam et al., 2015; Dickson et al., 2016; Fitchett et al., 2012; Larson et al., 2018; Siwatu, 2007, 2008; Siwatu et al., 2009, 2017). In addition to descriptive statistics, some researchers utilized experimental designs (i.e., Fitchett et al., 2012; Siwatu, 2011b). Other studies included correlational analysis (i.e., Chu \& Garcia, 2014; Larson et al., 2018; Siwatu et al., 2017; Siwatu \& Starker, 2010).

\section{Mixed Methods Studies}

All of the researchers who conducted mixed methods studies utilized the CRTSE survey as part of the quantitative portion of their study and then conducted follow-up interviews with participants (i.e., Malo-Juvera et al., 2018; Siwatu, 2011a; Whitaker \& Valtierra, 2018).

Malo-Juvera and colleagues (2018) used the CRTSE to develop typologies of teachers based on their self-efficacy towards culturally responsive practices. The authors used Q-factor analysis and follow-up interviews to gain a deeper understanding of why teachers rated themselves the way they did. Siwatu (2011a) also used the CRTSE to conduct a sequential 
explanatory mixed methods study. He used quantitative data from Phase 1 of his study to purposefully select participants from high and low self-efficacy groups for semi-structured interviews.

Whitaker and Valtierra (2018) conducted a two-year mixed-method case study with 22 preservice teachers that were earning a Master of Arts in Teaching degree. A pre- and post-test of the CRTSE was administered at the beginning and end of the cohort to all participants. Eight participants were also selected for in-depth follow-up interviews to better understand their growth throughout the program, as well as their intentions when working in CLD communities upon licensure.

\section{Quantitative and Qualitative Studies}

Two of the researchers who conducted self-efficacy studies used quantitative and qualitative measures in their research design (i.e., Siwatu et al., 2016; Siwatu \& Polydore, 2010). Siwatu and colleagues (2016) used quantitative and qualitative measures to explore self-efficacy doubts of preservice teachers. Researchers surveyed preservice teachers using the CRTSE scale and asked additional demographic questions. Descriptive means were calculated for each survey item, and follow-up interviews were conducted that focused on the five-lowest survey items for each participant to better understand the factors that impeded their self-efficacy.

Only one of the reviewed studies that included Siwatu did not use the CRTSE scale instrument that he developed (i.e., Siwatu \& Polydore, 2010). The researchers provided a case

study to preservice teachers and were given responses from four experienced teachers on ways to handle the conflict if it was in their classroom. The preservice teachers were unaware that the responses included both examples and non-examples of CRT. Teacher candidates ranked the response they thought was least and most appropriate to handle the conflict. Researchers wanted 
to gain a deeper understanding of how preservice teachers were able to determine the best intervention, so they coded answers and developed themes from each of the shared responses. Siwatu and Polydore (2010) noted the importance of understanding if preservice teachers could identify appropriate interventions to avoid the overidentification of CLD students in special education.

\section{Results}

Only two studies have been conducted with special education preservice teachers (i.e., Chu \& Garcia, 2014; Cruz et al., 2020), therefore it is important to understand the types of results that have been reported for inservice and preservice teachers from programs outside of special education. Of the researchers that used the CRTSE survey to identify item-specific mean scores, noted that items with higher CRTSE scores were about being caring and supportive teachers. In contrast, items on the scale that required deeper knowledge such as being able to communicate with families in their native language had lower self-efficacy scores (i.e., Chu \& Garcia, 2014; Cruz et al., 2020; Siwatu, 2007, 2008, 2009, 2011a, 2011b; Siwatu et al., 2009, 2016; Siwatu \& Starker, 2010).

Fitchett et al., (2012) used the CRTSE survey as a pre- and post-measure in a graduate course. Results indicated that when social studies curriculum was taught in conjunction with culturally responsive practices, it contributed to preservice teachers' overall perception of their ability to employ culturally responsive teaching practices, which aligns with Bandura's vicarious experience as a source of information that builds self-efficacy. The scale was used in its original construct and post-test attitudes towards CRTSE confidence $(M=425.88, S D=54.28)$ was significantly greater than the pretest scores $(M=380.69, S D=71.27)$. 
Chu and Garcia (2014) and Cruz et al., (2020) included participants with special education backgrounds. Chu and Garcia (2014) surveyed inservice special educators, and noted that participants with higher CRTSE scores were more likely to teach in resource rooms versus inclusive classrooms or self-contained classrooms over inclusive classrooms. They found that teachers who taught learners with mild/moderate disabilities also had higher CRTSE scores than those who taught learners with more significant disabilities.

Cruz and colleagues (2020) included preservice and inservice teachers from a various teaching backgrounds, including special education. Of the 245 participants, 50 identified as special education teachers, however, it is unclear how many of those participants identify as inservice or preservice special educators. Results indicated a positive correlation between increased years of service and an increase in overall CRTSE scores. Researchers also found (as mentioned above) that item-specific scores were higher for survey items that focused on building trusting relationships and lower overall mean scores for items that involved specific cultural knowledge or affirming native language or cultural contributions.

Table 1 summarizes the 18 CRTSE studies that were reviewed. Implications from this review will be discussed later in the chapter as it relates to research design for the current study. 
Table 1

Summary of Literature Review Results on Culturally Responsive Teaching Self-Efficacy

\begin{tabular}{|c|c|c|c|c|c|}
\hline Article & $\begin{array}{l}\text { Theoretical or } \\
\text { Framework }\end{array}$ & $\begin{array}{l}\text { Preservice } \\
\text { or Inservice }\end{array}$ & Participants & Instrument & Methodology \\
\hline $\begin{array}{l}\text { Chu \& } \\
\text { Garcia, } 2014\end{array}$ & Bandura & Inservice & $\begin{array}{l}N=344 \text { special } \\
\text { educators from } 10 \\
\text { largest districts } \\
n=155 \text { with } \mathrm{EL} \\
\text { experiences }\end{array}$ & $\begin{array}{l}\text { CRTSE and CRTOE ( } 5 \text { pt. } \\
\text { Likert, reduced \# of items } \\
\text { and added language of } \\
\text { disability); demographic } \\
\text { info }\end{array}$ & $\begin{array}{l}\text { Quantitative: ANOVA, } \\
\text { Multiple Regression } \\
\text { and Bi-Variate of } \\
\text { CRTSE and CRTOE }\end{array}$ \\
\hline $\begin{array}{l}\text { Cruz et al., } \\
2020\end{array}$ & Bandura & $\begin{array}{l}\text { Inservice } \\
\text { and } \\
\text { Preservice }\end{array}$ & $N=245$ & $\begin{array}{l}\text { CRTSE and demographic } \\
\text { info }\end{array}$ & $\begin{array}{l}\text { Quantitative; } \\
\text { Descriptive Analysis }\end{array}$ \\
\hline $\begin{array}{l}\text { Debnam et } \\
\text { al., } 2015\end{array}$ & Bandura & Inservice & $\begin{array}{l}N=142 \mathrm{~K}-8 \\
\text { teachers from } 6 \\
\text { elementary schools }\end{array}$ & $\begin{array}{l}\text { CRTSE ( } 6 \text { pt. Likert) and } \\
\text { ASSIST observation; } \\
\text { demographic info }\end{array}$ & $\begin{array}{l}\text { Quantitative: } \\
\text { Descriptive Analysis; } \\
\text { Regression Model of } \\
\text { ASSIST }\end{array}$ \\
\hline $\begin{array}{l}\text { Dickson et } \\
\text { al., } 2016\end{array}$ & Bandura & $\begin{array}{l}\text { Student } \\
\text { Measure }\end{array}$ & $\begin{array}{l}N=2807^{\text {th }} \text { and } 8^{\text {th }} \\
\text { grade students }\end{array}$ & $\begin{array}{l}\text { CRTSE (adapted for student } \\
\text { use); PSSM; CASS and } \\
\text { demographic info }\end{array}$ & Quantitative \\
\hline $\begin{array}{l}\text { Fitchett et al., } \\
2012\end{array}$ & Bandura & $\begin{array}{l}\text { Inservice } \\
\text { Master's } \\
\text { Level }\end{array}$ & $\begin{array}{l}N=20 \text { graduate } \\
\text { students in a social } \\
\text { studies course }\end{array}$ & $\begin{array}{l}\text { CRTSE (0-100) pre and } \\
\text { post }\end{array}$ & $\begin{array}{l}\text { Quantitative-pre- } \\
\text { experimental }\end{array}$ \\
\hline $\begin{array}{l}\text { Larson et al., } \\
2018\end{array}$ & Bandura & Inservice & $\begin{array}{l}N=274 \text { from } 18 \\
\text { schools } \\
n=106 \text { elem. } \\
n=168 \mathrm{MS}\end{array}$ & $\begin{array}{l}\text { Multicultural Efficacy Scale } \\
\text { (6 pt. Likert) }\end{array}$ & $\begin{array}{l}\text { Quantitative: Structural } \\
\text { Equation Modeling } \\
\text { (SEM) }\end{array}$ \\
\hline
\end{tabular}


Table 1 continued

Summary of Literature Review Results on Culturally Responsive Teaching Self-Efficacy

\begin{tabular}{|c|c|c|c|c|c|}
\hline Article & $\begin{array}{l}\text { Theoretical or } \\
\text { Framework }\end{array}$ & $\begin{array}{l}\text { Preservice } \\
\text { or Inservice }\end{array}$ & Participants & Instrument & Methodology \\
\hline $\begin{array}{l}\text { Malo-Juvera } \\
\text { et al., } 2018\end{array}$ & Bandura & Inservice & $\begin{array}{l}N=26 \text { elementary } \\
\text { teachers from } \\
\text { Midwestern elem. } \\
\text { school }\end{array}$ & $\begin{array}{l}\text { CRTSE (0-100) and follow- } \\
\text { up interviews }\end{array}$ & $\begin{array}{l}\text { Mixed Methods: Q } \\
\text { factor analysis and } \\
\text { semi-structured } \\
\text { interviews }\end{array}$ \\
\hline Siwatu, 2007 & Bandura & Preservice & $\begin{array}{l}N=275 ; \mathrm{n}=200 f \\
n=75 m\end{array}$ & $\begin{array}{l}\text { CRTSE \& CRTOE; } \\
\text { demographic info }\end{array}$ & $\begin{array}{l}\text { Quantitative: } \\
\text { Descriptive Analysis }\end{array}$ \\
\hline Siwatu, 2008 & Bandura & Preservice & $N=62$ & $\begin{array}{l}\text { CRTSE \& Multicultural } \\
\text { Teaching Survey }\end{array}$ & $\begin{array}{l}\text { Quantitative: } \\
\text { Descriptive Analysis }\end{array}$ \\
\hline Siwatu, 2009 & Bandura & Preservice & $N=50$ & CRTSE & Quantitative \\
\hline $\begin{array}{l}\text { Siwatu, } \\
2011 \mathrm{a}\end{array}$ & Bandura & Preservice & $N=192$ & $\begin{array}{l}\text { CRTSE \& Follow-up } \\
\text { interviews }\end{array}$ & Mixed Methods \\
\hline $\begin{array}{l}\text { Siwatu, } \\
2011 b\end{array}$ & Bandura & Preservice & $\begin{aligned} N & =34 ; \mathrm{n}=21 f \\
n & =13 \mathrm{~m}\end{aligned}$ & $\begin{array}{l}\text { CRTSE \& Sense of } \\
\text { preparedness questionnaire }\end{array}$ & $\begin{array}{l}\text { Quantitative: } \\
\text { Experimental design; } \\
\text { counterbalanced with } \\
\text { repeated measure }\end{array}$ \\
\hline $\begin{array}{l}\text { Siwatu et al., } \\
2016\end{array}$ & $\begin{array}{l}\text { Bandura \& } \\
\text { Skinner }\end{array}$ & Preservice & $N=8$ & $\begin{array}{l}\text { CRTSE and Follow-up } \\
\text { interviews; Demographic } \\
\text { information }\end{array}$ & $\begin{array}{l}\text { Quantitative \& } \\
\text { Qualitative }\end{array}$ \\
\hline
\end{tabular}


Table 1 continued

Summary of Literature Review Results on Culturally Responsive Teaching Self-Efficacy

\begin{tabular}{|c|c|c|c|c|c|}
\hline Article & $\begin{array}{l}\text { Theoretical or } \\
\text { Framework }\end{array}$ & $\begin{array}{l}\text { Preservice } \\
\text { or Inservice }\end{array}$ & Participants & Instrument & Methodology \\
\hline $\begin{array}{l}\text { Siwatu \& } \\
\text { Polydore, } \\
2010\end{array}$ & Bandura & Preservice & $\begin{array}{l}N=95 ; \mathrm{n}=75 f ; n= \\
20 m\end{array}$ & Case Study & $\begin{array}{l}\text { Quantitative \& } \\
\text { Qualitative; descriptive } \\
\text { statistics \& inductive } \\
\text { coding }\end{array}$ \\
\hline $\begin{array}{l}\text { Siwatu et al., } \\
2009\end{array}$ & Bandura & Preservice & $N=104$ & CRTSE & Quantitative \\
\hline $\begin{array}{l}\text { Siwatu et al., } \\
2017\end{array}$ & Bandura & $\begin{array}{l}\text { Preservice } \\
\text { and } \\
\text { Inservice }\end{array}$ & $N=380$ & $\begin{array}{l}\text { CRCMSE; CRTSE; Teacher } \\
\text { Efficacy Scale }\end{array}$ & $\begin{array}{l}\text { Quantitative: } \\
\text { Descriptive analysis, } \\
\text { principal axis analysis, } \\
\text { correlational analysis }\end{array}$ \\
\hline $\begin{array}{l}\text { Siwatu \& } \\
\text { Starker, } 2010\end{array}$ & Bandura & Preservice & $\begin{array}{l}N=84 ; n=66 f \\
n=18 m\end{array}$ & $\begin{array}{l}\text { CRTSE; Case Study; } \\
\text { Demographic Information }\end{array}$ & $\begin{array}{l}\text { Quantitative-Multiple } \\
\text { Regression }\end{array}$ \\
\hline $\begin{array}{l}\text { Whitaker \& } \\
\text { Valtierra, } \\
2018\end{array}$ & $\begin{array}{l}\text { Expectancy } \\
\text { Value Model }\end{array}$ & $\begin{array}{l}\text { Preservice } \\
\text { (Master's } \\
\text { Program) }\end{array}$ & $\begin{array}{l}N=22 \text { from a } \\
\text { Master's Cohort } \\
n=9 m ; n=13 f\end{array}$ & $\begin{array}{l}\text { CRTSE and follow-up } \\
\text { interviews with } 8\end{array}$ & $\begin{array}{l}\text { Mixed Methods: Case } \\
\text { Study }\end{array}$ \\
\hline $\begin{array}{l}\text { CRTSE-Cultu } \\
\text { CRTOE- Cult } \\
\text { CRCMSE- Cu }\end{array}$ & $\begin{array}{l}\text { ly Responsive } \\
\text { lly Responsiv } \\
\text { Irally Respons }\end{array}$ & $\begin{array}{l}\text { Teaching Self } \\
\text { Teaching Ou } \\
\text { ve Classroom }\end{array}$ & $\begin{array}{l}\text { Efficacy Scale (Siwatu } \\
\text { ome Expectancy Scal } \\
\text { Aanagement Self-Effic }\end{array}$ & $\begin{array}{l}2007) \\
\text { (Siwatu, 2007) } \\
\text { cy Scale (Siwatu, et al., 2017) }\end{array}$ & \\
\hline
\end{tabular}




\section{Teacher Education Programs' Inclusion of CRP}

The third focus of the literature review was to explore the ways in which TEPs have included culturally responsive competencies into their coursework and licensure programs to prepare preservice special educators to have cultural awareness. The current research base emphasizes the importance of experiential and field experiences to develop cultural competence. Twelve articles were reviewed for including their process of integrating CRP into their teacher preparation programs (i.e., Allen et al., 2017; Barrio et al., 2015; Brown-Jeffy \& Cooper, 2011; Dykes et al., 2012; Ellerbrock et al., 2016; Garcia et al., 2010; McCadden \& Rose, 2008; McHatton et al., 2013; Pappamihiel et al., 2010; Prater et al., 2008; Sleeter, 2008; Waddell, 2013).

Of the twelve TEPs reporting their process, five are general education programs (i.e., Allen et al., 2017; Brown-Jeffy \& Cooper, 2011; Ellerbrock et al., 2016; Garcia et al., 2010; Waddell, 2013). Two are special education programs (i.e., Barrio et al., 2015; Prater et al., 2008), and the remaining five included both general and special education programs (Dykes et al., 2012; McCadden \& Rose, 2008; McHatton et al., 2013; Pappamihiel et al., 2010; Sleeter, 2008).

Teacher educators have sought guidance from the literature when developing their TEPs to include cultural competencies across general and special education programs. Below, is a summary of the (a) frameworks that TEPs have used to guide their curricular decisions, the (b) curricular and programmatic changes TEPs have undergone to develop culturally competent preservice teachers, and the (c) outcome data reported to assist other teacher educators when including CRP into their programs. 


\section{CRP Frameworks Utilized by TEPs}

As more teacher educators consider ways to redesign or infuse cultural competencies into their programs, it is imperative to investigate the theoretical and conceptual frameworks that have guided TEPs in their process of including CRP in their curriculum. Many of the initial frameworks for CRP that were developed in the mid 1990's or early 2000's by seminal authors on cultural competence and pedagogy (discussed in Chapter 1) are still being utilized today. However, some two decades later, some TEPs are combining or integrating tenets from two or more frameworks to create new models of CRP. Four of the articles reviewed (i.e., Allen et al., 2017; Brown-Jeffy \& Cooper, 2011; Garcia et al., 2010; McCadden \& Rose, 2008) focused on the conceptual or theoretical models that the authors surmise will move TEPs forward in their quest to develop culturally responsive preservice teachers.

Two sets of authors (i.e., Allen et al., 2017; Brown-Jeffy \& Cooper, 2011) combined concepts from Critical Race Theory and Ladson-Billings' framework for CRP. Both sets of authors posit that you cannot have a culturally responsive framework unless you are also considering the impact that race plays on the normative standards of education (Allen et al., 2017). For example, Brown-Jeffy and Cooper (2011) combat the notion of being race-neutral or claiming to be colorblind as an essential tenet for TEPs. When White educators claim to be colorblind, they essentially ignore the realities of racism that do exist for many learners in PK-12 schools today. Additionally, teacher educators, as well as preservice teachers, have to move beyond just acknowledging that they see race, but recognizing it as an asset, as this will begin to chip away the power of White privilege in our education system (Brown-Jeffy \& Cooper, 2011). Whiteness is omnipresent in American schools; therefore, it is imperative that racism is a fundamental consideration when developing TEPs with CRP (Allen et al., 2017). 
Both Allen and colleagues (2017) as well as Brown-Jeffy and Cooper (2011) utilized principles from Ladson-Billings' framework on CRP. Allen et al., (2017) offer the following model as an integrated approach of Critical Race Theory and Ladson-Billings CRP Framework to systematically include CRP into TEPs: (a) posing questions that require a consistent and routine learning about self and others; (b) commitment to act on social injustices within teacher education programs and policies; and (c) developing critical reflection on courses offered and the instructional practices of faculty.

Brown-Jeffy and Cooper (2011) arrived at five tenets that they believe encompass the salient features of CRP from Critical Race Theory, Ladson-Billings' CRP Framework, and include components from Geneva Gay (1995) and Nieto's (1999) principles of culturally relevant teaching. The authors started with 35 broad themes compiled from the seminal works and grouped common ideas into five tenets: (a) identity and achievement, which includes the affirmation of diversity and validation of home-community cultures, (b) equity and excellence, meaning curriculum must move beyond cultural celebrations and symbols that are interwoven throughout the year versus specific inclusions (i.e., Black History Month), (c) developmental appropriateness, integrates the cognitive, emotional, social and psychological needs of students, (d) teach to the whole child by considering cultural contexts, and (e) student-teacher relationships that develop a connectedness between students and teachers as well as among students.

McCadden and Rose (2008) did not combine frameworks as they embarked on a programmatic redesign for their general education TEP. The authors incorporated the six strands of the Villegas and Lucas (2002) framework and created clusters that were systematically aligned with different courses/levels of the program beginning at the sophomore level. They also 
included field experiences beginning at sophomore level that aligned with theoretical concepts being taught in coursework.

Additionally, Garcia and colleagues (2010) discussed a broad theoretical continuum including the framework of Villegas and Lucas (2002) combined with academic considerations by Darling-Hammond and Bransford (2005). They recognized the importance of affirming the views of students when developing a framework for CRP. The authors believed that it was the task of teachers to move preservice teachers towards a greater consciousness in understanding themselves as individuals, as well as gaining an understanding of how power in education systems causes oppression and inequities (Garcia et al., 2010).

Culturally Responsive Pedagogy is a relatively new construct, and teacher educators are still seeking to understand the nuances of each framework by combining salient features from a variety of established frameworks. The integration of ideas supports the notion that CRP is a philosophy versus a set of items on a checklist to accomplish. Perhaps by embedding components from a variety of credible sources, TEPs are modeling for their teacher candidates that they too are adaptive to the needs of their learners when redesigning their teacher education programs. Next, I present the ways in which TEPs went about redesigning their programs to include cultural competencies.

\section{Redesigning TEPS to Include Cultural Competencies}

If we are to disrupt the deficit positionalities that preservice teachers may have about CLD students, then TEPs need to move beyond the one-stop-shop diversity classes that perpetuate implicit biases (Allen et al., 2017). Many universities have included stand-alone courses on diversity; however, these courses alone are not effective for developing cultural competence (Sleeter, 2008). For too long, TEPs have made incremental, rather than systemic, 
program changes (Rueda \& Stillman, 2012). Instead, they have relied on the interests of individual faculty members who have a passion for CRP rather than developing a comprehensive and racially diverse teacher preparation program (Sleeter, 2008). Sleeter further states that most TEPs have disjointed programs that do not coherently approach CRP.

Authors included in the section have discussed one of three subthemes for including CRP into their preparation program: (a) individual course redesigns; (b) combined general and special education teacher preparation programs; and (c) field experiences. It is important to note that although some authors discuss redesigning a single course, it is part of a larger programmatic change and not a stand-alone course on cultural competence.

\section{Course redesigns}

Two sets of authors discussed how they included cultural competencies into one of the courses that they teach (i.e., McHatton et al., 2013; Waddell, 2013). McHatton and colleagues (2013) described their method, First, Do No Harm, and likened it to the Hippocratic Oath that doctors take not to do any harm to their patients. A pilot study with a pre- and post-test was administered to determine overall intercultural developmental and perceived sensitivity. Participants answered 50 Likert-type questions (1-disagree to 5-agree). Results were analyzed, and participants were grouped based on their scores.

Data from the survey provided instructors with knowledge of the students' comfort levels as it relates to cultural competence. In turn, this allowed instructors to differentiate their instructional approach and provide scaffolds such as varied readings, discussion groups, and question prompts for those who need them. McHatton and colleagues (2013) maintain that if instructors continue to teach CRP in a lock-step fashion, we may actually cause some candidates to regress because they do not have the foundational schema to build upon (McHatton et al., 
2013). Conversely, instructors may also be able to encourage deeper and critical thinking for candidates that do have an awareness of cultural pedagogy.

Waddell (2013) looked to the literature to guide her course redesign. The course was experience-based; therefore, most of the course requirements occurred outside of the walls of the classroom. However, some foundational work occurred during in-class sessions. The course was grounded in constructivist theory, and Waddell (2013) wanted learners to construct their own understanding through in-class discussions and self-examination while investigating through their own cultural lens. In-class sessions were strategically planned throughout the semester to provide opportunities for candidates to discuss readings with one another, prepare for upcoming field experiences, and process their experiences. In-class sessions also included panels where experienced professionals shared tips and advice for working with families and conducting home visits.

Experiential activities such as community walks, interviews of school staff regarding their practices with families served as an opportunity for teacher candidates to move from a traditional lens of family and community assets to a collaborative approach of working with families. Additionally, students developed and administered surveys to families to understand their views on family/school interactions. Teacher candidates were also to attend three community or family events, attend parent/teacher conferences, and make 2-3 home visits (or at a location determined by the family). The final experience was for teacher candidates to plan and implement a family involvement activity that encompassed all that they had learned over the course of the semester. Candidates were encouraged to move beyond school-centric activities in order to respond to parent needs (Waddell, 2013). 
The approaches outlined above are both part of larger redesign efforts to include CRP, however, the authors were referring to specific changes that they made to the courses that they were teaching. Both sets of authors included outcome data on their efforts to include CRP, which will be discussed later in this chapter.

\section{Combined programs}

Three sets of authors outlined their process for combining individual degree programs such as general education, special education, and/or bilingual and EL programs into one program that included cultural competencies (i.e., Dykes et al., 2012; Pappamihiel et al., 2010; Prater et al., 2008). Two of the three programs reviewed below combined their undergraduate and master's programs together (i.e., Pappamihiel et al., 2010; Prater et al., 2008). Dykes et al., (2012) was the only program to combine at the undergraduate level.

Dykes and colleagues (2012) combined their early childhood, reading, special education, and curriculum and instruction departments into one licensure program. The catalyst for this change was a result of a survey completed by recent graduates and stakeholders that affirmed the need to make programmatic changes to meet the diverse needs of learners in their state. In their effort to combine programs, members from each department set aside time each week to review syllabi and identify redundancies within the programs to combine courses and maintain a licensure program that was 120-123 credit hours. The team added seven new courses to their new program: Introduction to Special Populations, Language and Literacy Acquisition, Managing Classrooms and Behavior in School Settings, Assessment for Instruction, Instructing Diverse Learners, English Language Learners, and Collaborating with Families and Community. Preexisting courses were also reworked to include modules to consider special education and EL standards. 
The new program was launched in four phases, which allowed faculty to continue to develop and make adjustments based on feedback. A student advisory council met twice during each semester to provide feedback on each implementation phase. The first phase included a 21credit hour load that included an introduction to teaching and special populations courses. The next phase consisted of 30 hours of field-work in conjunction with 15 credit hours of coursework. Phase three included 60 hours of field-work along with methods courses in math, science, social studies, and language arts. Finally, the fourth phase was student teaching.

Pappamihiel and colleagues (2010) completed 45 hours of EL coursework before embarking on a program redesign for their own professional development. They rejected the notion of a stand-alone endorsement for ELs and instead combined their SED and EL programs. The special education degree program at their university is a combined bachelor's and master's degree that permits graduates to teach learners with disabilities. Teacher candidates can choose from one of seven focus areas: high incidence disabilities, transition specialist, special education technology, early childhood special education, visual impairments, autism, or severe disabilities.

The authors deemed that learning is interwoven; therefore, faculty members from both the SED and EL departments began work on integrating EL methodology, curriculum, and cultural understanding into existing special education courses. Although special education faculty did take 45 hours of EL coursework, they recognized that they would need to enlist the expertise of their EL colleagues to teach specific topics, including applied linguistics and assessments for ELs. They designed a cohort model that would allow teacher candidates to progress through the program as a group. The first cohort had 25 preservice teachers who were beginning their junior year and graduating with their master's degree in special education with an endorsement in EL. 
Prater and colleagues (2008) initiated a plan to offer an undergraduate and graduate program that combined special education with an EL minor. The Bachelor of Science in Special Education was reestablished during the Fall of 2004 and included 50 credit hours of special education coursework, including assessment pedagogy, special education law, and multicultural education. Additionally, they provided 16 hours of EL courses focused on language acquisition and five CREDE standards (i.e., Joint Productivity, Language Development, Contextualization, Challenging Activities, and Instructional Conversations).

In each of these articles on combined programs, authors discuss the ways they collaborated with others outside of their program, their process for making curricular changes and the addition of EL and language acquisition to their newly configured program.

\section{Field-Experiences}

Several of the authors discussed the importance of field experiences as a way to encourage a depth of understanding of $\mathrm{CRP}$, and as an avenue to challenge assumptions, and an opportunity to recognize the assets of CLD students (Barrio et al., 2015; Ellerbrock et al., 2016; McCadden \& Rose, 2008; Sleeter, 2008).

Two sets of authors suggested that general and special education preservice teachers collaborate on culturally responsive practices during their field experiences as an essential part of their TEP (Barrio et al., 2015; Ellerbrock et al., 2016). Barrio and colleagues (2015) specifically discussed the importance of having general and special education preservice candidates collaborate on the response to intervention (RtI) process and learning practical application and implementation strategies that will benefit them in the future. Collaboration with preservice teachers in other licensure areas will promote problem-solving as they co-plan, co-teach, and co- 
assess the learning of their students. This type of collaboration can better equip both general and special education teacher candidates to teach all learners (Ellerbrock et al., 2016).

Traditionally TEPs include field experiences during the end of their program, but several authors discussed the adoption of earlier field experiences (Ellerbrock et al., 2016; McCadden \& Rose, 2008; Sleeter, 2008). Ellerbrock and colleagues (2016) created structured field experiences at the early, middle, and final stages of their program. The authors surmised that by placing preservice teachers in classroom and community settings early on, they built upon their cultural knowledge while still engaging in critical self-reflection of their own biases and assumptions. Sleeter (2008) agreed that early field experiences that include guided inquiry with extended reflections are effective. However, it is not just the additional time in school settings but rather the ongoing learning and guidance of university faculty that help guide candidates to question their assumptions (Sleeter, 2008).

Having strong examples of culturally responsive inservice teachers is also a critical component to field experiences (Ellerbrock et al., 2016; Sleeter, 2008). Preservice teachers need strong models of cooperating teachers working with marginalized learners (Sleeter, 2008). Ellerbrock and colleagues (2016) caution TEPs to be selective when assigning cooperating teachers to host teacher candidates. This is a critical stage of development for novice teachers. If not carefully paired, there can be a mismatch between what preservice teachers are being taught by university faculty and what they are observing at their clinical sites. Cooperating teachers are not the only influencers; it is also important for teacher educators or clinical faculty to be present and offer support that nurtures reflection and encourages CRP practice. Clinical faculty need to model CRP, as well as student-oriented teaching practices, to propel preservice teachers to further their stages of awareness and identity development (Ellerbrock et al., 2016). 
By linking field experiences to the readings and activities assigned during coursework, faculty could guide and shape the experiences of preservice teachers. As a result, the additional year in the schools had a profound impact on their preservice teachers and their developmental process (McCadden \& Rose, 2008). Faculty also believed that the earlier clinical experiences breathed new life into their foundational courses because teacher candidates made deeper connections to the content based on their classroom experiences (McCadden \& Rose, 2008). Including field experiences at the beginning, middle, and end of the teaching program, allowed for increased responsibility during each leg of clinical experiences (Ellerbrock et al., 2016). Candidates could start the semester by observing, assisting with one-on-one tutoring, and then move to assist small groups. In the middle experiences, preservice teachers would begin coteaching and then learn from practitioners in different disciplines as they are taking their methods courses and beginning to understand how to implement pedagogical decisions. During the final semester, preservice teachers would plan and teach lessons independently with feedback from cooperating teachers and university faculty (Ellerbrock et al., 2016).

McCadden and Rose (2008) outlined the lessons they learned from implementing field experiences during the sophomore year. They felt that to extend the field experiences, they need to hone their approach to four key areas: (a) placement with culturally responsive cooperating teachers, (b) alignment of coursework and field-work, (c) assessment of field experiences should be developmental and measure growth over time and (d) guidance from faculty and supervisors to enhance the success of field experiences. McCadden and Rose (2008) suggested using common language and a guided learning/inquiry model as a framework.

All of the authors in this section emphasized the importance of experiential and field experiences to develop cultural competence. This coincides with Bandura's (1977) theory of 
self-efficacy and the sources of information that influence these beliefs, with mastery experiences being the most effective predictors of self-efficacy as well as the observational experiences.

\section{Outcome Data}

Through the examination of TEPs across the country, it was noted that there is little published research on special education TEPs and even less that include outcome data to determine the effectiveness of efforts to include cultural competence in their programs (LewisPratl et al., 2021). Four of the reviewed articles included some type of outcome data to evaluate the effectiveness of their curricular changes (i.e., McCadden \& Rose, 2008; McHatton et al., 2013; Pappamihiel et al., 2010; Waddell, 2013).

McHatton and colleagues (2013) identified positive outcomes from their pilot study. By differentiating instruction at the appropriate developmental levels, participants could involve themselves in entry-level discussions if that is where their competencies were. In contrast , those participants that came into the class with foundational knowledge were able to engage in deeper level discussions to expand their understanding. This differentiated approach to class readings, discussions, and assignments resulted in positive growth on the post-assessment within the subcategories.

Waddell's (2013) qualitative data analysis suggested that candidates had experienced identifiable growth within five themes that emerged in their responses, (a) reduced fear and anxiety of working with families, (b) realization of importance in working with families, (c) responsibility for fostering caring relationships with families as partners, (d) perceptions on urban schools, and, (e) commitment to family-school relationships. Waddell (2013) noted that experiences alone do not result in increased cultural competence. Experiences coupled with the 
opportunity to reflect and share experiences with peers afford candidates the opportunity to question their thinking and construct new knowledge.

All of the articles that focused on how TEPs include CRP into their programs are summarized in Table 2 and include the theoretical or conceptual framework that guided their process, the type of program, and their process for addressing CRP. 
Table 2

Summary of TEP and CRP Literature Review Results

\begin{tabular}{|c|c|c|c|}
\hline Article & $\begin{array}{l}\text { Theoretical or } \\
\text { CRP Framework }\end{array}$ & $\begin{array}{l}\text { General or } \\
\text { SED TEP }\end{array}$ & TEPs process for addressing CRP \\
\hline $\begin{array}{l}\text { Allen et al., } \\
2017\end{array}$ & $\begin{array}{l}\text { Builds on Critical } \\
\text { Race Paradigm }\end{array}$ & $\begin{array}{l}\text { General } \\
\text { Education }\end{array}$ & $\begin{array}{l}\text { A conceptual paper that suggests a map for TEPs to include CRP into their } \\
\text { policies and curriculum through critical reflection, social justice, and critical } \\
\text { questioning. Authors also suggest governance and accountability to maintain } \\
\text { accreditation. }\end{array}$ \\
\hline $\begin{array}{l}\text { Barrio et al., } \\
2015\end{array}$ & $\begin{array}{l}\text { No specific } \\
\text { framework } \\
\text { mentioned }\end{array}$ & $\begin{array}{l}\text { Special } \\
\text { Education }\end{array}$ & $\begin{array}{l}\text { Scaffolded approach to critical reflection during field experiences to understand } \\
\text { CRP. Recommended collaboration between general and special education } \\
\text { preservice teachers regarding RtI to enhance knowledge and application. }\end{array}$ \\
\hline $\begin{array}{l}\text { Brown-Jeffy } \\
\& \text { Cooper, } \\
2011\end{array}$ & $\begin{array}{l}\text { Combined } \\
\text { frameworks of } \\
\text { Ladson-Billings, } \\
\text { Gay and Nieto }\end{array}$ & $\begin{array}{l}\text { General } \\
\text { Education }\end{array}$ & $\begin{array}{l}\text { Conceptual framework of CRP with five key tenets that include: identity and } \\
\text { achievement with affirmation of diversity, equity, and excellence, with high } \\
\text { expectations for all; developmental appropriateness with cultural variation; } \\
\text { teaching to the whole child; and student teacher relationships that are caring and } \\
\text { promote interaction. }\end{array}$ \\
\hline $\begin{array}{l}\text { Dykes et al., } \\
2012\end{array}$ & $\begin{array}{l}21^{\text {st }} \text { Century Skills } \\
\text { Framework with } \\
\text { influence of } \\
\text { Darling-Hammond } \\
\text { Framework }\end{array}$ & $\begin{array}{l}\text { General \& } \\
\text { Special } \\
\text { Education }\end{array}$ & $\begin{array}{l}\text { Combined four individual programs (Early childhood, reading, special education } \\
\text { and curriculum \& instruction) into one. The impetus for change came from } \\
\text { recent graduates and stakeholders who wanted more preparation for teaching } \\
\text { CLD learners as well as learners with disabilities. }\end{array}$ \\
\hline $\begin{array}{l}\text { Ellerbrock et } \\
\text { al., } 2016\end{array}$ & $\begin{array}{l}\text { Grounded in } \\
\text { Ladson-Billings f } \\
\text { and Cruz's } \\
\text { Diversity } \\
\text { Awareness }\end{array}$ & $\begin{array}{l}\text { General } \\
\text { Education }\end{array}$ & $\begin{array}{l}\text { The authors believed that by combining CRP pedagogy with identity } \\
\text { development, they could prepare teacher educators to include a CRP framework } \\
\text { that embodies a developmental process which included stages of awareness, } \\
\text { bombardment, reflection, dissonance and accommodation. }\end{array}$ \\
\hline
\end{tabular}


Table 2 continued

Summary of TEP and CRP Literature Review Results

\begin{tabular}{|c|c|c|c|}
\hline Article & $\begin{array}{l}\text { Theoretical or } \\
\text { CRP Framework }\end{array}$ & $\begin{array}{l}\text { General or } \\
\text { SED TEP }\end{array}$ & TEPs process for addressing CRP \\
\hline $\begin{array}{l}\text { Garcia et al., } \\
2010\end{array}$ & $\begin{array}{l}\text { Darling-Hammond } \\
\text { and Barnsford }\end{array}$ & $\begin{array}{l}\text { General } \\
\text { Education }\end{array}$ & $\begin{array}{l}\text { Authors discussed a modified framework that is designed to prepare teachers of } \\
\text { ELs that includes: knowledge of ELs including funds of knowledge, role of the } \\
\text { family and community; knowledge of the curriculum and making connections } \\
\text { between language, culture \& identity; knowledge of CRP and cultural sensitivity. }\end{array}$ \\
\hline $\begin{array}{l}\text { McCadden \& } \\
\text { Rose, } 2008\end{array}$ & $\begin{array}{l}\text { Villegas \& Lucas } \\
\text { Framework }\end{array}$ & $\begin{array}{l}\text { General \& } \\
\text { Special } \\
\text { Education }\end{array}$ & $\begin{array}{l}\text { Authors incorporated the six strands of the Villegas \& Lucas framework and } \\
\text { created clusters that aligned with coursework and field experiences beginning at } \\
\text { the sophomore level. Program was assessed throughout using self-assessment } \\
\text { scales and written reflections to be included in teacher portfolio. }\end{array}$ \\
\hline $\begin{array}{l}\text { McHatton, et } \\
\text { al., } 2013\end{array}$ & $\begin{array}{l}\text { No Specific } \\
\text { Framework } \\
\text { Mentioned }\end{array}$ & $\begin{array}{l}\text { General \& } \\
\text { Special } \\
\text { Education }\end{array}$ & $\begin{array}{l}\text { Authors used the DMIS as a conceptual framework to explore, assess and } \\
\text { understand preservice teachers' cultural viewpoints and dispositions. A pre-test } \\
\text { was administered that allowed instructors to differentiate how content was } \\
\text { presented. Providing scaffolds for those who needed it and encouraging deeper } \\
\text { and critical thinking activities for those who were ready. Results were not } \\
\text { statistically significant between pre and post-test scores, but authors did offer } \\
\text { implications for future. }\end{array}$ \\
\hline $\begin{array}{l}\text { Pappamihiel } \\
\text { et al., } 2010\end{array}$ & $\begin{array}{l}\text { Theoretical } \\
\text { Framework with } \\
\text { roots in Vygotsky }\end{array}$ & $\begin{array}{l}\text { General \& } \\
\text { Special } \\
\text { Education }\end{array}$ & $\begin{array}{l}\text { SED faculty participated in } 45 \text { hours of EL training to better understand theory } \\
\text { and curriculum. The faculty infused EL domains into SED coursework and } \\
\text { partnered with EL faculty to teach specific domains. Post survey responses of } \\
\text { cohort participants evidenced readiness to teach CLD learners and to be a change } \\
\text { agent. }\end{array}$ \\
\hline
\end{tabular}

(continued) 
Table 2 continued

Summary of TEP and CRP Literature Review Results

\begin{tabular}{|c|c|c|c|}
\hline Article & $\begin{array}{l}\text { Theoretical or } \\
\text { CRP Framework }\end{array}$ & $\begin{array}{l}\text { General or } \\
\text { SED TEP }\end{array}$ & TEPs process for addressing CRP \\
\hline $\begin{array}{l}\text { Prater et al., } \\
2008\end{array}$ & $\begin{array}{l}\text { No Specific } \\
\text { Framework } \\
\text { Mentioned }\end{array}$ & $\begin{array}{l}\text { Special } \\
\text { Education }\end{array}$ & $\begin{array}{l}\text { Faculty professional development on the CREDE standards; recruitment of } \\
\text { culturally diverse teacher candidates; Combined undergraduate and graduate SED } \\
\text { program with EL minor; Redesigned courses with CREDE standards infused. }\end{array}$ \\
\hline Sleeter, 2008 & $\begin{array}{l}\text { Villegas \& Lucas } \\
\text { Framework }\end{array}$ & $\begin{array}{l}\text { General \& } \\
\text { Special } \\
\text { Education }\end{array}$ & $\begin{array}{l}\text { A three-legged approach to CRP that includes university coursework, field } \\
\text { experiences and cross-cultural community-based learning. Immersion } \\
\text { experiences for semester long or } 4 \text {-week summer sessions were also suggested as } \\
\text { a way to contextualize student learning and grow in their sociopolitical } \\
\text { understanding. }\end{array}$ \\
\hline $\begin{array}{l}\text { Waddell, } \\
2013\end{array}$ & $\begin{array}{l}\text { Integrated } \\
\text { frameworks from } \\
\text { Milner, } \\
\text { Richardson \& } \\
\text { Dewey's }\end{array}$ & $\begin{array}{l}\text { General } \\
\text { Education }\end{array}$ & $\begin{array}{l}\text { Examined the effects of a course within an urban teacher preparation program. } \\
\text { The Working with Families and Communities course was taken by teacher } \\
\text { candidates during their sophomore year and was in conjunction with a practicum } \\
\text { experience where they were in classrooms three days per week. Teacher } \\
\text { candidates reflected on their own viewpoints and background as they learned } \\
\text { CRP and ways to interact with families and the communities. Outcomes based on } \\
\text { student reflection indicated a positive understanding of the collaboration between } \\
\text { teachers and families. }\end{array}$ \\
\hline
\end{tabular}




\section{Implications}

More research is needed to understand the culturally responsive teaching self-efficacy of special education preservice teachers. Two of the 18 studies included special educators as participants (i.e. Chu \& Garcia, 2014; Cruz et al., 2020). Researchers have largely focused on the CRTSE of inservice and preservice teachers in general education. The review of culturally responsive teaching self-efficacy studies has provided meaningful considerations for future research. The inclusion of the CRTSE survey as one of the measures to determine the CRTSE of special education preservice teachers should be explored since there is only one published study that has examined this with preservice special educators (Cruz et al., 2020) which is the aim of the current study.

In earlier works, Siwatu used quantitative methods only, but in later studies, he used quantitative and qualitative methods and even mixed methods because he felt that data could become "immensely more valuable," to teacher educators (Siwatu et al., 2016). Additionally, in one of the more recent studies conducted by Siwatu et al. (2016), he used qualitative methods to understand the self-efficacy doubts that preservice teachers held as it relates to culturally responsive teaching. The possibility still exists to conduct an investigation that focuses on preservice teachers that are seeking licensure in special education to understand the factors and experiences that influence their self-efficacy. The current study would add to the limited literature base that currently exists.

Previous studies have indicated that those with higher CRTSE responded to questions about being caring and supportive teachers, whereas items on the scale that required deeper knowledge, such as being able to communicate with families in their native language, had lower self-efficacy scores (i.e., Chu \& Garcia, 2014; Cruz et al., 2020; Siwatu, 2007, 2008, 2009, 
2011a, 2011b; Siwatu et al., 2009, 2016; Siwatu \& Starker, 2010). This highlights a need to investigate item-specific means in the current study.

The literature review on TEPs, and their inclusion of CRP within their programs also holds implications for the current study. Through the examination of TEPs, it was noted that there is little published research on special education TEPs, and even fewer include outcome data to determine the effectiveness of cultural competence in their programs. Several of the articles reviewed included conceptual or theoretical CRP frameworks to guide their decision-making process when including CRP.

The review of literature focused on CRTSE and the ways in which TEPs have included CRP into their preparation programs. The synthesis from these bodies of work informs the current study in both quantitative and qualitative phases. Overall, the CRTSE studies highlight the need for additional research that includes special education preservice teachers. Across studies, the CRTSE survey (Siwatu, 2007) was the predominant instrument choice amongst researchers. Psychometrically, the 100-point scale was determined to be stronger, therefore the current study design will include the CRTSE survey with the original 100-point scale.

Considering the research design of the CRTSE studies, has influenced the methods choices for the current study. The studies presented thus far have predominantly utilized quantitative approaches to understand CRTSE, however several aspects of CRTSE remain relatively unknown. Bandura (1977) discussed the sources of information that increase selfefficacy, and there is scant research on understanding the factors and experiences that preservice special educators attribute to their high or low self-efficacy beliefs. Taken together, the influence of vicarious and mastery experiences (Bandura, 1977) along with the themes that emerged within the TEP literature review on redesigned coursework and field experiences support the notion of 
including follow-up interviews with preservice special educators enmeshed in their clinical experiences to understand the sources of information (e.g., vicarious or mastery experiences) that have impacted their culturally responsive self-efficacy beliefs.

Culturally Responsive Pedagogy is still in its infancy, and researchers may want to consider the salient features of emerging CRP frameworks that are integrated with seminal frameworks. As researchers continue to investigate the effectiveness of CRP in their programs, they may want to develop quality indicators such as rejecting deficit views, sociocultural awareness, examination of attitudes and beliefs, as well as the inclusion of family and community instead of adherence to a particular framework. Using this information to guide analysis in the current study will illuminate experiences and specific sources of information that have impacted CRTSE. By designing a mixed methods study that focuses on the self-efficacy of special education preservice teachers and understanding the factors and experiences that impact their perceived preparedness to teach CLD learners, the present study aims to contribute to the existing gap in the body of research. 


\section{CHAPTER III: METHODOLOGY AND METHODS}

\section{Methodology}

We all bring a worldview into our research (Creswell, 2014). These beliefs and values inform not only how we go about conducting research, but also how the historical, political and cultural influences inform a researcher's choices about not only what they research, but why (Morgan, 2014). In researching the culturally responsive teaching self-efficacy of preservice special educators, I employed pragmatism as the research philosophy of the current study.

Pragmatism as a research paradigm includes inquiry as a problem-solving approach, where a researcher reflects on research questions and then makes conscious decisions about the type of inquiry that will provide the best outcome. Additionally, a pragmatist focuses on characteristics of inquiry as opposed to viewing them as abstract opposites (Morgan, 2014). Inquiry is rooted in the human experience, including our thoughts and beliefs, which influence all aspects of the research process. Therefore, it is understandable that inquiry is not linear, but instead a cyclical process that is grounded in social context (Morgan, 2014).

When investigating complex social issues like CRTSE it is understandable that a researcher may want to examine the phenomenon from multiple perspectives. Morgan (2014) asserts that there is a strong fit between social justice issues and pragmatism, as it centers the human experience within the investigation. The intent of the current study aims to understand the factors and experiences that preservice special educators attribute to their CRTSE beliefs. The pragmatic researcher finds value in both quantitative and qualitative approaches to inquiry, and considers how these approaches will provide meaningful outcomes. In order to achieve the purpose of this study, conscious decisions were made to integrate both quantitative and qualitative methods to understand the CRTSE beliefs of special education preservice teachers. 
The use of a quantitative instrument will provide objective data that can be compared to existing CRTSE studies, while qualitative measures provide an understanding of the lived experiences that participants attribute to influencing their CRTSE.

Just as inquiry is not linear, it is not rational either (Morgan, 2014), our thoughts and feelings influence every facet of the research process from the type of investigations we pursue to the judgments that are made during analysis. This chapter outlines the mixed methods design, researcher positionality and conceptual frameworks to provide insight into the varied influences that inform the study design and analysis.

\section{Mixed Methods Design}

This study utilized a mixed methods design (Tashakkori \& Teddlie, 2003) which is a procedure for collecting, analyzing, and integrating or mixing the characteristics of qualitative and quantitative data analysis at specified points throughout the research process. Furthermore, mixed methods typologies draw from the strengths of both quantitative and qualitative paradigms, which are intended to reduce the weaknesses that are attributed to both (Johnson \& Onwuegbuzie, 2004). Furthermore, mixed methods research can extend the discussion of a research problem due to the complementary nature of integrating the traditions of qualitative and quantitative research to best answer the research questions (Johnson \& Onwuegbuzie, 2004).

When choosing a mixed methods design Creswell (2003, p. 211) outlined four criteria to be considered when selecting a design strategy. The criteria include (a) the implementation or timing of the quantitative and qualitative data procedures and if they occur sequentially or concurrently, (b) priority of one paradigm over the other in the data collection and analysis, (c) integration or mixing of quantitative and qualitative data, and (d) the theoretical or conceptual 
perspectives that will be utilized in the study. Each of these criteria will be explained in this chapter, along with the mixed methods framework that was used to design this research study.

\section{Sequential Explanatory Design}

The first phase was a quantitative exploration using the CRTSE survey developed by Siwatu (2007) and adapted by Chu and Garcia (2014) to include the language of disability along with indicators of culturally responsive teaching practices within the 40-item Likert-type survey, which is discussed in greater detail below. Descriptive data gathered in this phase was used to address the possible relationship between academic and/or demographic backgrounds and culturally responsive self-efficacy beliefs of preservice special educators that are enrolled in clinical experiences. In the second phase, qualitative interviews were used to explore the factors and/or experiences that preservice teachers attribute as impacting their CRT self-efficacy.

The quantitative results from Phase 1 informed the purposeful selection of participants for follow-up interviews in Phase 2. Survey scores were compiled and ranked into quartiles. Two participants from each quartile were selected (participant selection is discussed in more detail later) conducted to gain perspective on the types of factors and experiences provided by participants who scored at the low, low-middle, high-middle and high ranges of CRTSE scores. This analysis allows for a comparison of high and low self-efficacy responses to determine similarities and differences of those responses.

\section{Implementation}

Sequential explanatory mixed methods, a two-phase typology, is the most straightforward of the major mixed methods approaches due to having clear and separate stages of inquiry (Creswell, 2003, p. 215). The sequential explanatory design is typically represented by the collection and analysis of quantitative methods in the first phase that is followed up with 
qualitative data collection and analysis that is used to expand upon the quantitative results. In this study, the same sequence was followed; a survey instrument was administered in phase one, and after analysis, participants were selected for the qualitative phase, which included a semistructured interview. Within each quartile, there were 3-7 participants who consented to a follow-up interview. Demographic information from each quartile was analyzed to select participants that were representative of the survey data, including racial/ethnicity, level of clinical experience, and program sequence. Since there was only one male who consented to a follow-up interview, he was selected to gain perspective from an otherwise all-female pool. The majority of participants were also enrolled in the LBS (learning behavior specialist) program, so it was important to choose a participant who was in the DHH (deaf or hard of hearing) program (no low vision candidates consented for Phase 2). Two participants were earning their EL endorsement, and one participant had taken more than three of the urban redesigned courses, so they were included in Phase 2 to gain an additional understanding of the factors and experiences that impacted their responses to the CRTSE survey.

\section{Priority}

The priority of paradigms in a sequential explanatory design is typically given to the quantitative strand since it is administered first (Creswell, 2003, p. 215). However, there is a variant of the sequential explanatory method known as the participant-selection variant (Creswell \& Plano Clark, 2011 p. 86), which places priority on the qualitative phase when the exploration of a phenomenon requires quantitative results to purposefully select participants for the qualitative phase. The focus of this study was on a cultural phenomenon that examined the factors and experiences that participants describe as having influenced their CRTSE self-efficacy scores in both high and low self-efficacy groups. The quantitative data allowed for purposeful 
participant selection for phase two interviews, which provided a deeper understanding of the phenomenon than would be possible with either method in isolation which speaks to the importance of mixing methods (Creswell, 2008).

\section{Integration}

The first opportunity of integration occurred between the analysis of the quantitative data in phase one, which was the analysis of the CRTSE survey data, which was divided into quartiles based on the overall sum score of each participant. The researcher selected two participants from each quartile and conducted a semi-structured interview to understand better the factors and experiences that influenced their ratings. This approach connected the two phases by using the quantitative results to shape the qualitative sampling and data collection to further understand the quantitative results. The level of integration between the two phases is interactive since the data is mixed before the final interpretation. Greene (2007) stated that the decision to integrate paradigms is the most critical decision when designing a mixed methods study.

Another opportunity for methodology integration occurred when determining the mean score for each of the 40 survey items during qualitative analysis to determine the five questions with the highest and lowest mean scores. Those questions were then explored in the qualitative phase during the interviews. They were coded and analyzed to determine the similarities and differences between participant responses on those individual items. Integration also occurred at the interpretation phase, where results from the quantitative phase and qualitative phase were integrated into a matrix to compare results within and across low and high self-efficacy groups.

\section{Researcher Positionality}

Very little research in the educational field can be value-free (Holmes, 2020); therefore, it is imperative for researchers to explore their positionality and how their characteristics and views 
shape their research and influence their interpretation of data. Below, I will share fixed characteristics as well as lived experiences and the professional lenses that have influenced my research.

I am a White, non-disabled educator who has been in the field of education for more than 23 years. I have earned both a bachelor's and master's degree in special education. My classroom experiences have predominantly been at the middle-school level teaching students with highincidence disabilities. For 15 years, I taught in a public school, and during that time, I had the opportunity to host dozens of clinical students from a local university who were in the final stages of their teacher preparation program. From there, I transitioned into higher education as a clinical assistant professor and began working with preservice special education teacher candidates and have been in this role for the last eight years. My experiences in education offer a lived familiarity with this research, as I am familiar with the language and possess a priori knowledge that allowed me to ask follow-up questions to gain a deeper understanding of the factors and experiences that participants share based on this knowledge. It is also important to note that while having insider positionality, which may provide some advantages, it is essential for me to reflect on my biases and avoid having a myopic view that prevents me from learning information that differs from my assumptions.

My experiences as a middle-level special educator have influenced my practice in higher education. While teaching middle school, I noticed that the majority of students in my instructional special education classes were male students of color who also qualified for free or reduced lunch. Once in higher education, I had the opportunity to redesign one of my courses with an emphasis on urban education, where I was immersed in a week-long experience in a metropolitan city with the third-largest school district in the United States. This experience was a 
three-pronged approach with an emphasis on community, public schools, and university resources to prepare teacher educators for culturally and linguistically diverse classrooms. It was this experience, along with my middle school experience, that influenced my understanding of disproportionality in special education and the need to prepare teachers for culturally diverse classrooms. These combined experiences have influenced the topics that I choose to investigate.

I am currently a doctoral candidate who has explored the literature in-depth to understand better the complex phenomenon of CRT and pedagogical practices. Through this process, my own theoretical perspectives have evolved. I once aligned my theoretical views solely in behaviorism, I now consider pragmatic perspectives such as experiential learning and social learning theory that influence my thinking. This has also expanded my methodological decisions in wanting to integrate paradigms to understand what could not be represented with a single method.

Additionally, entering into this research study, there were some assumptions that I held, based upon my experiences of participating in the urban redesign immersion trip. I held the belief that participants who took the urban redesigned courses or those who were earning their EL endorsement would have higher CRTSE scores. I share these characteristics, experiences, and assumptions to provide an interpretation of my positionality and consideration of how membership among different demographic communities is centered in this research.

\section{Conceptual Frameworks}

To investigate the self-efficacy of CRTSE, the researcher drew from a synthesis of conceptual and theoretical frameworks including social learning theory, tenets of seminal CRP frameworks and experiential learning that influenced the design and interpretation of both phases. 
Bandura's $(1977,1986,1997)$ theory of self-efficacy is grounded in Social Learning Theory is discussed in-depth in Chapter II and influences both phases of the study design. Within Phase 1, the survey instrument designed by Siwatu (2007) is rooted in Bandura's (1977) selfefficacy constructs. During Phase 2 the a priori codes used during interviews were aligned to Bandura's sources of information (i.e., discussed, observed, practiced) for growing self-efficacy. The a priori codes and coding process are discussed in detail later in the chapter.

Additionally, the combined conceptual/theoretical frameworks of seminal CRP influenced interpretation of the interview data during the coding process and analysis in Phase 2 of the study. Commonalities across seminal frameworks, discussed in Chapter I also informed interview analysis. The salient features of rejecting a deficit view of culture, having sociocultural awareness, examining attitudes and beliefs as well as including family and community as educational partners influenced the interpretative lens' in which the researcher developed codes, categories and themes.

Kolb and Kolb (2009) assert that our experiences have a transformational impact on our learning. This transformational process of creating new knowledge based on experiences results is complimentary of Bandura's social learning theory and the idea that mastery experiences are opportunities to develop self-efficacy. Experiential learning theory emphasizes the importance of observing, and reflecting on instructional practices that influence future instructional decisions (Servage, 2008). Experiential learning theory (Kolb \& Kolb, 2009) is based on six propositions that include: (a) learning as a process, (b) learning as re-learning, (c) learning requires resolution of conflicting models, (d) learning is a holistic process of adaptation, (e) learning is a synergetic transaction between person and environment, and (f) learning is the process of creating knowledge. 
Experiential learning is knowledge as a transformative process based on experiences

(Kolb \& Kolb, 2009). This transformative process aligns with the purpose of this research study, in understanding the factors and experiences that preservice special education teachers have attributed to their culturally responsive teaching self-efficacy. The six propositions of experiential learning influence the data collection procedures and analysis within Phase 2 of this study which will be discussed further during participant selection and analysis.

The integration of theory, sequential explanatory mixed methods, researcher positionality and conceptual frameworks have influenced the design of the current research study. Figure 1 illustrates the quantitative and qualitative design and how they are integrated within each phase to answer the research questions.

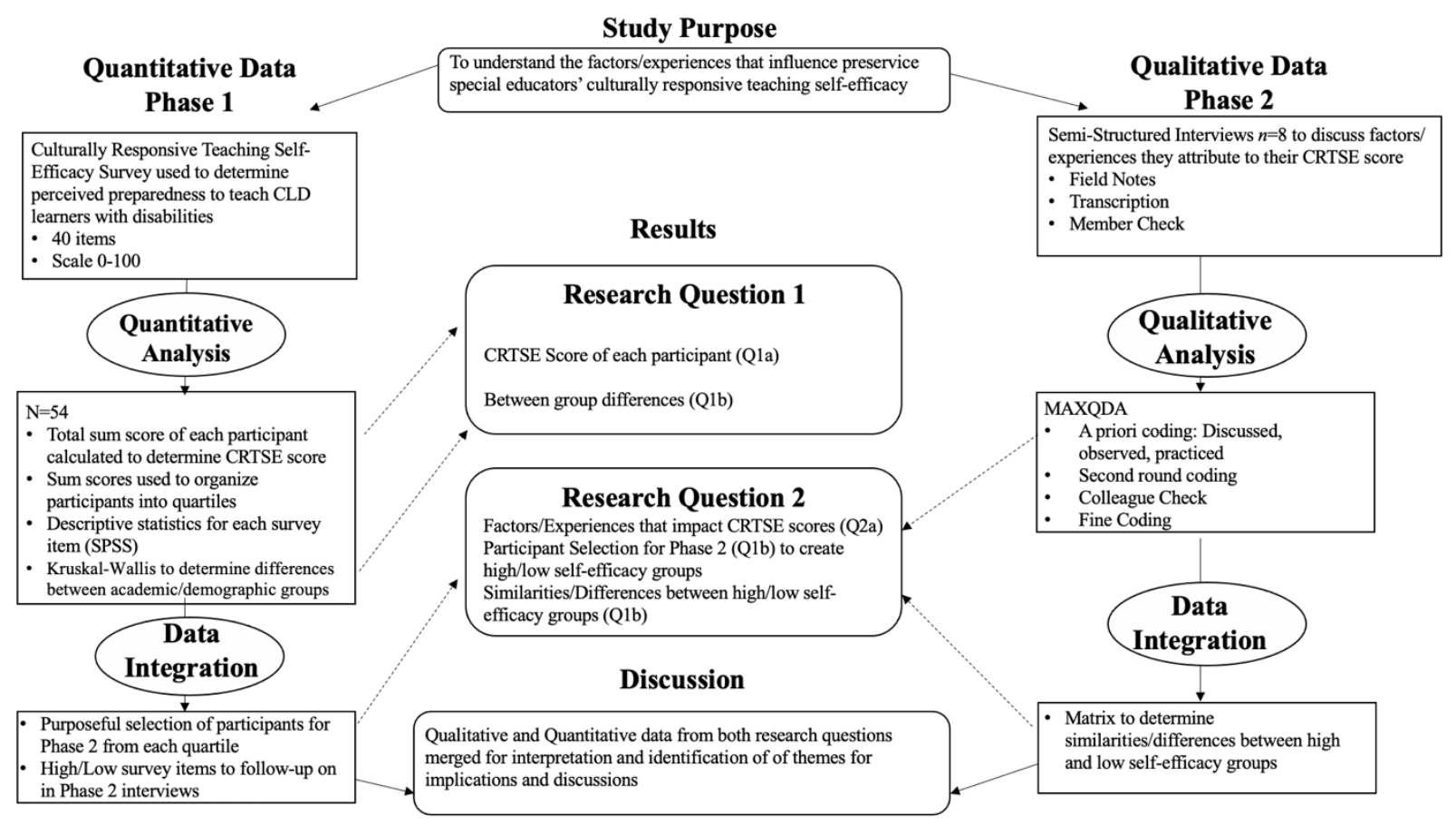

Figure 1. Visual Representation of Mixed Methods Design 


\section{Research Questions}

The research questions for this study were:

1. (a) What are preservice special educators' culturally responsive self-efficacy beliefs?

(b) To what extent do these beliefs differ based on academic and/or demographic backgrounds?

2. (a) what factors and/or experiences do preservice special educators describe as impacting their CRT self-efficacy? (b) How do these factors and/or experiences differ among those with high/low CRT self-efficacy scores?

\section{Phase 1}

\section{Ethical Considerations}

Prior to recruiting participants for the research study, two applications were submitted to the international review board (IRB) that detailed the study components and ethical considerations. One submission outlined both phases of the study that included the quantitative survey and follow-up interview. The second submission was for the survey only. This was done to mitigate any coercement because I am the instructor of record for one of the clinical groups that were to participate in the survey but were not invited to participate in phase 2 to maintain their anonymity. Upon obtaining permission from the IRB, participant selection began, and informed consent was shared prior to participating in the study. All survey participants were sent a link from Qualtrics, which utilized the anonymize responses feature to ensure that IP addresses and location data were not collected. Additionally, an anonymous link feature was used to distribute surveys which allowed participants to take the survey without using their university 
credentials to $\log$ in. All data are stored on a password-protected computer that was stored in a home office which required a login to access the computer, as well as an additional password to $\log$ into the software program where the survey data was collected.

\section{Identification and Recruitment}

The participants of this study were enrolled in a special education teacher preparation program from a Midwestern University. The population of participants that were enrolled in one of three clinical semesters (practicum, field-based, or student teaching) of their teacher preparation program. Additionally, participants could be enrolled in one of three programs: Deaf and Hard of Hearing (DHH), Learning and Behavior Specialist (LBS1), or Low Vision and Blindness (LVB). Additionally, some participants could be earning an EL endorsement in conjunction with their special education degree, or be enrolled in an urban redesigned course. Urban redesigned courses are purposefully designed to explore social issues that encircle disability, including cultural and linguistic pedagogy, disciplinary practices, and the inclusion of families and communities in the educational environment. Students can choose to enroll in a course that has been redesigned with an urban emphasis or take a traditional section of the course. However, it is important to note that professors who have re-designed their courses may teach all sections with an urban emphasis so there may not be a clear distinction between urban and non-urban sections. All participants were over the age of 18 and provided informed consent. Recruitment for participation began during the first week of the Fall 2020 semester. I contacted each coordinator of the DHH, LBS, and LVB clinical programs to schedule a brief introduction to the research study. I scheduled nine separate meetings during orientation week for each of the programs at the practicum, field-based, and student teaching level. I spent approximately ten minutes (virtually) with each group and explained the purpose of the study, 
and shared the survey link with them in the event that they were willing to answer questions about their perceived CRTSE. Clinical students were also informed that they could choose to be entered into a raffle for a gift card.

After the initial meeting during orientation week, I followed up with each of the coordinators to request that they remind the teacher candidates in their respective sections to complete the survey if they were willing. The survey remained open for one month. At the conclusion of the month, a random generator was used to select a participant for the gift card incentive. Twenty-nine participants consented to be included in the raffle and listed their email addresses. A table was created with each of those email addresses, along with a corresponding number. The chair of my committee used a random number generator to select the recipient who was participant number 18 .

Because I serve as the coordinator for one of the LBS1 clinical groups at the field-based level, a member of my dissertation committee conducted the recruitment procedures for the group of students I oversee without my presence. The teacher candidates that were enrolled in my section were given a link that was different from the one shared with the other groups of potential participants. This link included demographic questions as well as the 40 CRTSE survey items; however, it did not request consent for Phase 2 of the study, which was done to mitigate any coercement and to protect their anonymity.

\section{Population and Sampling}

Fifty-eight participants consented and accessed the survey; however, 54 participants completed the survey, which was $41 \%$ of the total population. Of the sample, 48 were female, four were male, and two chose not to disclose their gender. Participants were also asked their race/ethnicity: 41 indicated they were White, 10 indicated that they were Latino/a, along with 
two who were Black and one Asian. Academic levels were also collected: Practicum which is second semester of junior year where students are in clinical sites two days per week $(n=7)$, Field-based is first semester of senior year with four days a week of clinical experience $(n=20)$ and Student-teaching which is the final semester prior to licensure and full-time in clinical experience $(n=26)$ with one who did not indicate. Additional academic information will be discussed in the data collection section. See Table 3 


\section{Table 3}

Summary of Academic and Demographic Background Data

\begin{tabular}{|c|c|c|}
\hline Variable & $\begin{array}{l}\text { Phase } 1 \text { Participants } \\
\qquad N=54\end{array}$ & $\%$ \\
\hline \multicolumn{3}{|l|}{ Race } \\
\hline White & 41 & 76 \\
\hline Black & 2 & 4 \\
\hline Asian & 1 & 2 \\
\hline Hispanic/Latina/o & 10 & 18 \\
\hline I'd rather not disclose & 0 & \\
\hline \multicolumn{3}{|l|}{ Gender } \\
\hline Female & 48 & 89 \\
\hline Male & 4 & 7 \\
\hline I'd rather not disclose & 2 & 4 \\
\hline \multicolumn{3}{|l|}{ Academic Level } \\
\hline Practicum & 7 & 13 \\
\hline Field-based & 20 & 37 \\
\hline Student Teaching & 26 & 48 \\
\hline Did not answer & 1 & 2 \\
\hline \multicolumn{3}{|l|}{ Sequence } \\
\hline $\begin{array}{l}\text { Deaf and Hard of } \\
\text { Hearing }\end{array}$ & 5 & 9 \\
\hline Learning Behavior & 48 & 89 \\
\hline Specialist & & \\
\hline $\begin{array}{l}\text { Low Vision and } \\
\text { Blindness }\end{array}$ & 1 & 2 \\
\hline \multicolumn{3}{|l|}{ English Language } \\
\hline \multicolumn{3}{|l|}{ Endorsement } \\
\hline No & 46 & 85 \\
\hline Yes & 8 & 15 \\
\hline \multicolumn{3}{|l|}{ Urban Redesigned } \\
\hline 0 & 9 & 17 \\
\hline $1-2$ & 32 & 59 \\
\hline 3 or more & 13 & 24 \\
\hline
\end{tabular}

\section{Data Collection for Quantitative Phase}

Data collection for Phase 1 of the study consisted of quantitative measures, which included demographic and academic information as well as the CRTSE survey, which were both shared with participants via Qualtrics. The academic and demographic items were included to 
determine if there were any significant relationships between overall CRTSE scores and demographic group membership.

\section{Demographic and Academic Information}

Prior to the survey items, a demographic section was included to seek participant information about their gender identity, race/ethnicity, academic level, special education sequence, whether or not they added an EL endorsement or took any core courses that had been redesigned with a focus on urban education. Participants also had a selection that read, 'I'd rather not disclose," if they did not want to indicate. The special education sequences were represented as: DHH (5), LBS1(48), and LVB (1). Eight of the participants did have an English language endorsement, and 46 did not. See Table 3.

\section{Survey Instrument}

Quantitative data was collected using a modified version of Siwatu's (2007) CRTSE survey, rooted in Bandura's (1977) self-efficacy theory, and was designed to obtain information from preservice teachers on their efficacy in implementing culturally responsive teaching behaviors. Previous studies utilizing the CRTSE survey instrument have reported reliability with ranges from 0.94 to 0.96 (Siwatu, 2007, 2011a). The survey was comprised of 40 Likert-type items where participants were asked to rate their confidence level for engaging in culturally responsive teaching behaviors by indicating their comfort level on a scale of $0-100$. This scale is designed to develop a confidence rating from 0 (no confidence at all) to 100 (completely confident). Chu and Garcia (2014) expanded on the work of Siwatu (2007) by adapting the original CRTSE survey to include the language of disability within each survey item (e.g., the original item, "assess student learning using various types of assessments" was modified to as “use various types of assessments that are matched to English language learners' language 
proficiency and special needs"). A copy of this scale is provided in Appendix A. The demographic questions and survey items were added to Qualtrics and then shared with members of my committee to review prior to sharing the link during recruitment.

\section{Data Analysis for Quantitative Phase}

Once the survey closed, participant responses were exported from Qualtrics to the Statistical Packages for Social Sciences (SPSS), a statistical software program for analyzing quantitative data. The sum scores of each participant were computed to generate a total score. Total scores could range from 0 to 4000 , and participants with higher scores on the CRTSE scale identified as having higher competence than those with lower scores. Sum scores were then converted into a strengths-index score which was the total score divided by the number of survey items. For example, if a participant had an overall sum score of 3495 on the CRTSE scale, it was divided by 40 and resulted in a strength index score of 87.38 . Strength index scores could range from 0-100 and were a quantitative indicator of the strength of each participant's overall CRTSE score and beliefs.

Once the sum scores were computed, they were arranged in numerical order from lowest to highest to find the median ( $\mathrm{Mdn}=3,387)$ and then were divided into quartiles based on overall scores. Scores ranged from 1,997-4,000, and individual quartile (Q) scores were as follows: Q1 consisted of CRTSE scores from 1,997-3137, Q2 was 3,199-3.387, Q3 was 3,400-3,551, and Q4 was 3,569-4,000.

The sum of the self-efficacy data was used to select eight special education preservice teachers to participate in Phase 2 of the study. Two participants who had given consent to participate in the second phase of the study were selected from each quartile for follow-up interviews (which will be discussed in detail in Phase 2). Descriptive statistics were compiled 
using SPSS to compute a mean score for each item on the survey. The questions with the five lowest and five highest mean scores were noted and were integrated into Phase 2. During interviews in Phase 2, if a participant discussed one of the five highest or lowest indicators in their discussion, those responses were coded to understand if there were any patterns to explain why participants ranked those questions as high or low and if there may be implications for future practice or research.

Data were analyzed in SPSS using non-parametric tests because the small sample size did not meet the assumption of normally distributed populations that is necessary for ANOVA. I was specifically examining if there were any statistical differences between the independent variables of academic levels (practicum, field-based, and student teaching), race/ethnicity (Asian, Black, Latina/o, White), the different special education sequences (DHH, LBS or LVB), or the number of urban redesigned courses that a participant took $(0,1-2,3$ or more $)$.

\section{Phase 2}

\section{Identification and Recruitment}

There were 19 participants from Phase 1 who indicated a willingness to participate in Phase 2 of the study. Qualitative sampling should be purposeful to select participants that can best assist in understanding a central phenomenon (Creswell, 2014). Experiential Learning Theory guided my selection of two participants from each quartile to understand better the CRTSE self-efficacy beliefs of participants at the lower and higher ends of the CRTSE scale. Eight participants were emailed to determine if they were still interested in participating in the follow-up interviews. Seven of the participants responded immediately, and one participant did not respond after a follow-up email, so an alternate participant was selected that was also in the 
same quartile. During email correspondence, participants were asked for their availability, and interviews were scheduled to be completed within a two-week timeframe.

\section{Study Participants and Setting}

The demographics for the participants included seven female participants and one male. Five identified as White, two as Latina, and one participant identified as Asian. Academic levels were also recorded, six of the participants were enrolled in their student teaching experience, and two were in their field-based experience (semester prior to student teaching). Seven of the participants were in the LBS1 sequence and one DHH major within the special education sequences. Each of these participants were in clinical settings across their Midwestern state and was being interviewed from their respective homes.

\section{Data Collection for Qualitative Phase}

Once participants confirmed their willingness, an email with their numerical responses to each of the 40 survey items were included in a document for them to use as a reference during our interview. Additionally, a link to join a teleconference was provided to them. The teleconference software was set up, to begin with, cameras muted and a script was read asking for consent to record the interview. Once the record button was engaged, a disclaimer appeared, and the participant could click to indicate consent to record the interview. Each participant was also told that they could turn off their camera at any time or end the interview at any point.

Once consent was given, I used a script to ensure that I began each interview with the same information (Appendix B) and then moved into the semi-structured interview. Questions were open-ended and allowed the participant to elaborate on their experiences. I asked each participant if they had the document with the survey items (Siwatu, 2011a) and their numeric ranking, and I also had a printed copy of their rankings to write down anecdotal information as 
participants were responding to questions. Prior to the interviews, I established a priori deductive codes (discussed in the next section). During the interview, as the participant discussed the survey items, I color-coded specific survey items if the participant mentioned that they had discussed the item in coursework, observed it in practice, or had an opportunity to practice in a class or during their clinical experiences. I also took detailed notes as participants were responding to the questions. Merriam and Tisdell (2016, p.196) speak to the importance of analyzing data at a rudimentary level during data collection.

At the conclusion of the interview, I thanked the participants, immediately reviewed field notes, and wrote an initial summary of key takeaways from the interview. Bogdan and Biklen (2011) offered suggestions for analyzing data as they are being collected, including taking field notes throughout the process and writing memos about what is being learned. I then transcribed each of the recorded interviews using the transcription offering in the teleconference software. I listened to the interview in its entirety to correct errors that occurred during transcription and then sent it to the participant as a member check for accuracy. Interview times ranged from 24 minutes (Q1 participant) to 57 minutes (Q4 participant), with an average of 42 minutes across all eight interviews.

\section{Data Analysis for Qualitative Phase}

Data analysis for the qualitative phase consisted of three distinct rounds of coding. The first round of coding took place during interviews, second round of coding was the development of codes and categories to organize data, and finally a fine round of coding which combined codes and categories into themes. 


\section{First Round Coding}

Data collection during Phase 2, was primarily an inductive process with the exception of the deductive a priori codes of discussed, observed, or practiced that were identified in the Siwatu (2011a) study because of how these factors influence the development of self-efficacy (Bandura, 1997). I used a color-coding process to identify each of the a priori codes that participants discussed and then took field notes on their responses as they discussed each of the indicators on the survey. For each indicator, I would mark if the participant made mention of an item that had been discussed in their coursework and if they had an opportunity to observe either their professors or cooperating teachers demonstrate specific indicators or if they had opportunities to practice the indicator themselves in classes or at their clinical sites. I then tallied the number of items that had been discussed, observed, and practiced for each participant.

\section{Second Round Coding}

After the initial round of coding that was conducted during the interviews, I reviewed my field notes and summaries to develop categories that were discovered during the interview process. I uploaded the transcripts to MAXQDA, which is a qualitative data analysis software program. I listened to each interview multiple times and began a second round of coding. I developed an initial set of codes outside of the original a priori codes and inputted those into MAXQDA. Coding is a shorthand designation, often a word or phrase given to data that captures the essence of the data and allows for ease of retrieval (Merriam \& Tisdell, 2016 p. 199). I organized the codes into concepts, listened to each interview numerous times, and coded all eight interview transcriptions. Throughout the second round of coding, I created memos whenever I came across a piece of data that did not align with the codes that I created and considered the salient features of CRP frameworks and experiential learning theory to assign code names. 
Additionally, descriptive statistics from Phase 1 allowed me to evaluate the responses of the survey items with the five highest and lowest mean scores during the interview. I reviewed each of the transcripts to code any discussion of the ten questions within MAXQDA that fell into overall high and low overall self-efficacy.

\section{Fine Coding}

After the second round of coding, a colleague code check was conducted with members of my dissertation committee as a validity check on the process. As a result of this discussion, additional codes were developed to conduct fine coding. I reconciled the memos from the first round of coding and created new categories to consider along with more specificity in the coursework category, which was now broken down into specific courses that were mentioned during the interviews. After the development of additional codes and categories, I listened to each interview multiple times and re-coded the transcription. See Appendix C with a complete list of codes in the codebook.

\section{Matrix}

At the conclusion of fine coding, I developed a matrix to compile the responses for each coded section. I combined responses from participants across first and second quartiles and third and fourth quartiles to synthesize responses and generate a low (Q1/Q2) and high (Q3/Q4) selfefficacy group. The matrix had sections to represent what was similar and different across both self-efficacy groups across all coded sections. The matrix was beneficial for identifying essential themes that can be found in the codebook and will be discussed in detail in Chapter IV results.

\section{Reliability, Validity, and Ethics}

As previously mentioned, the CRTSE scale has proven to be a reliable measure for the 40-item survey, with internal reliability of .96 as determined by Cronbach's alpha (Siwatu, 2007). 
Traditionally, reliability is the likelihood that research findings can be replicated; however, within qualitative studies, reliability is problematic because the human experience is always in motion (Merriam \& Tisdell, 2016 p. 249). This does not mean that qualitative studies are not reliable, but it does depend on results being consistent with the data collected (Merriam \& Tisdell, 2016 p. 250). Tracy's (2013) criteria for conducting qualitative research was used as a framework for this study, including showing the transparency of methods. To increase reliability, each participant was given the opportunity to review transcriptions to verify accuracy. As soon as the interviews were transcribed, they were shared with individual participants to ensure that their responses were as they intended. Member checks are the single most important strategy to ensure that participants are not misinterpreted during the interview process (Merriam \& Tisdell, 2016 p. 246). Interviews were transcribed and shared with participants within 24 hours of the interview and prior to conducting another interview. This was purposefully done to prevent any overlap of interview responses and member checks. Another strategy that was implemented to ensure reliability during data analysis was peer examination, where colleagues on the dissertation committee who are familiar with the topic and methodology reviewed the process and offered feedback and additional considerations which were implemented during the fine coding phase of data analysis (Merriam \& Tisdell, 2016 p.249).

Lincoln and Guba (1985) recommend strategies that ensure consistency, like using triangulation procedures such as peer examination, the positionality of the researcher, and an audit trail. An audit trail is an explicit recount of the steps that the researcher took and allows others to investigate these steps of the process and make determinations on whether the process was valid. See Figure 2 below. The codebook is also presented below as an audit trail of the coding process. Deductive a priori codes of discussed, observed, and practiced were coded 
during the interview, and then additional codes were developed based on the initial analysis of interviews. After a peer review with dissertation committee members, additional codes were developed for fine coding.

First Round Coding: Open coding with a priori codes of discussed, observed, practiced along with field notes to identify emergent thematic categories

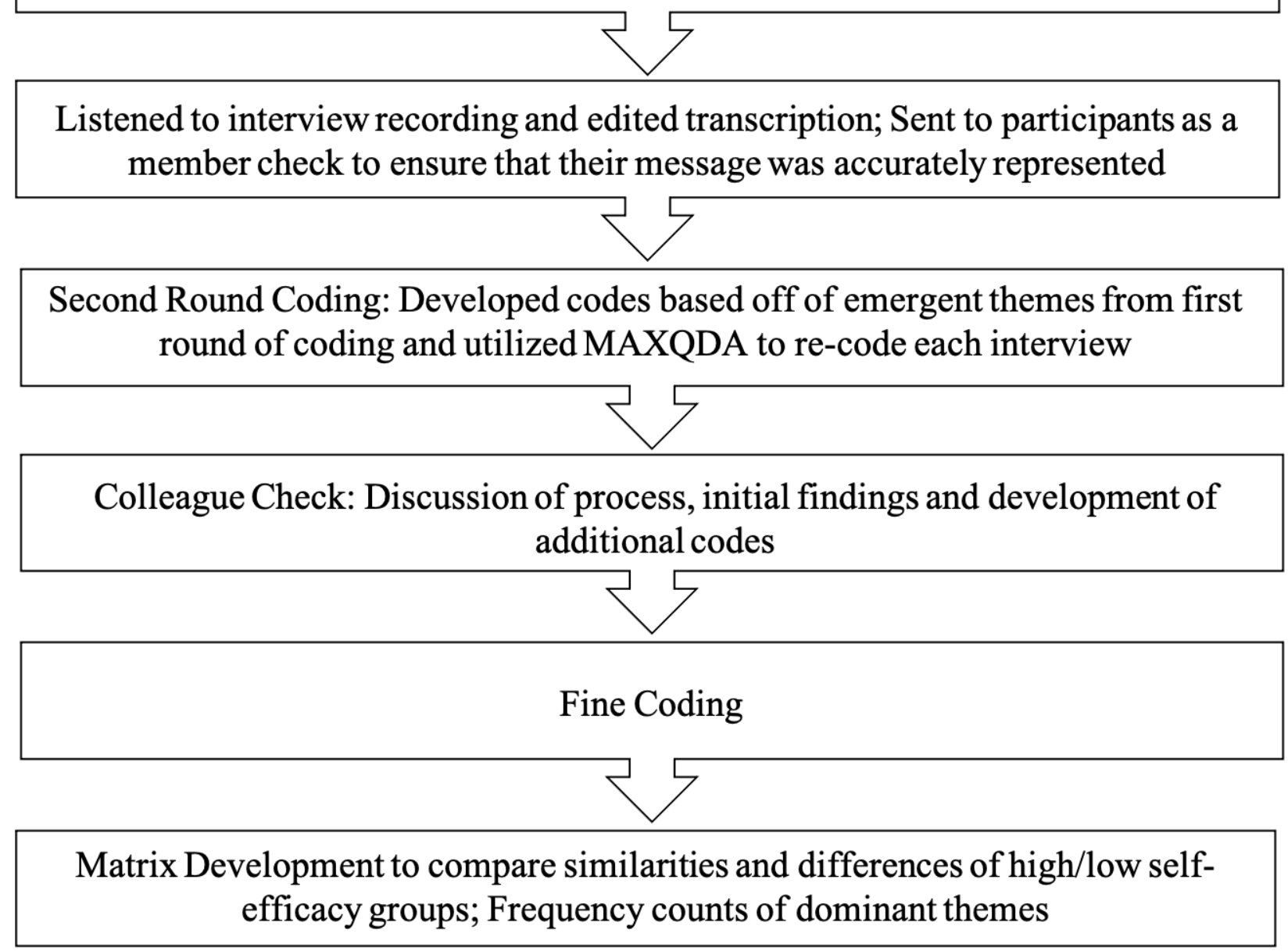

Figure 2:Qualitative Coding Process

\section{Summary}

An explanatory sequential mixed methods design was utilized for this two-phase research study. Phase 1 consisted of quantitative data collection through a survey to determine preservice special educators' culturally responsive teaching self-efficacy beliefs, followed by Phase 2 , the qualitative phase that was designed to offer deeper insight into the factors and experiences that 
influenced participant self-efficacy ratings in Phase 1. Data analysis consisted of descriptive statistics in Phase 1 to determine the overall CRTSE score of each participant, as well as the mean score for each survey item to determine the indicators that participants ranked with the highest overall self-efficacy scores as well as those that were ranked lowest. The Kruskal-Wallis, a non-parametric test, was also conducted to determine if there were any group differences between the academic and demographic groups that were identified. In Phase 2, data analysis consisted of interviews that were transcribed and coded to develop themes amongst high and low self-efficacy groups to understand the factors and experiences that influenced their overall CRTSE scores. 


\section{CHAPTER IV: RESULTS}

Chapter four represents the findings from a sequential explanatory mixed methods design study designed to answer the following questions:

RQ1: (a) What are preservice special educators' culturally responsive self-efficacy beliefs? (b) To what extent do these beliefs differ based on academic and/or demographic backgrounds?

RQ 2: (a) What factors and/or experiences do preservice special educators describe as impacting their CRT self-efficacy? (b) How do these factors and/or experiences differ among those with high/low CRT self-efficacy scores?

\section{Culturally Responsive Self-Efficacy Beliefs}

To determine the culturally responsive self-efficacy of special education preservice teachers, survey responses were summed to find the overall CRTSE score for each participant. In addition, the mean for each survey item was computed to understand better the competencies where preservice special educators felt more and less efficacious. This section will discuss descriptive statistics for both participants and survey items, and the impact of academic and demographic factors on the overall CRTSE score. Finally, quantitative results inform purposeful participant selection for Phase 2.

\section{Participant Mean Scores}

To determine the results for RQ1(a) What are preservice special educators' culturally responsive self-efficacy beliefs? An overall mean score was calculated for each participant using SPSS. The minimum mean was 49.93 with a frequency of one, and the maximum mean score was 100 with a frequency of two. The range between the minimum and maximum scores was 50.08 , and the overall mean score for all participants combined was $M=82.53$ and a $S D=11.08$. 
The $M D$ score was 84.84 , which indicates that the surveyed participants view themselves as having moderately high culturally responsive teaching self-efficacy. When investigating frequencies, most participants (28) had mean scores within the second to highest band that ranged between 80 and 89 . Overall, $74 \%$ or participants ranked themselves in the highest two band ranges. Table 4 illustrates the CRTSE ranges where participants ranked themselves and the number of participants who scored within each range.

\section{Table 4}

Participant Mean Score Ranges

\begin{tabular}{ccc}
\hline $\begin{array}{c}M \text { CRTSE Score } \\
\text { Range }\end{array}$ & $N=54$ & $\%$ \\
\hline $40-59.99$ & 4 & 7.5 \\
$60-69.99$ & 4 & 7.5 \\
$70-79.99$ & 6 & 11 \\
$80-89.99$ & 28 & 52 \\
$90-100$ & 12 & 22 \\
\hline
\end{tabular}

\section{Descriptive Statistics for Survey Items}

To understand the culturally responsive self-efficacy beliefs of preservice special educators (RQ1a), it is essential to investigate the item-specific means to identify the areas where participants feel self-efficacious and where they don't. Therefore, descriptive statistics were computed to find the mean scores of each survey item. The mean, median, standard deviation, and range are listed for each of the survey items in Table 5. Items with an asterisk also indicate the survey items with the highest and lowest mean scores which were further investigated in Phase 2 during interviews. Please see Appendix A for the complete list of survey items. 
Table 5

Descriptive Statistics for Each Survey Item

\begin{tabular}{|c|c|c|c|c|}
\hline Measure & $M$ & $M D$ & $S D$ & Range \\
\hline CRTSE 1 & 74.29 & 74.00 & 13.77 & $40-100$ \\
\hline CRTSE $2 *$ & 68.70 & 70.00 & 18.59 & $20-100$ \\
\hline CRTSE 3 & 81.33 & 83.50 & 15.48 & $40-100$ \\
\hline CRTSE 4 & 78.57 & 80.00 & 14.54 & $45-100$ \\
\hline CRTSE 5 & 78.13 & 81.00 & 15.79 & $30-100$ \\
\hline CRTSE 6* & 72.09 & 72.00 & 19.42 & $22-100$ \\
\hline CRTSE 7 & 76.44 & 79.50 & 17.61 & $40-100$ \\
\hline CRTSE 8 & 81.59 & 85.50 & 17.94 & $21-100$ \\
\hline CRTSE 9 & 84.00 & 85.50 & 14.98 & $38-100$ \\
\hline CRTSE 10 & 76.44 & 80.00 & 19.75 & $10-100$ \\
\hline CRTSE 11 & 79.79 & 80.50 & 15.69 & $10-100$ \\
\hline CRTSE $12 *$ & 72.35 & 75.00 & 19.52 & $8-100$ \\
\hline CRTSE 13 & 75.83 & 79.50 & 16.69 & $25-100$ \\
\hline CRTSE $14^{* * *}$ & 93.12 & 97.50 & 8.68 & $68-100$ \\
\hline CRTSE $15^{*}$ & 72.42 & 79.50 & 20.64 & $3-100$ \\
\hline CRTSE 16 & 82.09 & 82.00 & 15.60 & $29-100$ \\
\hline CRTSE 17 & 84.98 & 89.00 & 16.73 & $10-100$ \\
\hline CRTSE 18 & 87.98 & 91.00 & 15.46 & $32-100$ \\
\hline CRTSE $19^{* * *}$ & 90.98 & 97.00 & 12.50 & $53-100$ \\
\hline CRTSE 20 & 87.29 & 91.50 & 15.78 & $34-100$ \\
\hline CRTSE 21 & 86.51 & 91.00 & 15.41 & $44-100$ \\
\hline CRTSE $22^{* *}$ & 93.03 & 97.00 & 9.92 & $53-100$ \\
\hline CRTSE 23 & 87.72 & 92.00 & 14.37 & $32-100$ \\
\hline CRTSE 24 & 86.33 & 90.00 & 14.31 & $40-100$ \\
\hline CRTSE 25 & 86.96 & 92.00 & 15.46 & $36-100$ \\
\hline CRTSE 26 & 78.22 & 85.50 & 23.65 & $9-100$ \\
\hline CRTSE 27 & 76.87 & 90.00 & 26.94 & $2-100$ \\
\hline CRTSE 28 & 86.70 & 90.50 & 15.21 & $41-100$ \\
\hline CRTSE 29 & 76.09 & 87.50 & 27.95 & $5-100$ \\
\hline CRTSE 30 & 90.09 & 91.50 & 10.89 & $48-100$ \\
\hline CRTSE 31 & 81.81 & 85.50 & 18.09 & $21-100$ \\
\hline CRTSE 32 & 82.33 & 86.00 & 17.89 & $17-100$ \\
\hline CRTSE 33* & 73.03 & 77.00 & 24.24 & $17-100$ \\
\hline CRTSE $34^{* *}$ & 94.09 & 97.00 & 8.20 & 62.00 \\
\hline CRTSE 35 & 87.35 & 92.00 & 14.22 & $44-100$ \\
\hline CRTSE 36 & 85.94 & 86.50 & 13.13 & $47-100$ \\
\hline CRTSE $37 * *$ & 92.62 & 93.50 & 8.22 & $62-100$ \\
\hline CRTSE 38 & 84.53 & 90.00 & 17.02 & $30-100$ \\
\hline CRTSE 39 & 86.40 & 89.00 & 13.68 & $46-100$ \\
\hline CRTSE 40 & 86.20 & 90.00 & 16.13 & $13-100$ \\
\hline
\end{tabular}

Note. *five lowest mean scores; ** five highest mean scores 
The items with the five highest and five lowest scores were identified to further investigate the participants' factors or experiences to support their self-rating. The survey items with the five lowest means are: CRTSE 2 (68.70), CRTSE 6 (72.09), CRTSE 15 (72.42), and CRTSE 33 (73.03). The survey items with the highest means were: CRTSE 19 (90.98), CRTSE 37 (92.62), CRTSE 22 (93.03), CRTSE 14 (93.12), CRTSE 34 (94.09). These 10 items were further analyzed by examining the language within each indicator to determine if any patterns existed amongst low and high indicators. Additionally, in Phase 2, candidates' responses to each of these items were analyzed during the semi-structured interviews to better understand the factors and experiences that participants attributed to their score.

\section{Impact of Academic and Demographic Backgrounds on CRTSE}

Data from the CRTSE survey was used to answer RQ1B: To what extent do these beliefs differ based on academic and/or demographic backgrounds? To determine the appropriateness of ANOVA, assumptions were first considered. I first examined the independence assumption which was met, as the sample was randomly and independently selected. To determine if the data was normally distributed, the Kolmogorov-Smirnov and Shapiro-Wilk tests were run which both resulted in a .001 significance which should be $>$ than .05 to meet the assumption of normality. Since the result was less than .05 the data did not meet the assumption of normality. The overall CRTSE mean scores were non-normally distributed with a skewness of $-1.126(\mathrm{SE}=.325)$ and kurtosis of $1.410(\mathrm{SE}=.639)$.

The data did meet the assumption of homogeneity of variance for ANOVA with a significance score $>.05$ across all demographic variables using the Levene statistic. Since the CRTSE mean data did not meet the assumption of normality, the Kruskal-Wallis test, which does 
not assume normality was run to determine if independent demographic/academic variables had a significant impact on the dependent variable of CRTSE scores. Results of the Kruskal-Wallis test indicated that demographic variables did not have a significant impact on the independent variable of participant CRTSE scores. All results were $>.05$. See Table 6 for specific statistical information.

Table 6

Non-Parametric Kruskal-Wallis Test for Demographic Group Differences

\begin{tabular}{lccccc}
\hline & Gender & Race & $\begin{array}{c}\text { Academic } \\
\text { Level }\end{array}$ & $\begin{array}{c}\text { Course } \\
\text { Sequence }\end{array}$ & $\begin{array}{c}\text { Urban Re- } \\
\text { Designed } \\
\text { Course }\end{array}$ \\
\hline Total $N$ & 54 & 54 & 53 & 54 & 54 \\
Test Statistic & 2.30 & 3.41 & 5.81 & 1.24 & .93 \\
Degree of & 2 & 3 & 2 & 2 & 2 \\
Freedom & & & & .539 & .629 \\
Sig. & .319 & .333 & .055 & & \\
\hline
\end{tabular}


Table 7

Descriptive Statistics of Independent Variables

\begin{tabular}{|c|c|c|c|c|c|c|c|c|}
\hline Variable & $n$ & $M$ & $S D$ & $\begin{array}{l}\text { Std. } \\
\text { Error }\end{array}$ & $\begin{array}{l}\text { Lower } \\
\text { Bound }\end{array}$ & $\begin{array}{l}\text { Upper } \\
\text { Bound }\end{array}$ & Min. & Max. \\
\hline \multicolumn{9}{|c|}{ Gender } \\
\hline Female & 48 & 83.01 & 10.73 & 1.55 & 79.89 & 86.13 & 49.93 & 100 \\
\hline Male & 4 & 84.87 & 6.88 & 3.44 & 73.93 & 95.81 & 78.43 & 93.08 \\
\hline $\begin{array}{l}\text { Rather Not } \\
\text { Disclose }\end{array}$ & 2 & 66.58 & 20.44 & 14.45 & -117.03 & 250.18 & 52.13 & 81.03 \\
\hline Total & 54 & 82.53 & 11.08 & 1.51 & 79.51 & 85.56 & 49.93 & 100 \\
\hline \multicolumn{9}{|c|}{ Race } \\
\hline Asian & 1 & 78.43 & - & - & - & - & 78.43 & 78.43 \\
\hline $\begin{array}{l}\text { Black or } \\
\text { African } \\
\text { American }\end{array}$ & 2 & 77.33 & .24749 & .16 & 75.10 & 79.55 & 77.15 & 77.50 \\
\hline Latino/Latina & 10 & 83.66 & 9.84 & 3.11 & 76.62 & 90.70 & 69.10 & 100.00 \\
\hline White & 41 & 82.62 & 11.78 & 1.84 & 78.90 & 86.34 & 49.93 & 100.00 \\
\hline Total & 54 & 82.53 & 11.08 & 1.51 & 79.51 & 85.56 & 49.93 & 100.00 \\
\hline \multicolumn{9}{|c|}{ Academic Level } \\
\hline Practicum & 7 & 77.18 & 10.46 & 3.95 & 67.50 & 86.85 & 59.00 & 90.28 \\
\hline Field-based & 20 & 80.33 & 9.38 & 2.10 & 75.93 & 84.72 & & \\
\hline $\begin{array}{l}\text { Student } \\
\text { Teaching }\end{array}$ & 26 & 85.28 & 11.96 & 2.35 & 80.45 & 90.12 & 49.93 & 100.00 \\
\hline Total & 53 & 82.34 & 11.095 & 1.52 & 79.28 & 85.40 & 49.93 & 100.00 \\
\hline \multicolumn{9}{|c|}{ Special Education Sequence } \\
\hline $\mathrm{DHH}$ & 5 & 85.56 & 4.562 & 2.040 & 79.89 & 91.23 & 77.50 & 88.60 \\
\hline LBS1 & 48 & 82.08 & 11.60 & 1.67 & 78.71 & 85.45 & 49.93 & 100.00 \\
\hline LVB & 1 & 89.23 & - & - & - & - & 89.23 & 89.23 \\
\hline Total & 54 & 82.53 & 11.08 & 1.51 & 79.51 & 85.56 & 49.93 & 100.00 \\
\hline \multicolumn{9}{|c|}{ Number of Urban Redesigned Courses Taken } \\
\hline 0 & 9 & 83.80 & 8.63 & 2.87748 & 77.16 & 90.43 & 67.50 & 97.65 \\
\hline $1-2$ & 32 & 80.94 & 12.22 & 2.16077 & 76.53 & 85.35 & 49.93 & 96.63 \\
\hline 3 or more & 13 & 85.59 & 9.41 & 2.60995 & 79.90 & 91.28 & 69.10 & 100.00 \\
\hline Total & 54 & 82.53 & 11.08 & 1.50 & 79.51 & 85.56 & 49.93 & 100.00 \\
\hline
\end{tabular}


An independent T-test was conducted for the dichotomous variable of whether or not participants would graduate with an EL endorsement which did not result in any significance $\mathrm{t}(52)=4.18, \mathrm{p}=.338$ which is greater that .05 . Those who did not have an EL endorsement $(n=$ 46) had a higher CRTSE mean $M=81.0(S D=9.5)$ than those that were graduating with an EL endorsement $(n=8)$ had a CRTSE score $M=81.0(S D=9.5)$.

\section{Data to Inform Participant Selection for Phase 2}

Quantitative results from Phase 1 were used for the purposeful selection of participants in Phase 2. The CRTSE sum scores for all 54 participants were arranged numerically from least $(1,997)$ to greatest $(4,000)$ to create quartiles. Overall CRTSE ranges for each quartile were as follows: Q1 (1,997-3,137), Q2 (3,199-3,387), Q3 (3,400 -3,551) and Q4 (3,569-4,000). Once participants from Phase 1 were organized into quartiles, I then highlighted those that provided consent to be part of Phase 2. Within each quartile, there were 3-7 individuals who agreed to be interviewed. Three participants from both Q2 and Q4 consented to be part of Phase 2. Whereas six participants from Q1, and seven from Q3 were willing to be part of Phase 2. Two consenting participants were selected from each quartile (procedures explained in Chapter 3). In Table 8, participant demographic information is shared, which was a factor in their selection. 
Table 8

Participant Demographics for Phase 2

\begin{tabular}{|c|c|c|c|c|c|c|}
\hline Participant & Gender & Race & $\begin{array}{l}\text { Academic } \\
\text { Level }\end{array}$ & Sequence & $\begin{array}{c}\text { EL } \\
\text { Endorsement }\end{array}$ & $\begin{array}{c}\text { Number of } \\
\text { Urban } \\
\text { Courses } \\
\text { Taken }\end{array}$ \\
\hline Piper & Female & Latina & $\begin{array}{l}\text { Field- } \\
\text { based }\end{array}$ & LBS1 & No & 3 or more \\
\hline Travis & Male & Asian & $\begin{array}{l}\text { Student } \\
\text { Teaching }\end{array}$ & LBS1 & No & $1-2$ \\
\hline Ciana & Female & White & $\begin{array}{l}\text { Field- } \\
\text { based }\end{array}$ & LBS1 & No & $1-2$ \\
\hline Julie & Female & White & $\begin{array}{l}\text { Student } \\
\text { Teaching }\end{array}$ & LBS1 & Yes & $1-2$ \\
\hline Callie & Female & Latina & $\begin{array}{l}\text { Student } \\
\text { Teaching }\end{array}$ & LBS1 & Yes & 3 or more \\
\hline Kelly & Female & White & $\begin{array}{l}\text { Student } \\
\text { Teaching }\end{array}$ & $\mathrm{DHH}$ & No & 3 or more \\
\hline Jillian & Female & White & $\begin{array}{l}\text { Student } \\
\text { Teaching }\end{array}$ & LBS1 & No & $1-2$ \\
\hline Amanda & Female & White & $\begin{array}{l}\text { Student } \\
\text { Teaching }\end{array}$ & LBS1 & No & 0 \\
\hline
\end{tabular}

In Table 9, CRTSE sum scores and the strengths index are listed for each of the participants. Pseudonyms were given to each participant to protect anonymity. To form an overall high and low self-efficacy group, participants from Q1/Q2 formed the low self-efficacy group, and participants in Q3/Q4 formed the high self-efficacy beliefs group. 
Table 9

CRTSE Beliefs Among Phase 2 Participants

\begin{tabular}{lccccccccccc}
\hline & \multicolumn{3}{c}{$\begin{array}{c}\text { Participants with low self- } \\
\text { efficacy beliefs } \\
(n=4)\end{array}$} & \multicolumn{5}{c}{$\begin{array}{c}\text { Participants with high self- } \\
\text { efficacy beliefs } \\
(n=4)\end{array}$} \\
\hline Variable & Piper & Travis & Ciana & Julie & $\begin{array}{c}\text { Group } \\
\text { Avg. }\end{array}$ & Callie & Kelly & Jillian & Amanda & $\begin{array}{c}\text { Group } \\
\text { Avg. }\end{array}$ \\
$\begin{array}{l}\text { CRTSE } \\
\text { total } \\
\text { score }\end{array}$ & 2786 & 3137 & 3241 & 3277 & 3110 & 3495 & 3495 & 3711 & 3760 & 3615 \\
$\begin{array}{l}\text { CRTSE } \\
\text { strength } \\
\text { index }\end{array}$ & 70 & 78 & 81 & 82 & 78 & 87 & 87 & 93 & 94 & 90 \\
\hline
\end{tabular}

\section{Factors and Experiences that Impact CRTSE}

Interview data were analyzed to answer RQ2: (a) What factors and experiences do preservice special educators describe as impacting their CRT self-efficacy? (b) How do these factors and/or experiences differ among those with high/low self-efficacy scores? Before interviews, three a priori codes had been established (Siwatu, 2011a). As participants responded to questions during the semi-structured interviews, their responses were coded as discussed, observed, or practiced to identify an initial understanding of the survey indicators that participants had experienced. Participants were asked to review the items on the survey as well as the rating that they assigned to themselves for each item and to share if any of the survey items had been addressed in their special education teacher preparation program, either through coursework or at their clinical sites. The total number of items that were discussed, observed, or practiced are shown in Table 10. As summarized in the table below, the high self-efficacy group indicated that more CRTSE survey items were discussed and practiced in their special education program. Although both groups reported similar opportunities to observe items in practice, the 
high self-efficacy group reported more discussion and practice. These results will be discussed more in-depth as they are embedded in the themes described later in this chapter.

Table 10

Average Number of CRTSE Practices that were Discussed, Observed, Practiced

\begin{tabular}{|c|c|c|c|c|c|c|c|c|c|c|}
\hline \multirow[b]{2}{*}{ Variable } & \multicolumn{4}{|c|}{$\begin{array}{c}\text { Participants with low self- } \\
\text { efficacy beliefs }\end{array}$} & \multirow[b]{2}{*}{$\begin{array}{l}\text { Group } \\
\text { Avg. }\end{array}$} & \multicolumn{4}{|c|}{$\begin{array}{c}\text { Participants with high self- } \\
\text { efficacy beliefs }\end{array}$} & \multirow[b]{2}{*}{$\begin{array}{l}\text { Group } \\
\text { Avg. }\end{array}$} \\
\hline & Piper & Travis & Ciana & Julie & & Callie & Kelly & Jillian & Amanda & \\
\hline $\begin{array}{l}\text { Number } \\
\text { of CRTSE } \\
\text { practices } \\
\text { Discussed }\end{array}$ & 17 & 2 & 22 & 23 & 16 & 22 & 15 & 38 & 35 & 27.5 \\
\hline $\begin{array}{l}\text { Number } \\
\text { of CRTSE } \\
\text { practices } \\
\text { Observed }\end{array}$ & 11 & 1 & 13 & 7 & 8 & 4 & 1 & 6 & 20 & 7.75 \\
\hline $\begin{array}{l}\text { Number } \\
\text { of CRTSE } \\
\text { practices } \\
\text { Practiced }\end{array}$ & 10 & 6 & 13 & 11 & 10 & 9 & 9 & 16 & 22 & 14 \\
\hline
\end{tabular}

\section{Participant Response to High and Low Survey Items}

During Phase 2, one of the aims was to better understand the factors and experiences that participants from higher and lower self-efficacy groups attributed to their CRTSE. Quantitative data from Phase 1 was used to further explore the survey items with the highest and lowest mean scores. Table 11 includes the five highest and lowest survey items. The indicators are ranked, with 40th being the lowest and 1st being the indicator with the highest overall mean score. The mean scores for each efficacy group are also listed for comparison. Additionally, phrases are bolded or italicized to highlight patterns and similarities between items that were ranked both high or low. 


\section{Table 11}

Survey Items with the Lowest and Highest Mean Scores

\begin{tabular}{|c|c|c|c|c|}
\hline Item Number and Description & Rank & $\begin{array}{c}\text { Overall } \\
M \\
N=54\end{array}$ & $\begin{array}{c}M \text { for Low } \\
\text { CRTSE Group } \\
n=4\end{array}$ & $\begin{array}{c}M \text { for High } \\
\text { CRTSE Group } \\
n=4\end{array}$ \\
\hline
\end{tabular}

Low Self-Efficacy Survey Items

2. Design appropriate instruction that

is matched to English language learners' language proficiency and special needs.

6. Use various types of assessments that are matched to English language learners' language proficiency of special needs.

12. Implement interventions that minimize the effects of cultural mismatch between home and school.

15. Assist my students to be successful by supporting the native language of my students with disabilities who have limited English proficiency.

33. Design a lesson that shows how other cultural groups have made use of mathematics. $\begin{array}{llll}40 & 68.70 & 56.75 & 78\end{array}$

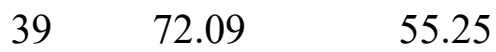

$\begin{array}{lll}38 & 72.35 & 65\end{array}$

$37 \quad 72.42$

65

70.75

$\begin{array}{lll}36 & 73.03 & 65.25\end{array}$

71.5 High Self-Efficacy Survey Items

19. Help my students develop positive interactions with each other. 37. Use the interests of my students to make learning meaningful for them.

22. Build a sense of trust in my students 14. Create a caring, supportive, and warm learning environment for my students from CLD backgrounds.

34. Help students feel like important members of the classroom.

$\begin{array}{cccc}5 & 90.98 & 94 & 99.75 \\ 4 & 92.62 & 92 & 97.5 \\ 3 & 93.03 & 93.5 & 100 \\ 2 & 93.12 & 98.5 & 94.5 \\ & & & \\ 1 & 94.09 & 85 & 96\end{array}$

Note. ${ }^{*}$ Italicized phrases indicate language proficiency needs **Bolded phrases relate to pedagogical knowledge ** Italicized words in the high self-efficacy group relate to respect and rapport 


\section{Survey Items with the Lowest Mean Scores}

The survey items where participants felt the least efficacious are related to the areas of language proficiency needs (italicized) and pedagogical knowledge including designing instruction, and implementing interventions and assessments (bolded), which are indicated by the italicized and bolded highlights in Table 5. Three of the five survey items that scored in the low category include language that focuses on English language learners' needs, knowledge of assessments that match English language learner's level of proficiency, and how to support students with disabilities who have limited English proficiency. Four of the five indicators have an emphasis on instruction or assessment, which are indicated by the bolded words within the indicators where participants reported feeling less capable. The other two survey items with low mean scores focus on implementing an intervention that minimizes cultural mismatch and designing a lesson that shows how other cultures have made use of mathematics. For the survey items with the lowest ranking (40-36), the mean scores of those in the low self-efficacy group were all below the total participant mean score $(N=54)$ included from Phase 1 , and the mean scores from the high self-efficacy group were all above the overall mean scores.

Coded responses from participant interviews provide additional understanding on why these indicators were ranked lower. Participants from both low and high self-efficacy groups noted that they learned the importance of supporting EL learners, but they did not feel that they had any specific resources or strategies that they could employ. In terms of assessments, a participant from the high self-efficacy group stated that she had learned that standardized tests could be biased toward minoritized groups and the importance of finding non-discriminatory assessments, but hadn't had any opportunities to practice this. Other factors that were discussed amongst participants in the low self-efficacy group related to a lack of experience. They had yet 
to encounter any learners that spoke languages other than English and felt that they would be uncertain of what to do. One participant stated, when it comes to language differences, this is where they felt the least knowledgeable and learned the least.

Callie, a participant in the high self-efficacy group, is also earning her EL endorsement. In her interview, she mentioned that she was able to observe interactions between students and their teachers conversing in their native language; however, she felt that this was because she enrolled in bilingual courses, which expanded her understanding of the use of native language and she may not have had this opportunity otherwise.

\section{Survey Items with the Highest Mean Scores}

When analyzing the indicators with the five highest mean scores, participants have high self-efficacy as it relates to respect and rapport through caring and supportive learning environments that makes learners feel like important members of the classroom. All five of the items with the highest means include language that focuses on respectful relationships between the student and teacher as well as between the learners having positive interactions with one another. There are notable patterns found within the indicators that were ranked as the five highest and lowest overall mean scores. For the indicators with the highest ranking (1-5), participants from the low self-efficacy group were nearly at or above the overall mean score, as was the high self-efficacy group. Interestingly, for indicator 14, the mean score of the low selfefficacy group was above that of the overall mean and the high self-efficacy group. This is the only instance where the low self-efficacy group had a higher mean than the high self-efficacy group. 


\section{Qualitative Themes from Interviews}

It was through the a priori coding during the initial interview sessions that additional codes were formed as a result of participant responses. During additional rounds of coding, there were 44 codes, eight categories, and four themes that emerged. Through analysis of interview transcriptions, four major themes emerged: (a) acquiring knowledge of CRT, (b) professor impact on CRT, (c) application and practice of CRT, and (d) experiences with CRT. In Figure 3, the themes and their subthemes will be reported below are represented. Each theme is organized to first include the similarities held by both high and low self-efficacy groups and followed-up with any differences between groups. A complete list of initial codes, categories, and themes, along with definitions, are included in Appendix C.

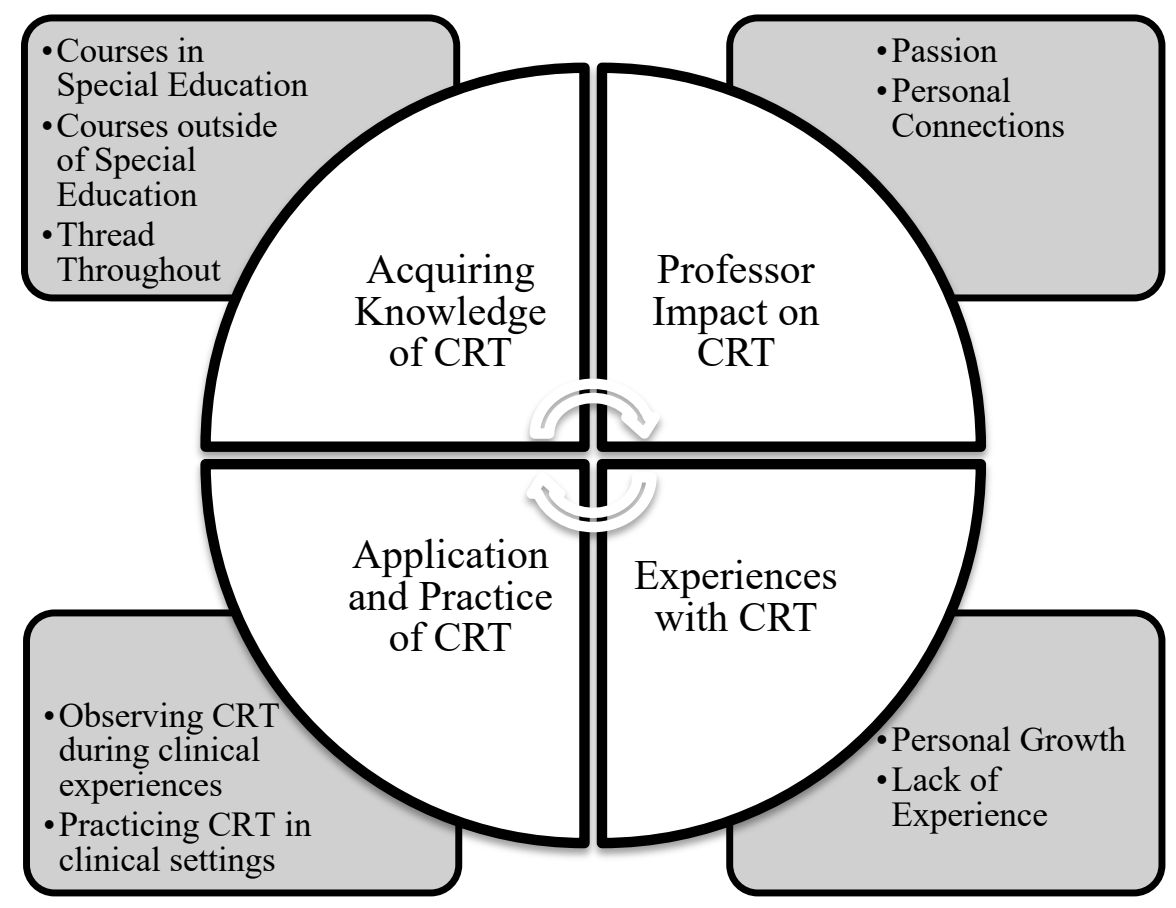

Figure 3. Interview Themes and Subthemes

\section{Acquiring Knowledge of CRT}

Participants identified their coursework as a primary source in their acquisition of CRT knowledge. Within this acquisition theme, subthemes emerged as participants distinguished the 
differences between courses that were taught in their special education courses at the foundations and methods level as well as those courses that were taken in other education departments. Participants also discussed how CRT was thread throughout their special education coursework.

\section{Special Education Coursework}

Within the special education undergraduate program where this study was conducted, there are 100 and 200 level courses that are considered foundational in their program and 300 level courses that are considered methods courses. In interviews, participants identified these two levels of coursework as instrumental in their development of CRT skills.

At the foundations level, two of the required courses, one on Collaboration as well as an Assessment course, had the most mentions amongst high and low self-efficacy groups as having impacted their overall CRTSE.

Both high and low self-efficacy groups noted that their Collaboration course emphasized learning about the importance of strengths-based language and to avoid using deficit language. Additionally, participants from both groups discussed learning about the importance of family interviews and considering cultural backgrounds that are different than their own.

In addition to collaborating with families and using strengths-based language, participants from the high self-efficacy group indicated that they learned about recognizing their own bias to gain better insight into working with families. Amanda, a participant in the high selfefficacy group, stated that the Collaboration course was one of the most influential courses in her special education program because it taught her how to interact with families from diverse backgrounds.

The Assessment course is another course that participants from both high and low selfefficacy groups identified as their initial introduction to learning about bias in standardized 
assessments. Likewise, participants from both groups discussed learning about the importance of providing an interpreter or translator if families speak languages other than English. Participants from both groups also shared that they learned ways to respectfully interact with families during meetings by speaking directly to family members and offering eye contact as opposed to speaking to the interpreter.

Jillian, a participant in the high self-efficacy group, shared that the readings assigned in the assessment course contributed to her understanding of how to teach learners from CLD backgrounds. Amanda, who is also in the high self-efficacy group, discussed learning about case law and non-discriminatory evaluation and the importance of ensuring that learners are assessed in their appropriate language. She also discussed learning the importance of critically examining the curriculum that you are teaching to determine if it appropriately represents CLD groups because this may have an impact on their content understanding which could negatively impact assessment results.

There were four methods courses at the 300 level that participants identified as significant influences on acquiring knowledge on culturally responsive teaching. Two of these were literacy courses that special education candidates were required to take. These courses are discussed as one since this is how the participants referred to them during the interview.

The Language and Literacy courses were identified as impactful by participants from both groups. Participants in the low self-efficacy group discussed learning about the importance of choosing authors and resources that are representative of the learners and/or community where they are teaching. Piper, a participant who was in the low self-efficacy group, discussed a class assignment where they selected and reviewed books that could serve as windows, mirrors, and doors to determine how they might use these books in their own classrooms. She also shared a 
quote that she remembered learning in one of her literacy courses, "Don't dip your pen in someone else's blood," which she went on to explain the issues with cultural appropriation and authors who do not hold membership in a community should not be the ones telling the stories. Ciana stated that she learned about assessments that might be appropriate for English language learners, yet this was the area where she felt the least efficacious and wasn't sure she would know how to execute these assessments because she didn't have an opportunity to practice. Participants in the high self-efficacy group discussed learning about cultural differences as well as dialect when considering literacy for instruction and assessment. They also discussed incorporating native language while delivering reading instruction in English. Those in the high self-efficacy group also discussed interventions that could be used with EL learners at their level of language proficiency.

Both high and low self-efficacy groups discussed another influential course, Math Methods, and attributed learning about different ways to demonstrate kno and how to incorporate learner interests into their instruction. Participants from the high self-efficacy group also shared that they learned about flipped learning and how to differentiate instruction to meet learners where they are.

Participants across both self-efficacy groups shared that they learned about the importance of unpacking their own bias and critically examining stereotypes that may be a result of those biases in their Behavior Supports class. Both groups also discussed learning about historical trauma and the impact that this can have on their learners. Ciana, a participant in the low self-efficacy group, identified restorative justice as a practice that she learned about that builds community. Jillian, in the high self-efficacy group, shared that she learned about universal discussion techniques where you consider the types of topics you bring to your learners. For 
example, instead of asking about a vacation that they went on over summer break, reframe that by asking them to describe their ideal summer day because this eliminates disparity of experiences.

Additional courses within special education programming were mentioned but had fewer than 15 mentions during the eight interviews. However, it is important to note that participants from both high and low self-efficacy groups identified their Transition to Adulthood as a course that emphasized the importance of working with families and considering culture when developing a transition plan that reflects the parents' vision. Members from the high self-efficacy group discussed learning about surveys and interest inventories as tools to communicate with families. Additionally, participants identified their Severe Disabilities course and their Systematic Instruction course as integral to learning how to build trusting relationships with families and students. They also noted that in these courses, they learned about a variety of teaching methods that would benefit a variety of diverse learners.

During the field-based clinical experience, teacher candidates continue to take coursework that focuses on theory to practice. Participants from the low self-efficacy group discussed learning about different family structures and how to represent culturally diverse learners through inclusion in their instructional materials. Ciana discussed learning about the cultural contributions that other groups have made to society and the importance of investigating instructional resources to ensure that they have not been Whitewashed or stolen from the original creators.

Participants that were in both high and low self-efficacy groups discussed the impact of the mock IEP (individualized education program) meetings that they participated in as a way to learn about diverse family perspectives. One participant, Amanda, who was in the high self- 
efficacy group, stated that having choice board assignments allowed her an opportunity to implement instructional activities with a cultural focus that was specific for her learners.

\section{Thread Throughout}

A sub-theme that was part of the acquisition of CRT knowledge was that participants across both self-efficacy groups discussed CRT being taught across their special education coursework. All eight participants made specific mentions of how CRT was thread throughout their coursework. From the low self-efficacy group, Piper shared that all of her urban education courses focused on culturally responsive practices. Travis expressed that his CRT knowledge was due to a culmination of instruction across his program. Ciana shared that nearly all of her classes discussed strategies that could be implemented with culturally diverse learners.

Julie and Callie are both earning their EL endorsement and took additional coursework with a focus on bilingual education and shared that all of their EL courses had a focus on culturally responsive practices as well as their special education coursework. Kelly, a participant in the high self-efficacy group, was the only participant in the DHH program, and she shared that culturally responsive practices were taught across her programming. She mentioned courses with literacy and accommodation focus were where CRT was discussed.

Jillian, from the high self-efficacy group stated, "Honestly, every single class that I had that was a 300-level course was very focused on culturally responsive teaching; it was at the center of everything we learned." Amanda, who was also in the high self-efficacy group, shared that CRT was taught during her entry level-coursework at the 100 and 200 level as well as during her methods coursework and during clinicals. 


\section{Coursework Outside of Special Education}

Special education majors do take courses in other departments in addition to their program curriculum, and participants did mention some of those courses as having an influence on their culturally responsive teaching knowledge. It is important to note that the courses discussed with the special education program were mentioned across interviews in high and low self-efficacy groups. The courses from other programs were mentioned fewer times, including educational foundations with one participant mention. A psychology course on child growth and development was mentioned by one participant in both the high and low self-efficacy groups as well as a general education math course that was also mentioned by one participant in both the high and low self-efficacy groups. Finally, one participant in the low self-efficacy group mentioned a course on cross cultural teaching and learning.

One participant from both the high and low self-efficacy group mentioned a general education math course where they learned about ways that math might be taught in other countries or that they are currently using techniques that they learned in that course to teach CLD learners in their current clinical site. Another course that was mentioned across both high and low self-efficacy groups was a course that focused on child growth and development. Piper, a participant in the low self-efficacy group, shared that this was her first course that had been redesigned with an emphasis on urban education, and it motivated her to sign up for other redesigned courses to learn more about culturally responsive practices. Amanda, who was in the high self-efficacy group, shared that there was a cooperating teacher who was associated with the course, and she was able to observe the ways she interacted with her students and then explained how she incorporated what she had learned in the getting to know you activities into her later instruction to ensure she was connecting to student culture and interest. 
Julie and Callie were the two participants who were also earning their EL endorsements, and they each discussed the impact that those five courses had on their understanding of CRT practices. Julie was in the low self-efficacy group and discussed learning about existing assessments for learners whose first language was not English as well as how to modify and create assessments. Julie also discussed how she learned about the importance of creating a welcoming environment for students and their families. Callie was in the high self-efficacy group and discussed learning how to modify and design instructional materials for learners from CLD backgrounds. She also discussed learning about assessment bias of standardized assessments.

One participant, Ciana, shared that she learned about racism, classism, sexism, and communication differences between home and school in her Social Foundations of Education course and to consider how to develop positive relationships with her students as well as helping them build positive relationships with one another.

\section{Professor Impact}

Another theme that was identified throughout the interview analysis was professor impact. In coding the interview data, it was necessary to delineate between a mention of a professor's name to identify the course they taught versus the way a participant discussed how a professor delivered content that stood out to participants as influential to their own CRT development. Across both high and low self-efficacy groups, each of the participants discussed one or two professors that made a particular impact on their understanding of CRT. The similarities across both groups were the passion that these professors held for culturally responsive practices and the personal connections that they made with their students. Since the comments were unique examples of individual experiences, they will be reported by efficacy groups below. 


\section{Low Self-efficacy}

Piper shared that all of the professors from the urban redesigned courses shared their personal experiences when discussing content, and this really helped her to understand the content on a deeper level. She elaborated by expressing how their personal experiences were eye-opening in helping her understand more about teaching in an urban setting. Piper also shared a story about a professor and how he shared additional resources with her on African American Vernacular English (AAVE) because this was an interest of her.

Travis explained that he had a professor who challenged him to think deeper than he was. "She asked me to stretch, which made me more aware of how I should be thinking about the importance of families and the intersection between home and school," Ciana stated that she felt like she learned so much just from watching her professors and the ways in which they interacted with their students as a model for how she should engage with her future learners.

Julie had this to say about a professor that taught her behavior supports class, "She's super passionate about different cultures, and making sure everyone's included. We talked so much about CRT". She concluded by saying that she isn't sure that others who took the same course but with a different instructor would focus as much on CRT since this was such a passion of this particular professor.

\section{High Self-Efficacy}

Callie and Amanda both discussed a professor that they had for their behavior supports course and how she influenced their understanding of the importance of home life and culture. Callie discussed how this professor really talked to them from her own experiences of how to plan for and include all of their learners. 
Kelly was a student teacher in the DHH program who discussed a professor that she had for many courses within her sequence that she attributes to supporting her personally. "She got me through this program, and she makes her students feel like important members of the class; she makes us feel valued." She continued to share that she felt comfortable coming to this professor to ask her questions about a variety of topics that increased her knowledge.

Jillian spoke about three of her methods instructors specifically and their impact on her development of CRT. "I would go to their classes, and they would make me want to be better for my own students." Jillian followed-up by stating how her professors encouraged her to really get to know her CLD learners and make an effort to learn about their backgrounds through phone calls or home visits. She added that her professors shared their experiences so effortlessly that it naturally became something that she started to incorporate into her clinical experiences. Jillian also shared that when she would have discussions with her professors that she really saw them as "more knowledgeable others" and never felt that they were talking down to her or leveraging power; instead, it always felt like a conversation where they shared what they knew and cared about as it related to culturally responsive teaching practices.

\section{Culturally Responsive Teaching in Action}

A theme that was established during interview analysis was related to the opportunity to apply CRT during clinical experiences. The number of coded comments related to clinical experiences were almost as many as the comments pertaining to special education coursework. Participants discussed their experiences of observing and learning from their cooperating teachers as well as their own opportunities to include CRT into their instruction. A commonality amongst participants in both self-efficacy groups centered on relationships built on trust as well as creating a warm, supportive learning environment. Having Communicating with families and 
sharing information related to the IEP was another experience that the majority of participants discussed in their interviews as well.

\section{Learning through Observation}

Piper, a participant in the low self-efficacy group, shared many examples of how observations of her cooperating teacher impacted her ability to incorporate CRT into her own teaching. She said she had opportunities to observe her cooperating teacher interacting with parents and teaching units with a social justice focus and learned how to navigate complex topics and questions as a result. Travis discussed the influence of one of his cooperating teachers and how he helped change a deficit view that he had about his learners. Travis said that he came into the EBD classroom with a perception that his students couldn't be trusted, but his cooperating teacher modeled trust and giving learners some freedom to make their own choices to build their independence. Ciana referred to one of her cooperating teachers as "the greatest person I've ever met" and explained that she learned from observations of how she praised learners, collaborated with the instructional team as well as parents. Julie discussed how her cooperating teacher taught her how to modify instructional materials for the EL learners in their class by adding visual supports. She also shared the ways in which she collaborated and communicated IEP progress and goals with families.

Within the high self-efficacy group, participants spoke less frequently about observing their cooperating teachers, but several participants did share learning opportunities. Kelly stated that she observed her cooperating teacher support a variety of learners from different cultures, and as a student teacher in the DHH program, this was particularly meaningful, she mentioned due to the differences in signing and/or communicating with learners. The majority of 
participants shared that they observed their cooperating teacher reach out to families to discuss upcoming IEP meetings.

\section{Application of CRT}

All of the participants in the low self-efficacy group discussed opportunities to create warm and inviting learning environments, establishing trusting relationships with students as well as student interactions with one another. Piper shared that in an attempt to build relationships every other week, she and her cooperating teacher would visit the homes of their students to give materials and rewards since they were remote learning and did not see their students face to face. This exposure to families allowed her to gain experience communicating with families and considering different ways to incorporate what she was learning from families into her lesson.

Travis discussed being able to choose materials at his clinical site that represented the culture of his learners. This provided a unique experience where Travis was able to support English for one of his learners while, in turn, the learner was able to help Travis with his Spanish as they read through the text. He said that this also helped build connections between learners as they were able to understand their similarities and differences as a result of the discussions that resulted from the text.

Within the high self-efficacy group, all of the participants mentioned using interest inventories or surveys sent home to families as a way to get to know their learners. This was a catalyst amongst the group for rapport-building and implementing interests into lessons. The majority of the participants also discussed their opportunities to make curricular decisions that

incorporated culture. Kelly mentioned taking note of the types of foods her learners ate during lunch and then created recipes for their functional cooking class that represented their culture. 
Several of the participants discussed the ways that they sought to build relationships with learners that were reluctant. Kelly said she would pay careful attention to notice if someone was disconnected in the learning environment and would make attempts to connect with them individually. Callie shared how mental and emotional health were a priority for her, and she had daily check-ins with specific students to understand where they were emotionally.

Jillian and Amanda both discussed having opportunities to differentiate the types of assessments they were using with students. Jillian said she offered flexible options for learners to share their knowledge or offered modified assessments based on the level of support needed. Amanda talked about making sure that her assessments were relatable to her learners by including everyday items that were familiar to them.

\section{Experiences with CRT}

A recurring theme across participant interviews was personal experiences that they attributed to their overall CRTSE. Across both self-efficacy groups, participants discussed their personal growth throughout their educational program, as well as their lack of experience or

comfortability with certain aspects of culturally responsive teaching. As may be expected, those in the high self-efficacy group had more examples of their personal growth and fewer areas where they felt they lacked experience, and the low self-efficacy group highlighted fewer examples of their personal development but identified more areas where they were not yet comfortable with their own ability to implement culturally responsive practices.

\section{Personal Growth}

Participants in both high and low self-efficacy groups expressed increased confidence in their CRT abilities, as well as being able to apply what was learned in coursework to their 
clinical settings. There were additional areas of personal growth that were discussed in individual interviews that will be shared across high and low self-efficacy groups.

Kelly, a participant in the high self-efficacy group, expressed her personal growth through her eagerness to learn a new language and understand culture. In addition to having a willingness to learn, she felt comfortable reaching out to professors to learn more if there was an area where she lacked confidence. She believes that having experiences with people from differing cultures from her own has also contributed to her growth. Jillian discussed how the application of strategies that were taught increased her personal growth because she was able to see the effectiveness of what she taught. She also found opportunities to share her knowledge on bias and CRT with her cooperating teacher and other members of her school community during professional development days. Jillian also felt that self-reflection was critical for her continued growth.

In the low self-efficacy group, Piper spoke about increased confidence due to her involvement in an immersive summer opportunity that is coordinated through the College of Education, where she lives with a host family in an underserved neighborhood in Chicago and worked with students during summer programming. She explained that through this experience and additional professional development that was offered, she had a better understanding of privilege and racism, which translated to having more confidence in completing her clinicals in an urban environment. Travis spoke about his growth as it relates to working with learners from diverse backgrounds that require behavior supports. He said that he now understands the importance of a strengths-based perspective and reciprocal teaching, where he invites students to share their knowledge with one another. Travis also said that he is able to understand how 
culture might impact how or if a student will ask or accept help and recognizes this from his own culture as an Asian student who felt it wasn't appropriate for him to ask for additional assistance.

\section{Lack of Experience}

Across both self-efficacy groups, participants indicated areas where they felt less efficacious in their ability to execute certain aspects of CRT. Across both groups, participants shared that they lacked experience actually developing an IEP for learners from CLD backgrounds. Additionally, participants from both groups shared that they were unsure if it was appropriate to greet a student in their native language as they felt that they had learned conflicting information on whether or not this was welcoming or presumptive. Communicating with students and families whose native language was not English was also an area of concern with both groups of participants.

In addition to the shared concerns that were mentioned above, Callie, a participant in the high self-efficacy group, expressed concern that even though she took EL courses for her endorsement, she didn't learn what to do if a student with limited English proficiency also had a disability. She felt like there was little integration between the two programs, either disabilityfocused or English language-focused. Jillian shared that although there were some areas where she lacks experience, she felt confident that she would know how to find a resource that she could use to support her learners.

Participants from the low self-efficacy group discussed having curricular knowledge but lacking confidence about implementing it. The majority of participants in this group expressed concern with delivering appropriate instruction, interventions, and assessments to learners whose first language was not English. They described having knowledge but were lacking specific strategies to support instruction. Travis discussed how he understood the importance of including 
culture in his instructional plans, but felt as if he was doing this as an add-on or that a student would feel singled out because it wasn't fully integrated into the lesson. Another participant, Julie, mentioned that she wasn't confident in her abilities to examine an existing curriculum to determine if it accurately represented CLD groups. Additionally, two of the questions on the CRTSE survey related to cultural contributions in math and science, and candidates in the low self-efficacy group felt that they had not considered this in their practice.

\section{Conclusions}

This chapter includes the quantitative and qualitative findings of this study. Fifty-four participants completed the survey in the first phase of this study, and eight participants (two from Q1 and Q2 and two from Q3 and Q4) participated in Phase 2. Participants were all preservice special educators who were enrolled in one of their three clinical semesters. Interview questions were semi-structured and analyzed to understand the factors and experiences that influenced each participant's CRTSE score as well as to determine differences between high and low selfefficacy groups.

During data analysis, there were three rounds of coding, including: (a) a priori, (b) attribute, and (c) fine coding. Next, common codes were combined into categories which then developed into four themes. The four themes were: (a) acquiring knowledge of CRT, (b) professor impact, (c) culturally responsive teaching in action, and (d) experiences with CRT.

During the first phase of this study, overall self-efficacy scores indicated that most participants have moderate to high self-efficacy, with $74 \%$ of participants scoring within the top two CRTSE band ranges (i.e., 80-89 and 90-100). There were no significant demographic factors that influenced CRTSE scores. Item-specific means are consistent with other studies, where the survey items with the highest rating relate to classroom environment and relationships 
whereas the indicators with the lowest rating are related to native language and instructional design. During the second phase of this study, interviews were analyzed to determine similarities and differences between the types of responses given from those with high self-efficacy and those who rated themselves as having lower culturally responsive teaching self-efficacy. Four themes emerged from coding interviews that focused on how preservice special educators acquired their knowledge of CRT, the impact of their professors, culturally responsive teaching in action and personal experiences with CRT. Chapter V includes the summary for the analysis and discussion of the four themes. 


\section{CHAPTER V: DISCUSSION}

There has been a decades long problem of CLD learners being disproportionality referred for special education services (Cyr et al., 2012). While the issues surrounding this are complex, one possible cause is the cultural dissonance of a predominantly White, middle class teaching force that may not embody the cultural awareness needed to be effective teachers (Imler, 2009; Kahn et al., 2014; Taylor, 2010; Trent et al., 2008). Teacher education programs play a role in developing culturally competent teachers (Allen et al., 2017) and have begun to include CRP into their curriculums and field experiences. However, there has been little outcome data to better understand if their efforts are indeed developing culturally competent teachers (Lewis-Pratl et al., 2021; Trent et al., 2008). Understanding the culturally responsive teaching self-efficacy of preservice teachers has been one way that some researchers have examined the cultural competence of educators entering the field (i.e., Cruz et al., 2020; Siwatu, 2007, 2008, 2009, 2011a, 2011b; Siwatu \& Starker, 2010; Siwatu et al., 2009, 2016, 2017; Whitaker \& Valtierra, 2018).

The purpose of this sequential explanatory mixed methods study was to add to the body of research on culturally responsive teaching and special education preservice teacher's selfefficacy to teach learners from CLD backgrounds. Siwatu (2007) developed the CRTSE scale that has been administered to both inservice and preservice teachers (i.e., Chu \& Garcia, 2014;

Cruz et al., 2020; Debnam et al., 2015; Dickson et al., 2016; Fitchett et al., 2012; Malo-Juvera et al., 2018; Siwatu, 2007, 2008, 2009, 2011a, 2011b; Siwatu \& Starker, 2010; Siwatu et al., 2009, 2016, 2017; Whitaker \& Valtierra, 2018. Chu and Garcia (2014) sought to expand on this work by including language of disability within the survey indicators to determine the self-efficacy of inservice special educators. The purpose of this mixed methods study was to expand both the 
work of Siwatu (2011a) as well as that of Chu and Garcia (2014) in two ways. Specifically, the study aimed to answer the following questions:

RQ1: (a) What are preservice special educators' culturally responsive self-efficacy beliefs? (b) To what extent do these beliefs differ based on academic and/or demographic backgrounds?

RQ 2: (a) what factors and/or experiences do preservice special educators describe as impacting their CRT self-efficacy? (b) How do these factors and/or experiences differ among those with high/low CRT self-efficacy scores?

First, there is scant literature that specifically examines special education preservice teachers and their self-efficacy for teaching in culturally diverse environments. Siwatu (2011a) researched the self-efficacy of general education preservice teachers through the use of the CRTSE scale and follow-up interviews. Chu and Garcia (2014) conducted a quantitative study that used a modified version of the CRTSE survey to investigate the self-efficacy of inservice special education teachers. This CRTSE scale was modified to include language of disability and was distributed to teachers with 1-15 years of experience. Only one study (i.e., Cruz et al., 2020) included special education preservice teachers as part of their participant pool.

A second difference that expanded existing literature was to examine the factors and experiences that contributed to the CRTSE scores of special education preservice teachers. Of the existing studies that used the CRTSE instrument, the majority were quantitative and only four (i.e., Malo-Juvera et al., 2018; Siwatu, 2011a; Siwatu et al., 2016; Whitaker \& Valtierra, 2018) conducted follow-up interviews (all of which are general education studies). To do this, I took a pragmatic approach and combined quantitative data to identify participants for a semistructured interviews to gain an understanding of the factors and experiences that influenced 
participants from both high and low CRTSE groups including commonalities between groups and differences.

Chapter V includes a discussion of the key findings as well as themes that developed during analysis. Since there is little comparison data, the discussion includes findings from the literature review, salient features of CRP frameworks, and discussion of TEPs and their attempts to redesign their special education programs to include CRP. Additionally, the discussion considers Bandura's $(1977,1986,1997)$ theory of self-efficacy. Limitations and implications for practice and future research are also discussed.

\section{Interpretation of the Findings}

The current study represents the CRTSE beliefs of 54 special education preservice teachers from a TEP in the Midwest. This is the largest investigation of special education preservice teacher's culturally responsive teaching self-efficacy to date. There is one existing study (i.e. Cruz et al., 2020) which included preservice special educators in their population, however it is unknown how many participants are included. The current study investigated overall self-efficacy beliefs and sought to understand if there were demographic or academic influences on CRTSE. Additionally, this study was the first mixed methods study to include CRTSE and special education preservice teachers. Follow-up interviews were conducted to understand the factors and experiences that preservice special educators attribute to their CRTSE beliefs. This is an important addition to the body of literature, while statistical data is informative to understanding CRTSE beliefs, we cannot extrapolate the experience from the data without additional methods of inquiry.

Overall, preservice special educators who participated in this study have a moderately high self-efficacy related to culturally responsive teaching. The overall mean amongst 
participants was $M=82.53$. Fourteen participants scored below the mean, and 40 participants scored at or above the mean. However, there were no significant differences in self-efficacy scores based on academic or demographic backgrounds. One expected finding that was unfounded was that participants who participated in urban redesigned courses or those earning their EL endorsement in addition to their special education licensure would have significantly higher self-efficacy scores than those who did not. In part, this could be due to the small number of participants, or it could be that those who have more of an awareness of CLD classrooms may recognize all that they still have to learn. The two studies that examined the CRTSE of special educators (i.e., Chu \& Garcia, 2014; Cruz et al., 2020) also collected demographic information to investigate if there were any impact on CRTSE scores. Chu and Garcia (2014) found that nonWhite educators had a significantly higher CRTSE than their White counterparts, and that knowing a language other than English also resulted in higher CRTSE scores. Adversely, Cruz et al., (2020) found that having a first language other than English resulted in a lower CRTSE score. Results from both studies found that the number of years taught had a positive impact on CRTSE scores.

\section{Item Specific-Means}

Item-specific means were examined to determine targeted areas where preservice special educators felt most and least self-efficacious in their ability to implement culturally responsive teaching practices. Preservice teacher candidates had higher self-efficacy scores for indicators based on the ability to develop positive, supportive, and caring relationships with their CLD learners and make learning meaningful by incorporating learner interests. These results coincided with previous research that found that participants had higher self-efficacy on indicators that related to the classroom environment and showing student care (i.e., Chu \& Garcia, 2014; Cruz 
et al., 2020; Siwatu, 2007, 2008, 2009, 2011a, 2011b; Siwatu et al., 2009, 2016; Siwatu \& Starker, 2010).

Teacher care and establishing a supportive learning environment may be viewed as indicators requiring little skill (Siwatu, 2011a); however, it is important to note that teacher attitudes, beliefs, and perceptions play a significant role in becoming a culturally responsive educator. When teachers manifest affirming attitudes about their learners, the result is greater student achievement (Ladson-Billings, 1995). Villegas and Lucas (2002) also posit that the attitudes that teachers have regarding their learners greatly impacts what students learn. While teacher care may be a less complex skill, it is encouraging that the data reflects that the majority of participants surveyed have high self-efficacy as it relates to creating warm and welcoming learning environments for learners from CLD backgrounds. The survey indicators that were ranked the highest had a mean range of 90-94 out of a possible 100.

Preservice special educators felt less self-efficacious when designing and assessing instruction or implementing interventions that aligned with the language proficiency needs of their CLD students with special education needs. These findings are consistent with the literature review on published self-efficacy studies. Ten previous studies, one of which included special education preservice teachers, had similar findings (i.e., Chu \& Garcia, 2014; Cruz et al., 2020; Siwatu, 2007, 2008, 2009, 2011a, 2011b; Siwatu et al., 2009, 2016; Siwatu \& Starker, 2010). As teacher educators begin to make considerations on ways to target support for these complex skills, perhaps they can consider the curricular changes that two programs made within their TEP to include more robust EL instruction. Pappamihiel et al. (2010) and Prater et al. (2008) both combined their undergraduate and master's level special education programs to include additional EL coursework. This type of collaboration between disciplines can provide additional 
understanding of the ways that disability and language proficiency needs may intersect versus viewing them as two separate entities with autonomous characteristics. Preservice teachers in one program (i.e., Prater et al., 2008) graduated with an EL minor. Neither of these programs used the CRTSE to evaluate self-efficacy, but they did use survey data that indicated positive outcomes. However, combining programs and earning a graduate degree may not be ideal for all TEPs or for their students. Altering the current path to licensure by adding additional years of coursework may be a deterrent to some.

\section{Qualitative Themes}

Semi-structured interviews were conducted, and responses were interpreted and analyzed to better understand the factors and experiences influencing CRTSE beliefs. Responses were categorized into low and high self-efficacy groups, and similarities and differences were examined to determine if these factors and experiences differed between the two groups.

\section{Acquiring Knowledge of CRT}

The acquisition of CRT knowledge through coursework was a major theme that was identified during participant interviews. Gay (1995) asserted that all graduates from TEPs should have a strong foundation in understanding the role of culture in both teaching and learning. Irvine (2012) stated that culturally responsive pedagogy should be a foundational part of the curriculum for all educators. To address this, many TEPs include diversity courses; however, Hayes and Juarez (2012) advised TEPs to move beyond the one-stop diversity courses that covered CRT at a superficial level and perpetuate implicit bias. Additionally, coursework on CRT has long been taught in silos, where preservice teachers begin to think of culture as a fixed set of traits (Rueda \& Stillman, 2012) 
The participants in this study from both high and low self-efficacy groups expressed how cultural competencies were thread throughout their coursework. Coursework experiences were broken into different sub-themes that included coursework at the foundational, methods, and clinical levels. Results from the current study indicate that participants in Phase 2 identified their foundational level courses as having a significant impact on their overall CRP acquisition. When coding interviews, the Family, Communication, and Collaboration course and the Assessment Foundations course had the highest frequency of mentions across both high and low self-efficacy groups. Further emphasizing the importance of introducing CRP to prospective teachers early in their programs. To ensure that CRP is being integrated into foundations level courses, teacher educators may want to consider conducting a syllabus review (i.e., Dykes, et al., 2012) to ensure that CRP is being introduced within early coursework experiences.

Additional themes emerged for course experiences outside of the special education department, including earning an EL endorsement. Participants in both low and high selfefficacy groups discussed topics covered in their courses related to CRT. Still, those in the high self-efficacy group often spoke to specific strategies or resources shared. The only exception was related to the literacy courses, those in the low self-efficacy group, shared more examples of what they learned, such as identifying meaningful text that represents a variety of cultures and experiences. A recommendation for the field, is for TEPs to explicitly teach strategies for implementing CRT strategies (Cruz et al., 2020), as those in the low self-efficacy group have an awareness but are unfamiliar with specific strategies or resources to employ when working with CLD learners.

These results of CRT discussion across coursework differ from Siwatu (2011a) as he noted a lack of CRT instruction within methods courses according to the participants he 
interviewed. Siwatu (2011a) asserted that by including CRT in methods courses, preservice teachers would have furthered their knowledge and development of their CRTSE. Results from the current study indicate that TEPs are moving beyond a one-stop-shop approach to diversity training (Hayes \& Juarez, 2012), and are including discussion in foundations, methods, and clinical courses. Recommendations for practice would be to ensure that not only is CRT being discussed across coursework, but that CRP is integrated in a systematic way across a program to understand what is being taught at each level (Rueda \& Stillman, 2012).

\section{Professor Impact}

To transform TEPs, teacher educators must also epitomize the dispositions and mindset that transform them to be culturally responsive models who instill academic achievement and critical consciousness as models for the students they will teach (Allen et al., 2017). A factor that candidates in both high and low self-efficacy groups discussed was the overall impact that their professors had on their CRT knowledge. They further discussed that it was not only the content that they taught but how their professors made them feel. Participants referenced many of the salient features of CRP frameworks that their professors embodied, such as viewing students from an asset-based perspective, as well as examining their attitudes, beliefs, and perceptions. Participants shared how each of these factors impacted their understanding of CRT. Conversely, this contrasts findings from Siwatu (2011a), where he examined the perceptions that participants had of their professor's qualifications and mentioned that participants noted that there were missed opportunities where professors could have expanded their knowledge on CRT.

A participant from the lower self-efficacy group discussed how he had a professor challenge his thinking in a way that made him realize she wasn't going to let him maintain the status quo where he was comfortable being, but rather encouraged him to have a depth of 
thinking as it related to families and cultural competence. Having high expectations of students is one of the core tenets of CRP (Ladson-Billings, 1995).

A difference that emerged from the high self-efficacy group was how participants viewed their professors as co-contributors of knowledge construction. They didn't feel like there were power constructs between the professor and students but rather viewed them as collaborators in learning. This aligns with the work of Villegas and Lucas (2002), where educators and students construct new knowledge together versus previous notions that students were empty vessels that educators pour knowledge into. Although participants never named a particular CRP framework, their professors were exhibiting integrated characteristics of several frameworks that TEPs have used to shape their program redesigns. There were several qualities that participants identified as being especially meaningful attributes of their professors, including how they shared personal experiences and provided additional resources that aligned with their interests. Additionally, they explained that professors with high impact were approachable and that they learned from observing them. Observing professors and seeing successful models of CRT in action, reinforces Bandura's (1977) assertion that vicarious experiences are a source of information that develops self-efficacy. Participants in the high self-efficacy group, indicate that the passion and knowledge of their professors have made them want to be that kind of teacher for their future students, which evidences that when teachers manifest a positive and affirming attitude it has shown an increase in student achievement (Ladson-Billings, 1995). Teacher educators may want to examine that they are not only including CRP into their curriculum, but also reflect on the seminal CRP frameworks (i.e., Ladson-Billings, 1995, 2014; Villegas \& Lucas, 2002; Yosso, 2005) to consider how they are exhibiting these qualities or if self-reflection illuminates gaps, 
consider ways to grow knowledge by reaching out to colleagues who hold expertise in that area (i.e., Pappamihiel et al., 2010 ; Prater et al., 2008).

\section{Culturally Responsive Teaching in Action}

Those in the low self-efficacy group spoke more about the influence of their cooperating teachers on their understanding of CRT than those in the high self-efficacy group. This is in contrast to Siwatu (2011a), where participants in the high self-efficacy group had on average seven more mentions of the impact that observations during clinical experiences had on their

overall CRTSE. In the current study, participants observed the ways in which their cooperating teachers interacted positively with families as well as their educational team. Participants also indicated that they had the opportunity to observe how they navigated challenging topics and conversations. Learning how to modify instructional activities was another important factor that influenced the CRTSE of those in the low self-efficacy group.

Participants from the high self-efficacy group noted the ways they saw their cooperating teachers communicate with families in regard to upcoming IEP meetings. Perhaps those in the low self-efficacy were influenced more by their cooperating teachers because these vicarious experiences allowed those with low self-efficacy to see a task successfully performed and then held the belief that they could do it themselves (Bandura, 1977). Seeking out high-quality mentors for special education teacher candidates is something that was noted in the literature review on TEPs and their process for including CRP into field experiences (i.e., Ellerbrock et al., 2016; Sleeter, 2008). Teacher educators may want to explore the process for selecting cooperating teachers that have had positive experiences teaching learners from CLD backgrounds to ensure that they have strong models for their clinical students. 
As it relates to practicing CRT, participants shared their experiences of being in the classroom. Those in the high self-efficacy group discussed more opportunities to practice CRT in their clinical settings than those in the low self-efficacy group. This aligns with Siwatu (2011a) who also found that those with high self-efficacy identified more than three times the number opportunities to practice CRT in their clinical settings than those in the low self-efficacy group. The responses from participants in the low self-efficacy group mentioned the ways in which they were able to practice building relationships with their learners and create a warm and supportive learning environment. This qualitative data aligns with the quantitative survey data and the indicators with the highest mean scores related to teacher care and supportive learning environments.

Participants from the high self-efficacy group discussed ways in which they were able to incorporate learner interest into the lessons that they were teaching. All of the participants in the high self-efficacy group discussed sending home interest inventories or family surveys that served as a source to understand the interests and backgrounds of their learners and use this for instructional purposes. Specifically, participants mentioned making curricular adaptations to include items that were familiar to the learners that they work with, as well as ways that they differentiated assessments to meet learner needs. Having high self-efficacy as it relates to including learner interests into instruction aligns with the quantitative data where the indicators around student interest had an overall high mean score $(M=92.62)$.

A more complex skill that was discussed related to how they differentiated assessments based on learner strengths and needs. In the quantitative portion of the study, this was an indicator with the second-lowest overall mean score, which indicates that those in the higher self-efficacy group were making progress towards some of those more challenging skills that 
were identified on the CRTSE survey. It could be that those with higher self-efficacy have had more opportunities to practice teaching CRT, as Bandura (1977) indicates that mastery experiences are the most influential factor in increased self-efficacy. These experiences also help preservice teachers evaluate their effectiveness. One consideration that TEPs could make as it relates to field experiences, is to create structured experiences that occur at the beginning, middle and end of their program (i.e. Ellerbrock et al., 2016; McCadden \& Rose, 2008; Sleeter, 2008). Ellerbrock et al., (2016) asserts that having structured clinical experiences with guided inquiry provides an opportunity for preservice teachers to build their cultural knowledge while being guided to engage in critical self-reflection that focuses on biases and assumptions.

\section{Experiences with CRT}

A theme that developed during interview analysis was how participants recognized their growth throughout their coursework and clinical experiences. Participants from both selfefficacy groups attributed personal growth as a major factor that impacted their overall CRTSE rating. Those in the high self-efficacy group shared more instances of how their personal growth has influenced their practice than those in the low self-efficacy group. Both groups state that they have increased confidence as it relates to CRT. Within the low self-efficacy group, participants speak about having a deeper understanding that either influenced a previously held mindset to a strengths-based approach or additional knowledge on privilege and race. Those in the high selfefficacy group speak about having opportunities to apply and practice what they've learned as the biggest factor of their increased confidence. These findings help us understand the different experiences that have impacted the overall CRTSE scores amongst participants in the high and low self-efficacy groups. 
Both groups stated that they lacked experience with writing IEPs for learners from CLD backgrounds. Additionally, they had concerns about whether or not they would accurately support the native language for non-English speakers. Another interesting finding was that participants from both groups expressed confusion as it relates to an indicator that asked about greeting a student in their native language. Participants felt like they had learned conflicting information where some instructors shared that this would be offensive, whereas others thought this would be affirming to students. To prevent conflicting messages on the appropriateness of using native language with CLD learners, teacher educators may want to follow the example of those who collaborated with professionals in bilingual or EL programs (i.e., Dykes et al., 2012; Pappamihiel et al., 2010; Prater et al., 2008) to inform the accuracy of their practice.

Specifically, within the low self-efficacy group, participants believed they lacked the ability to embed CRT into their lessons without it seeming like an add-on, nor did they feel like they could evaluate a curriculum to determine if it was culturally appropriate for their learners. For those in the high self-efficacy group, participants lacked experience on ways to determine if a learner has a disability or if it is indeed is a language proficiency need. Implications for practice would be for TEPs to include cultural considerations that should be made during the IEP process, from eligibility to annual goals.

Overall, the high self-efficacy group reported more examples of their personal growth and shared fewer examples where they lacked experience where the adverse is true for the participants in the low self-efficacy group.

\section{Limitations}

There are limitations within both phases of the study that should be considered before making generalizations regarding the outcomes of this study. The first limitation is the small 
number of CRTSE studies that include special education preservice teachers, therefore much of the comparative data come from inservice or general education teachers. Another limitation of the study is the small sample of preservice teachers who are all from the same special education teacher education program. Within phase 1, the mean scores that are distributed within quartiles are close in range which could be considered a limitation, as three-fourths of the participants had a mean score of 80 or above. This could indicate that preservice teachers may have an inflated sense of efficacy due to the level of support they receive from their cooperating teacher and entering into a learning environment that has already been established (Knobloch, 2006). Within Phase 2, It is also important to consider that although participants were chosen for Phase 2 based on quartile rankings, the factors and experience shared by these participants may not be representative of those not interviewed. Additionally, both the quantitative and qualitative results are based on participant perceptions which may be limiting and could skew the results as it does not consider other sources to corroborate.

\section{Recommendations for Practice and Future Research}

There are several recommendations for practice and future research. Including the current study, there are three CRTSE studies to date that include special education participants as part of the population, it would benefit the field to continue this investigation to determine if preservice special educators are more self-efficacious as it relates to teaching CLD learners. Future researchers may want to consider expanding this study beyond one special education program and include participants from several universities to see if the results are similar. Additionally, some of the demographic groups were so small that they couldn't be compared. It will be meaningful to determine if any of the demographic and academic factors correlate to higher CRTSE when there is a larger participant pool. There are a limited number of studies with 
empirical data to determine the cultural responsiveness of future teachers; therefore, researchers may want to administer the CRTSE as a pre-and post-test measure at the beginning and end of their clinical experiences (i.e., Fitchett et al., 2012; Whitaker \& Valtierra, 2018) to determine individual growth throughout a program. One limitation to the current study was that selfefficacy scores can be skewed due to over confidence. To solve for this, future research could include observations and/or artifacts in addition to survey data. The inclusion of observations conducted by either university staff or cooperating teachers could provide additional qualitative data to either support CRTSE scores or offer examples that conflicts with self-reported scores. Including artifacts that evidence culturally responsive practices would provide participants the opportunity to share what they have done versus considering what they would do in culturally diverse classrooms. The process of selecting artifacts may encourage participants to be more reflective in their own self-evaluation as they complete the CRTSE survey.

Implications for teacher educators signal the need for their programs to systematically infuse CRP across their coursework and ensure that they are starting this work early in their foundational level courses. Reviewing syllabi and ensuring that CRP standards are being included across the program beginning at the foundational level or identifying potential gaps where standards are not being included (Dykes et al., 2012). When embarking on this inquiry process, teacher educators may also begin to explore the survey items that have consistently earned low self-efficacy ratings across several research studies (i.e., Chu \& Garcia, 2014; Cruz et al., 2020; Siwatu, 2007, 2008, 2009, 2011a, 2011b; Siwatu et al., 2009, 2016; Siwatu \& Starker, 2010). While most of those studies have been with general education populations, it would be prudent of special education TEPs to consider how they plan to solve this. One recommendation would be for teacher educators in special education departments to reach out to colleagues that 
are in bilingual or English Language programs to understand the types of assessments or interventions that would be appropriate for learner's from CLD backgrounds. Additionally, the commonality amongst several of the indicators with the lowest overall mean score related to instructional design or implementation for learner's from CLD backgrounds. When teacher educators model ways to differentiate instruction for learners with disabilities, perhaps they can include learners from diverse cultural backgrounds and explain the way they considered culture in their design and delivery. We know that vicarious experiences (Bandura, 1977) are a meaningful way to increase self-efficacy, and results from this study indicate the powerful impact that professors have on the CRTSE of the preservice teachers that they instruct.

The impact of the professor and their influence on a preservice teacher's culturally responsive self-efficacy was an unanticipated result of this study. Teacher educators should continue to strengthen their understandings of CRP and examine their own biases by participating in professional development or begin their own investigation into identity and cultural awareness. When embarking on a redesign, researchers who engaged in this process outlined the extensive professional development they undertook (i.e., Pappamihiel et al., 2010; Prater et al., 2008) to grow in their knowledge. They also noted the collaboration with professionals from other departments that benefited their process.

Professors may want to investigate the seminal frameworks that were discussed in Chapter I, including the work of Ladson-Billings (1995, 2014), Villegas and Lucas (2002) or Yosso (2005). Faculty are also encouraged to seek out readings related to combatting colorblindness, moving beyond race neutrality and challenging the normative standards in education that have created systems of oppression and inequity (Allen et al., 2017; Brown-Jeffy \& Cooper, 2011). Another source of professional development that faculty may want to access is through 
CREDE, they have a set of five standards that represent the commonalities found in the literature and offer recommendations across cultural, racial and linguistic groups (Prater et al., 2008).

\section{Conclusion}

Using the CRTSE to measure special education pre-service teachers' culturally responsive teaching self-efficacy indicated that overall participants have a moderately high CRTSE $(M=82.53)$. Item-specific means indicate that teacher candidates are confident in their ability to create a warm learning environment and foster relationships built on trust. Areas where preservice special educators feel less self-efficacious are related to complex understandings of language proficiency and how to plan instruction, assessment, and interventions for learners whose first language is not English. Academic and demographic factors did not reveal any significance in CRTSE scores between groups.

The results of the qualitative phase of this study illuminated the four themes that participants identified as the factors and experiences that impacting their overall culturally responsive teaching self-efficacy. The four themes were: (a) acquisition of knowledge, (b)

professor impact, (c) culturally responsive teaching in action, and (d) experiences with Culturally Responsive Teaching. Interviews and analysis through qualitative coding highlighted the different types of responses offered from participants in the low and high self-efficacy groups. While there were many commonalities across the four themes, those in the high self-efficacy group could speak to specific assessments, interventions, and restorative practices familiar to them. Additionally, those in the high self-efficacy group discussed more opportunities to practice CRT in their field experiences. Conversely, those in the low self-efficacy group discussed having had fewer opportunities to practice CRT skills, which resulted in their being less confident in their ability to execute. Having fewer experiences aligns with Bandura's (1977) assertion that 
mastery experiences are the most effective for increasing self-efficacy. As special education TEPs continue to evaluate effectiveness of the infusion of CRP into their programs, perhaps this will offer them next steps in continuing their efforts. 


\section{REFERENCES}

Allen, A., Hancock, S. D., Lewis, C. W., \& Starker-Glass, T. (2017). Mapping culturally relevant pedagogy into teacher education programs: A critical framework. Teachers College Record, 119, 1-26.

Bandura, A. (1977). Self-efficacy: Toward a unifying theory of behavioral change. Psychological Review, 84, 191-215. https://doi.org/10.1037/0033-295x.84.2.191

Bandura, A. (1986). The explanatory and predictive scope of self-efficacy theory. Journal of social and clinical psychology, 4(3), 359-373. https://doi.org/10.1521/jscp.1986.4.3.359

Bandura, A. (1993). Perceived self-efficacy in cognitive development and functioning. Educational psychologist, 28(2), 117-148. https://doi.org/10.1207/s15326985ep2802_3

Bandura, A. (1997). The anatomy of stages of change. American journal of health promotion: AJHP, 12(1), 8. https://doi.org/10.4278/0890-1171-12.1.8

Barrio, B. L., Lindo, E. J., Combes, B. H., \& Hovey, K. A. (2015). Ten years of response to intervention: Implications for general education teacher preparation programs. Action in Teacher Education, 37, 190-204. doi:10/1080/01626620.2015.1004603

Bogdan, R. C., \& Biklen, S. K. (2011). Qualitative research for education: An introduction to theories and methods ( $5^{\text {th }}$ ed.). Boston: Pearson.

Brown-Jeffy, S., \& Cooper, J. E. (2011). Toward a conceptual framework of culturally relevant pedagogy: An overview of the conceptual and theoretical literature. Teacher Education Quarterly, 38, 65-84.

Chu, S. Y., \& Garcia, S. (2014). Culturally responsive teaching efficacy beliefs of in-service special education teachers. Remedial and Special Education, 35(4), 218-232. doi:10.1177/0741932513520511 
Clark, S. (2020). Examining the development of teacher self-efficacy beliefs to teach reading and to attend to issues of diversity in elementary schools. Teacher Development, 24(2), 127142. https:doi.org/10.1080/13664530.2020.1725102

Creswell, J. W. (2003). Research design (pp. 155-179). Thousand Oaks, CA: Sage publications.

Creswell, J. W. (2008). Educational research: Planning, conducting, and evaluating quantitative and qualitative research (3rd ed.). Upper Saddle River, NJ: Pearson Education.

Creswell, J. W. (2014). A concise introduction to mixed methods research. SAGE publications.

Creswell, J. W., \& Plano Clark, V. L. (2011). Designing and conducting mixed methods research. $\left(2^{\text {nd }}\right.$ ed.). Thousand Oaks, CA: Sage.

Cruz, R. A., Manchanda, S., Firestone, A. R., \& Rodl, J. E. (2020). An Examination of Teachers' Culturally Responsive Teaching Self-Efficacy. Teacher Education and Special Education, 43(3), 197-214. https://doi.org/10.1177/0888406419875194

Cyr, E., McDiarmid, P., Halpin, B., Stratton, J., \& Davis-Delano, L. (2012). Creating a dual licensure program in elementary and special education that prepares culturally responsive teachers. Interdisciplinary Journal of Teaching and Learning, 2(3), 158-168.

Darling-Hammond, L., \& Bransford, J. (Eds.). (2005). Preparing teachers for a changing world: What teachers should learn and be able to do. San Francisco: Jossey-Bass.

Debnam, K. J., Pas, E. T., Bottiani, J., Cash, A. H., \& Bradshaw, C. P. (2015). An examination of the association between observed and self-reported culturally proficient teaching practices. Psychology in the Schools, 52(6), 533-548. https://doi.org/10.1002/pits.21845

DeCastro-Ambrosetti, D., \& Cho, G. (2011). A Look at "Lookism": A Critical Analysis of Teachers' Expectations Based on Students Appearance. Multicultural Education, 18(2), $51-54$ 
Dickson, G. L., Chun, H., \& Fernandez, I. T. (2016). The development and initial validation of the student measure of culturally responsive teaching. Assessment for Effective Intervention, 4l(3), 141-154. https://doi.org/10.1177/1534508415604879

Dray, B. J., \& Basler-Wisneski, D. (2011). Mindful reflection as a process for developing culturally responsive practices. TEACHING Exceptional Children, 44, 28-36. https://doi.10.1177/004005991104400104

Dykes, F. O., Gilliam, B. K., Neel, J., \& Everling, K. (2012). Peeking inside pandora's box: One university's journey into the redesign of teacher educator preparation. Current Issues in Education, 15(2).

Ellerbrock, C. R., Cruz, B. C., Vásquez, A., \& Howes, E. V. (2016). Preparing culturally responsive teachers: Effective practices in teacher education. Action in Teacher Education, 38, 226-239. doi:10.1080/01626620.2016.1194780

Fitchett, P. G., Starker, T. V., \& Salyers, B. (2012). Examining culturally responsive teaching self-efficacy in a preservice social studies education course. Urban Education, 47(3), 585-611. https:// doi.org/10.1177/0042085912436568

Garcia, E., Arias, M. B., Harris Murri, N. J., \& Serna, C. (2010). Developing responsive teachers: A challenge for a demographic reality. Journal of Teacher Education, 61(1-2), 132-142. doi:10.1177/0022487109347878

Garcia, S. B., \& Ortiz, A. A. (2013). Intersectionality as a framework for transformative research in special education. Multiple Voices for Ethnically Diverse Exceptional Learners, 13(2), $32-47$. 
Gay, G. (1995). Building cultural bridges: A bold proposal for teacher education. In J. Q. Adams \& J. R. Welsch (Eds.), Multicultural education: Strategies for implementation in colleges and universities (Vol. 4, pp-95-106). Springfield, IL: Illinois State Board of Higher Education.

Gay, G. (2010). Culturally responsive teaching: Theory, research, and practice (2 nd ed.). New York, NY: Teachers College Press.

Gibson, S., \& Dembo, M. H. (1984). Teacher efficacy: A construct validation. Journal of educational psychology, 76(4), 569-582. http://doi.org/10.1037/0022-0663.76.4.569

Greene, J. C. (2007). Mixed methods in social inquiry (Vol. 9). John Wiley \& Sons.

Gulati-Partee, G., \& Potapchuk, M. (2014). Paying attention to white culture and privilege: A missing link to advancing racial equity. The Foundation Review, 6, 25-38. doi:10.9707/1944-5660.1189

Hayes, C., \& Juarez, B. (2012). There is no culturally responsive teaching spoken here: A critical race perspective. Democracy and Education, 20, 1-14.

Holmes, A. G. D. (2020). Researcher Positionality--A Consideration of Its Influence and Place in Qualitative Research--A New Researcher Guide. Shanlax International Journal of Education, 8(4), 1-10. doi:10.34293/education.v8i4.3232

Hoover, J. J. (2012). Reducing unnecessary referrals: Guidelines for teachers of diverse learners. TEACHING Exceptional Children, 44(4), 38-47.

Hussar, W. J., \& Bailey, T. M. (2020). Projections of Education Statistics to 2028 (NCES 2020024). U.S. Department of Education, Washington, DC: National Center for Education Statistics. 
Imler, S. J. (2009). Becoming culturally responsive: A need for preservice teacher candidates. Teacher Education and Practice, 22(3), 351-367.

Irvine, J. J. (2012). Complex relationships between multicultural education and special education: An African American perspective. Journal of Teacher Education, 63, 268274. doi: $10.1177 / 0022487112447113$

Johnson, R. B., \& Onwuegbuzie, A. J. (2004). Mixed methods research: A research paradigm whose time has come. Educational researcher, 33(7), 14-26.

Kahn, L. G., Lindstrom, L., \& Murray, C. (2014). Factors contributing to preservice teachers' beliefs about diversity. Teacher Education Quarterly, 41(4), 53-70.

Kea, C. D., \& Trent, S. C. (2013). Providing culturally responsive teaching in field-based and student teaching experiences: A case study. Interdisciplinary Journal of Teaching and Learning, 3(2), 82-101.

Knobloch, N. A. (2006). EXPLORING RELATIONSHIPS OF TEACHERS'SENSE OF EFFICACY IN TWO STUDENT TEACHING PROGRAMS. Journal of agricultural education, 47(2), 36.

Kolb, A. Y., \& Kolb, D. A. (2009). Experiential learning theory: A dynamic, holistic approach to management learning, education and development. The SAGE handbook of management learning, education and development, 42, 68.

Ladson-Billings, G. (1995). Toward a theory of culturally relevant pedagogy. American Educational Research Journal, 32, 465-491. doi:10.2307/1163320

Ladson-Billings, G. (2014). Culturally relevant pedagogy 2.0: Aka the remix. Harvard Educational Review, 84, 74-84. doi:10.17763/haer.84.1.p2rj131485484751 
Larson, K. E., Pas, E. T., Bradshaw, C. P., Rosenberg, M. S., \& Day-Vines, N. (2018).

Examining how proactive management and culturally responsive teaching relate to student behavior: Implications for measurement and practice. School Psychology Review, 47(2), 153-166. https://doi.org/10.17105/spr-2017-0070.v47-2

Lee, S., \& Klein, H. J. (2002). Relationships between conscientiousness, self-efficacy, selfdeception, and learning over time. Journal of Applied Psychology, 87(6), 1175.

Lewis-Pratl, K., Cuenca-Carlino, Y., \& Mustian, A. (2021). Preparing preservice special educators for culturally and linguistically diverse classrooms: A systematic review of teacher preparation programs. Special Education Research, Policy and Practice.

Lincoln, Y. S., \& Guba, E. G. (1985). Naturalistic inquiry. Beverly Hills, CA: Sage.

Malo-Juvera, V., Correll, P., \& Cantrell, S. (2018). A mixed methods investigation of teachers' self-efficacy for culturally responsive instruction. Teaching \& Teacher Education, 74, 146-156. https://doi.org/10.1016/j.tate.2018.05.003

McCadden, B., \& Rose, M. (2008). A system-wide approach to culturally responsive teacher preparation: The value of intensive early program field experiences. AILACTE Journal, 5, $13-28$.

McHatton, P. A., Smith, M., Brown, K. H., \& Curtis, J. (2013). "First, do no harm": Purposeful preparation of culturally competent educators. Multiple Voices for Ethnically Diverse Exceptional Learners, 13(2), 19-31.

Merriam, S. B., \& Tisdell, E. J. (2016). Qualitative research: A guide to design and implementation. San Francisco, CA: John Wiley \& Sons 
Moll, L. C., Amanti, C., Neff, D., \& Gonzalez, N. (1992). Funds of knowledge for teaching: Using a qualitative approach to connect homes and classrooms. Theory into practice, 31(2), 132-141.

Moore, B. A. (2018). Developing Special Educator Cultural Awareness Through Critically Reflective Professional Learning Community Collaboration. Teacher Education and Special Education, 41(3), 243-253. doi.org/10.1177/0888406418770714

Morgan, D. L. (2014). Pragmatism as a paradigm for social research. Qualitative inquiry, 20(8), 1045-1053.

Nasir, N. S., Rosebery, A. S., Warren, B., \& Lee, C. D. (2006). Learning as a cultural process: Achieving equity through diversity. In K. Sawyer (Ed.), Handbook of the learning sciences (pp. 489-504). New York, NY: Cambridge University Press.

Nieto, S. (1999). The light in their eyes: Creating multicultural learning communities. New York, NY: Teachers College Press.

Pajares, F., Hartley, J., \& Valianted, G. (2001). Response format in writing self-efficacy assessment: Greater discrimination increases prediction. Measurement and evaluation in counseling development, 33(4), 214-221. https://doi.org/10.1080/07481756.2001.12069012

Pappamihiel, N. E., Al Otaiba, S., \& Hudson, R. F. (2010). Integrating English as a second language into special education teacher personnel preparation programs. Teacher Education and Practice, 23, 495-506.

Prater, M. A., Wilder, L. K., \& Dyches, T. T. (2008). Shaping one traditional special educator preparation program toward more cultural competence. Teaching Education, 19, 137151. doi:10.1080/10476710802040765 
Pugach, M. C., Blanton, L. P., \& Florian, L. (2012). Unsettling conversations: Diversity and disability in teacher education. Journal of Teacher Education, 63, 235-236. doi:10.1177/0022487112487112447573

Robinson, S., \& West, J. (2012). Preparing inclusive educators: A call to action. Journal of Teacher Education, 63, 291-293. doi: 10.1177/0022487112447574

Rueda, R., \& Stillman, J. (2012). The 21st century teacher: A cultural perspective. Journal of Teacher Education, 63, 245-253. doi:10.1177/0022487112446511

Rychly, L., \& Graves, E. (2012). Teacher characteristics for culturally responsive pedagogy. Multicultural Perspectives, 14, 44-49.

Scott, L. A., Alexander, Q., Fritton, S., \& Thoma, C. (2014). An evaluation of culturally responsive practices in Special Education program for preservice educators. Journal of Curriculum and Teaching, 3(2), 79-93. doi:10.5430/jct.v3n2p79

Servage, L. (2008). Critical and transformative practices in professional learning communities. Teacher Education Quarterly, 35(1), 63-77.

Siwatu, K. O. (2007). Preservice teachers' culturally responsive teaching self-efficacy and outcome expectancy beliefs. Teaching and teacher education. 23(7). 1086-1101. doi: 10.1016/j.tate.2006.07.011

Siwatu, K. O. (2008). Teaching in the era of no child left behind: Preservice teachers' selfefficacy beliefs and teaching concerns. Multicultural Learning and Teaching, 3(2), 30-47. https://doi.org/10.2202/2161-2412.1034

Siwatu, K. O. (2009). Student teachers' self-efficacy beliefs regarding culturally responsive teaching and their professed classroom practices. Teacher Education and Practice, 22(3), $323-333$ 
Siwatu, K. O. (2011a). Preservice teachers' culturally responsive teaching self-efficacy-forming experiences: A mixed methods study. Journal of Educational Research, 104(5), 360-369. https://doi.org/10.1080/00220671.2010.487081

Siwatu, K. O. (2011b). Preservice teachers' sense of preparedness and self-efficacy to teach in America's urban and suburban schools: Does context matter? Teaching \& Teacher Education, 27(2), 357-365. doi:10.1016/j.tate.2010.09.004

Siwatu, K. O., Chesnut, S. R., Alejandro, A. Y., \& Young, H. A. (2016). Examining preservice teachers' culturally responsive teaching self-efficacy doubts. Teacher Educator, 51(4), 277-296. https://doi.org/10.1080/08878730.3026.1192709

Siwatu, K. O., \& Polydore, C. L. (2010). Resolving a cultural conflict in the classroom: An exploration of preservice teachers' perceptions of effective interventions. Journal of Negro Education, 79(4), 458-472.

Siwatu, K. O., Polydore, C. L., \& Starker, T. V. (2009). Prospective elementary school teachers' culturally responsive teaching self-efficacy beliefs. Multicultural Learning and Teaching, 4(1), 1-15. https://doi.org/10.2202/2161-2412.1040

Siwatu, K. O., Putman, S. M., Starker-Glass, T., \& Lewis, C. W. (2017). The culturally responsive classroom management self-efficacy scale: Development and initial validation. Urban Education, 52(7), 862-888. https://doi.org/10.1177/0042085915602534

Siwatu, K. O., \& Starker, T. (2010). Predicting preservice teachers' self-efficacy to resolve a cultural conflict involving an African American student. Multicultural Perspectives, 12(1), 10-17. doi:10.1080/15210961003641302 
Skiba, R. J., Artiles, A. J., Kozleski, E. B., Losen, D. J., \& Harry, E. G. (2016). Risks and Consequences of Oversimplifying Educational Inequities: A Response to Morgan et al. (2015). Educational Researcher, 45(3), 221-225.

https://doi.org/10.3102/0013189X16644606

Skiba, R. J., Simmons, A. B., Ritter, S., Gibb, A. C., Rausch, M. K., Cuadrado, J., \& Chung, C. G. (2008). Achieving equity in special education: History, status, and current challenges. Exceptional Children, 74(3), 264-288.

Sleeter, C. E. (2008). Preparing White teachers for diverse students. In M. Cochran-Smith, S., Feiman-Nemser, \& J. McIntyre (Eds.), Handbook for research in teacher education: Enduring issues in changing contexts (3 ${ }^{\text {rd }}$ ed., pp. 559-582). New York, NY: Routledge. Snyder, T. D., and Dillow, S. A. (2015). Digest of Education Statistics 2013 (NCES 2015-011). National Center for Education Statistics, Institute of Education Sciences, U.S. Department of Education. Washington, DC.

Sobel, D. M., Gutierrez, C., Zion, S., \& Blanchett, W. (2011). Deepening culturally responsive understandings within a teacher preparation program: It's a process. Teacher Development, 15, 435-452. doi:10.1080/13664530.2011.635526

Tashakkori, A., \& Teddlie, C. (2003). Issues and dilemmas in teaching research methods courses in social and behavioural sciences: US perspective. International journal of social research methodology, 6(1), 61-77.

Taylor, R. W. (2010). The role of teacher education programs in creating culturally competent teachers: A moral imperative for ensuring the academic success of diverse student populations. Multicultural Education, 17(3), 24-28. 
Terry, N. P., \& Irving, M. A. (2010). Cultural and linguistic diversity: Issues in education. Special Education for all Teachers, 5, 109-132.

Tracy, S. J. (2013). Qualitative research methods: Collecting evidence, crafting analysis, communicating impact. Hoboken, NJ: Wiley-Blackwell.

Trent, S. C., Kea, C. D., \& Oh, K. (2008). Preparing preservice educators for cultural diversity: How far have we come? Exceptional Children, 74(3), 328-350.

Urbach, J., Moore, B. A., Klingner, J. K., Galman, S., Haager, D., Brownell, M. T., \& Dingle, M. (2015). "That's My Job" Comparing the Beliefs of More and Less Accomplished Special Educators Related to Their Roles and Responsibilities. Teacher Education and Special Education, 38(4), 323-336. doi:10.1177/088840615591220

U.S. Department of Education, Office of Planning, Evaluation and Policy Development, Policy and Program Studies Service. (2016). The State of Racial Diversity in the Educator Workforce. Washington, DC: Author.

U.S. Department of Education, Office of Planning, Evaluation and Policy Development, Policy and Program Studies Service. (2021). The State of Racial Diversity in the Educator Workforce. Washington, DC: Author.

Villegas, A. M., \& Lucas, T. (2002). Preparing culturally responsive teachers: Rethinking the curriculum. Journal of Teacher Education, 53, 20-32. doi:10.1177/0022487102053001003

Waddell, J. H. (2013). Working with families in urban teacher education: A critical need for all students. Teacher Educator, 48, 276-295. doi:10.1080/08878730.2013.826767 
Whitaker, M. C., \& Valtierra, K. M. (2018). Enhancing preservice teachers' motivation to teach diverse learners. Teaching \& Teacher Education, 73, 171-182. doi:10.1016/j.tate.2018.04.004

Williams, P. (2007). Disproportionality and overrepresentation (module 5). Building the legacy: IDEA 2004 training curriculum.

Williams Shealey, M. (2006). The promise and perils of "scientifically based" research for urban schools. Urban Education, 41, 1-16. doi: 10.1177/0042085905282250

Yosso, T. J. (2005). Whose culture has capital? A critical race theory discussion of community cultural wealth. Race Ethnicity and Education, 8, 69-91. doi:10.1080/13613320520003410 


\section{APPENDIX A: DEMOGRAPHIC AND SURVEY ITEMS}

\section{Demographic Questions:}

What is your gender identity?

Female

Male

Non-binary

I would rather not answer

Not listed (open answer choice)

What is your race/ethnicity?

American Indian or Alaska Native

Asian

Black or African American

Native Hawaiian or Pacific Islander

Hispanic or Latino origin

White

I would rather not disclose

What is your current academic level?

Practicum

Field-based

Student Teaching

What is your course sequence?

$\mathrm{DHH}$

LBS1

LVB

How many of the urban redesigned courses have you taken?

0

$1-2$

3 or more

Will you graduate with an EL endorsement?

Yes

No 


\section{Survey Items}

Please rank your confidence level as it relates to implementing culturally responsive practices for learners with disabilities. *Culturally and Linguistically Diverse (CLD)

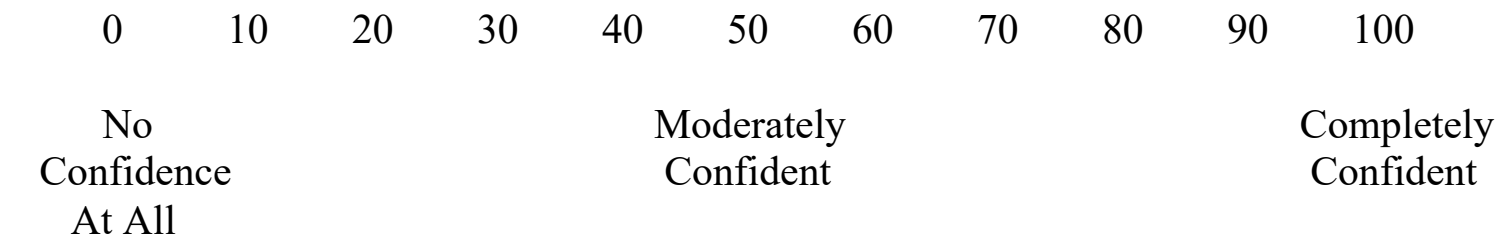

I am able to:

1. modify instructional activities and materials to meet the developmental needs and learning interests of my students with disabilities from CLD backgrounds.

2. design appropriate instruction that is matched to English language learners' language proficiency and special needs.

3. create a learning environment that reflects the various backgrounds of my CLD students.

4. develop appropriate Individual Education Plans for my students with disabilities who are from CLD backgrounds.

5. use my students prior knowledge related to their cultural and linguistic backgrounds to help make learning meaningful.

6. use various types of assessments that are matched to English language learners' language proficiency of special needs.

7. critically examine the curriculum to determine whether it appropriately represents CLD groups.

8. identify the differences between student behavior/communication at home and student behavior/communication at school.

9. use a variety of teaching methods to assist my students in learning the content.

10. communicate with students with disabilities who are English Language Learners.

11. identify cultural differences when communicating with parents regarding their child's educational progress.

12. implement interventions that minimize the effects of cultural mismatch between home and school.

13. distinguish linguistic/cultural differences from learning difficulties from students with disabilities.

14. create a caring supportive, and warm learning environment from my students from CLD backgrounds.

15. assist my students to be successful by supporting the native language of my students with disabilities who have limited English proficiency.

16. structure parent-teacher conferences (e.g., IEP meetings) that are comfortable to allow CLD parents to participate.

17. identify the ways standardized tests may be biased against students who come from diverse backgrounds.

18. build positive relationships with CLD parents. 
19. help my students develop positive interactions with each other.

20. obtain information about my students' preferred learning styles (e.g., cooperative groups or individual work.

21. obtain information about my students' home life.

22. build a sense of trust in my students.

23. develop a community of learners when my class consists of students from diverse backgrounds.

24. use my students' prior knowledge to help them make sense of new information.

25. obtain information about my students' cultural background.

26. teach students about their cultures' contributions to science.

27. greet English Language Learners with a phrase in their native language.

28. obtain information about my students' academic weaknesses.

29. praise English Language Learners for their accomplishments using a phrase in their native language.

30. help students to develop positive relationships with their classmates.

31. revise instructional material to include a better representation of cultural groups.

32. critically examine the curriculum to determine whether it reinforces negative cultural stereotypes.

33. design a lesson that shows how other cultural groups have made use of mathematics.

34. help students feel like important members of the classroom.

35. use a learning preference inventory to gather data about how my students like to learn.

36. explain new concepts using examples that are taken from my students' everyday lives.

37. use the interests of my students to make learning meaningful for them.

38. implement cooperative learning activities for those students who like to work in groups.

39. design instruction that matches my students' developmental needs.

40. teach students about their cultures' contributions to society. 


\section{APPENDIX B:INTRODUCTION SCRIPT AND INTERVIEW QUESTIONS}

Upon entry into the virtual meeting space: Thank you for your willingness to meet with me today. (Time for greetings)

This interview will be recorded. You have the option to leave your camera on, or turn your camera off. All identifying information will be changed to protect your anonymity.

Do you agree to being recorded? Great then I will begive recording now.

Thank you again for completing the survey a few weeks ago.

Offered as a reminder of what self-efficacy is: Teacher self-efficacy has been characterized as a teacher's belief in their ability to positively affect student learning and achievement which is based on the belief that to be an effective teacher, one must possess knowledge as well as skills and put those skills into action.

Preparing for the interview: If you wouldn't mind opening up the document that I sent to you last week, we are going to use that as a reference of the questions that were asked, and includes the ranking that you assigned to yourself for each question. I'll give you a minute to review your responses before I begin the interview process.

\section{Semi-structured Interview Questions}

1. Which of the items on the survey were discussed in your teacher preparation courses?

2. Can you specifically name the courses?

3. Have you had opportunities to observe any of the practices?

4. How did these opportunities influence your self-efficacy beliefs?

5. Which items on the CRTSE scale have you observed being executed by someone?

6. Which items on the CRTSE scale have you had the opportunity to practice? Where?

Did you have any opportunities to practice these skills within your college classes? 
APPENDIX C: CODEBOOK FRAMEWORK AND DEFINITIONS

\begin{tabular}{|c|c|c|c|}
\hline Theme & Concept & Code & Definition \\
\hline \multirow[t]{10}{*}{$\begin{array}{l}\text { Strengths and } \\
\text { Needs within } \\
\text { CRTSE } \\
\text { (explored } \\
\text { separately and } \\
\text { connected to } \\
\text { Quantitative } \\
\text { Data) }\end{array}$} & $\begin{array}{l}\text { High Self- } \\
\text { Efficacy } \\
\text { Questions }\end{array}$ & Question 34 & $\begin{array}{l}\text { help students feel like important members of the } \\
\text { classroom. }\end{array}$ \\
\hline & & Question 14 & $\begin{array}{l}\text { Create a caring supportive, and warm learning } \\
\text { environment for my students from CLD } \\
\text { backgrounds. }\end{array}$ \\
\hline & & Question 22 & build a sense of trust in my students. \\
\hline & & Question 37 & $\begin{array}{l}\text { use the interests of my students to make learning } \\
\text { meaningful for them. }\end{array}$ \\
\hline & & Question 19 & $\begin{array}{l}\text { help my students develop positive interactions } \\
\text { with each other. }\end{array}$ \\
\hline & $\begin{array}{l}\text { Low Self- } \\
\text { Efficacy } \\
\text { Questions }\end{array}$ & Question 2 & $\begin{array}{l}\text { design appropriate instruction that is matched to } \\
\text { English language learners' language proficiency } \\
\text { and special needs }\end{array}$ \\
\hline & & Question 33 & $\begin{array}{l}\text { design a lesson that shows how other cultural } \\
\text { groups have made use of mathematics. }\end{array}$ \\
\hline & & Question 15 & $\begin{array}{l}\text { assist my students to be successful by } \\
\text { supporting the native language of my students } \\
\text { with disabilities who have limited English } \\
\text { proficiency. }\end{array}$ \\
\hline & & Question 12 & $\begin{array}{l}\text { implement interventions that minimize the } \\
\text { effects of cultural mismatch between home and } \\
\text { school. }\end{array}$ \\
\hline & & Question 6 & $\begin{array}{l}\text { use various types of assessments that are } \\
\text { matched to English language learners' language } \\
\text { proficiency of special needs. }\end{array}$ \\
\hline \multirow[t]{3}{*}{$\begin{array}{l}\text { Experiences } \\
\text { with CRT }\end{array}$} & Experiences & $\begin{array}{l}\text { Personal } \\
\text { Growth }\end{array}$ & $\begin{array}{l}\text { Participant discussed their own personal growth } \\
\text { as it relates to culturally responsive practices }\end{array}$ \\
\hline & & $\begin{array}{l}\text { CRP as a } \\
\text { Journey* }\end{array}$ & $\begin{array}{l}\text { Participant views CRP as a journey vs. } \\
\text { something you arrive at }\end{array}$ \\
\hline & & $\begin{array}{l}\text { Growth } \\
\text { Between } \\
\text { Survey \& } \\
\text { Interview* }\end{array}$ & $\begin{array}{l}\text { Participant discussed their own growth from the } \\
\text { time of the survey to where they viewed } \\
\text { themselves at the time of the interview }\end{array}$ \\
\hline
\end{tabular}




\begin{tabular}{|c|c|c|c|}
\hline Theme & Concept & Code & Definition \\
\hline & & $\begin{array}{l}\text { Incorrect } \\
\text { Rating* }\end{array}$ & $\begin{array}{l}\text { Participant noted that they either rated } \\
\text { themselves too low or too high for a particular } \\
\text { indicator }\end{array}$ \\
\hline & & $\begin{array}{l}\text { Lack of } \\
\text { Experience }\end{array}$ & $\begin{array}{l}\text { Participant discussed not having any experience } \\
\text { with a particular skill }\end{array}$ \\
\hline & & $\begin{array}{l}\text { Could Find a } \\
\text { Resource* }\end{array}$ & $\begin{array}{l}\text { Participant noted that although they lacked } \\
\text { experience, they felt confident that they would } \\
\text { be able to find an appropriate resource }\end{array}$ \\
\hline & & Community & $\begin{array}{l}\text { Participant discussed the importance of } \\
\text { community as an asset }\end{array}$ \\
\hline & & $\begin{array}{l}\text { School } \\
\text { Experience }\end{array}$ & $\begin{array}{l}\text { Participant discussed an immersion trip to an } \\
\text { urban school/community or a summer long } \\
\text { immersion experience (STEP-UP) }\end{array}$ \\
\hline \multirow[t]{4}{*}{$\begin{array}{l}\text { Professor } \\
\text { Specific }\end{array}$} & Factors & Intuitive* & $\begin{array}{l}\text { Participant felt that they knew something } \\
\text { intuitively vs. being taught a particular skill }\end{array}$ \\
\hline & & $\begin{array}{l}\text { Urban Re- } \\
\text { designed } \\
\text { course }\end{array}$ & $\begin{array}{l}\text { Courses that have been re-designed to address } \\
\text { urban education }\end{array}$ \\
\hline & & $\begin{array}{l}\text { Professor } \\
\text { Specific }\end{array}$ & $\begin{array}{l}\text { Participant discussed the passion of the } \\
\text { professor that went beyond the curricular } \\
\text { materials }\end{array}$ \\
\hline & & $\begin{array}{l}\text { Family } \\
\text { Influence }\end{array}$ & $\begin{array}{l}\text { Participant discussed family members that have } \\
\text { influenced their understanding of CRT }\end{array}$ \\
\hline \multirow[t]{4}{*}{$\begin{array}{l}\text { Acquisition of } \\
\text { CRT }\end{array}$} & $\begin{array}{l}\text { Exposure to } \\
\text { CRT }\end{array}$ & Discussed & Specific skills were discussed in coursework. \\
\hline & & Observed & $\begin{array}{l}\text { Participant had the opportunity to observe CRT } \\
\text { either in their coursework or clinical experiences }\end{array}$ \\
\hline & & Practiced & $\begin{array}{l}\text { Participant had the opportunity to practice a } \\
\text { CRT skill in their coursework or clinical } \\
\text { experience }\end{array}$ \\
\hline & & $\begin{array}{l}\text { Thread } \\
\text { throughout }\end{array}$ & $\begin{array}{l}\text { Participant noted that CRT was thread } \\
\text { throughout their coursework }\end{array}$ \\
\hline \multirow{5}{*}{$\begin{array}{l}\text { Application } \\
\text { and Practice of } \\
\text { CRT }\end{array}$} & & $\begin{array}{l}\text { Clinical } \\
\text { Experience }\end{array}$ & $\begin{array}{l}\text { Practicum, field-base or student teaching } \\
\text { classroom experiences }\end{array}$ \\
\hline & $\begin{array}{l}\text { Special } \\
\text { Education }\end{array}$ & $\begin{array}{l}\text { Family, } \\
\text { Community } \\
\text { Collaboration }\end{array}$ & $\begin{array}{l}\text { CRT was discussed, observed or practiced in } \\
\text { this specific course }\end{array}$ \\
\hline & & Assessment & $\begin{array}{l}\text { CRT was discussed, observed or practiced in } \\
\text { this specific course }\end{array}$ \\
\hline & & $\begin{array}{l}\text { Literacy } \\
\text { Courses }\end{array}$ & $\begin{array}{l}\text { CRT was discussed, observed or practiced in } \\
\text { this specific course }\end{array}$ \\
\hline & & Transition & $\begin{array}{l}\text { CRT was discussed, observed or practiced in } \\
\text { this specific course }\end{array}$ \\
\hline
\end{tabular}




\begin{tabular}{|c|c|c|c|}
\hline Theme & Concept & Code & Definition \\
\hline & & $\begin{array}{l}\text { Severe } \\
\text { Disabilities }\end{array}$ & $\begin{array}{l}\text { CRT was discussed, observed or practiced in } \\
\text { this specific course }\end{array}$ \\
\hline & & $\begin{array}{l}\text { Systematic } \\
\text { Instruction }\end{array}$ & $\begin{array}{l}\text { CRT was discussed, observed or practiced in } \\
\text { this specific course }\end{array}$ \\
\hline & & $\begin{array}{l}\text { Special } \\
\text { Education } \\
\text { Math }\end{array}$ & $\begin{array}{l}\text { CRT was discussed, observed or practiced in } \\
\text { this specific course }\end{array}$ \\
\hline & & $\begin{array}{l}\text { Behavior } \\
\text { Supports }\end{array}$ & $\begin{array}{l}\text { CRT was discussed, observed or practiced in } \\
\text { this specific course }\end{array}$ \\
\hline & & $\begin{array}{l}\text { Field-Base } \\
\text { Courses }\end{array}$ & $\begin{array}{l}\text { CRT was discussed, observed or practiced in } \\
\text { this specific course }\end{array}$ \\
\hline & EL Courses & $\begin{array}{l}\text { Methods for } \\
\text { bilingual } \\
\text { learners }\end{array}$ & $\begin{array}{l}\text { CRT was discussed, observed or practiced in } \\
\text { this specific course for those who have an EL } \\
\text { endorsement }\end{array}$ \\
\hline & & $\begin{array}{l}\text { Effective } \\
\text { Practices for } \\
\text { EL Learners }\end{array}$ & $\begin{array}{l}\text { CRT was discussed, observed or practiced in } \\
\text { this specific course for those who have an EL } \\
\text { endorsement }\end{array}$ \\
\hline & & $\begin{array}{l}\text { Assessment } \\
\text { of bilingual } \\
\text { learners }\end{array}$ & $\begin{array}{l}\text { CRT was discussed, observed or practiced in } \\
\text { this specific course for those who have an EL } \\
\text { endorsement }\end{array}$ \\
\hline & & $\begin{array}{l}\text { Methods and } \\
\text { materials for } \\
\text { bilingual and } \\
\text { EL learners }\end{array}$ & $\begin{array}{l}\text { CRT was discussed, observed or practiced in } \\
\text { this specific course for those who have an EL } \\
\text { endorsement }\end{array}$ \\
\hline & $\begin{array}{l}\text { Other } \\
\text { Courses }\end{array}$ & $\begin{array}{l}\text { Cross } \\
\text { cultural } \\
\text { teaching and } \\
\text { learning }\end{array}$ & $\begin{array}{l}\text { CRT was discussed, observed or practiced in } \\
\text { this specific course }\end{array}$ \\
\hline & & $\begin{array}{l}\text { Dimensions } \\
\text { of numerical } \\
\text { reasoning }\end{array}$ & $\begin{array}{l}\text { CRT was discussed, observed or practiced in } \\
\text { this specific course }\end{array}$ \\
\hline & & $\begin{array}{l}\text { Child } \\
\text { Growth and } \\
\text { Development }\end{array}$ & $\begin{array}{l}\text { CRT was discussed, observed or practiced in } \\
\text { this specific course }\end{array}$ \\
\hline & & $\begin{array}{l}\text { Social } \\
\text { foundations } \\
\text { of education }\end{array}$ & $\begin{array}{l}\text { CRT was discussed, observed or practiced in } \\
\text { this specific course }\end{array}$ \\
\hline
\end{tabular}

